\title{
COMPLIANCE BEHAVIOUR OF NEW ZEALAND EXPORTERS WITH BEST PRACTICES OF SUPPLY CHAIN SECURITY
}

BY

VINKA PAOLA CISTERNAS TORRES

A thesis submitted in fulfilment of the requirements for the degree of Master of Commerce in International Business

Supervised by

DR ELDREDE KAHIYA

Victoria University of Wellington

School of Marketing and International Business

2020 


\section{To my sons:}

\section{Samuel and Sebastian Parkman-Cisternas}

We went through this together; we sacrificed quality time and many things. I cannot thank you enough for your ongoing support and understanding that mum needed to study. My dear sons follow your dreams, I know you both can fly high and I will be there to support you on your chosen path. 


\begin{abstract}
This thesis investigates the compliance behaviour of New Zealand exporters that are part of the Authorised Economic Operator programme for Supply Chain Security. In an attempt to secure global supply chains for a smooth and efficient movement of goods across borders, the World Customs Organisation introduced the Authorised Economic Operator programme in the mid-2000s. Several countries have adopted this programme that is based on modern distribution systems to improve the management and control of global logistics structures. New Zealand has its own programme called the Secure Export Scheme. While this programme is voluntary in nature, firms entering the programme are required to adopt and maintain standards of security for their supply chain. These standards of security are based on a number of best practices involving export documentary processes and handling of cargo with the aim of firms becoming international trusted operators.
\end{abstract}

The Authorised Economic Programme is a new concept, and while there is scholarly research on other types of voluntary standards, research in this particular area is minimal. To the best of the researcher's knowledge, this is one of the first studies to examine the compliance behaviour of Authorised Economic Operators that have been part of the programme since inception. Accordingly, this study is guided by the various views of the compliance theory and proffers a conceptual framework to delineate the different actors and factors that influence firms' compliance behaviour. The study measured compliance and non-compliance of firms to understand the underlying patterns with specific best practices. This study contributes towards our understanding of compliance behaviour. While, overall, the compliance of the New Zealand exporters with the best practices is high, there are some areas of concern. The study further identified that a number of firms were not compliant with certain best practices. This finding indicates that other factors, such as, the way the governing body presents its written requirements might influence the compliance behaviour with those specific best practices. The conceptual model proposed in this study lays the foundation for subsequent research seeking to probe compliance behaviour of Authorised Economic Operators in other contexts

Key words: Authorised economic operators, compliance behaviour, export industry, international trade, secure export scheme, supply chain security, standards, best practices, World Customs Organisation 


\section{ACKNOWLEDGEMENTS}

I would first like to thank my thesis supervisor Doctor Eldrede Kahiya of the School of Marketing and International Business. From the moment you took the task to supervise my work you provided me with consistent support and invaluable wisdom. Your drive and energy kept me motivated in difficult times. Your feedback in every task accomplished finally helped me to steer in the right direction. I cannot thank you enough for understading my personal circumstances when there was no time to commit to this. I appreciate very much for the time and effort you put supporting me to get here.

I would also like to thank Doctor Weiting Zheng who intially was my supervisor and who unfortunatelly left before I got to here. I appreciate you took the time to leave me in the best hands to continue with this task.

I would like to acknowledge my dear longtime friend Stuart Foster for your ongoing advice on conducting academic research and your moral support in hard times. Thank you for the words of wisdom from your academic background.

My thanks are also extended to my workplace New Zealand Customs Service for the ongoing support and facilitating the execution of this research. An special thanks to Chrissy Lyons, Manager of the Learning and Development team who saw the potential in me and supported me through this journey. The Secure Export Scheme team for providing highly valuable data and the ongoing support from the managers. Thank you for your continuous interest on how my research was developing. Thank you all for believing in me, without your support I would not be able to be here.

To my manager David and colleagues Sue, Amanda and Allex from the Trade Policy team, my gratitude goes towards you for the interest on my research and listening to my ongoing conversations about standards and compliance. To the whole team, for putting up with my absences at lunch time, you knew I was dedicating that time to study. I can now join the coffe and lunch club and be a real team member!

Many thanks to my dear friend Gabriel Faifman, thank you for reviweing my thesis draft and for providing your expert view on standards and conformance. I am gratefully indebted for your valuable comments - Gracias senor de los anillos! 


\section{ABBREVIATIONS}

AEO Authorised Economic Operatir

ANZSIC Australian and New Zealand Standard Industrial Classification

BASC Business Alliance for Secure Commerce

C-TPAT Customs-Trade Partnership Against Terrorism

GDP Gross Domestic Product

ISO International Organisation for Standardisation

MNCs Multinational Corporations

OECD Organisation for Economic Cooperation and Development

PIP Partners in Protection

PTA Privacy Threshold Assessment

SES Secure Export Scheme

SMEs Small and Medium Enterprises

TFA Trade Facilitation Agreement

TPL Third Party Logistic

WCO World Customs Organisation

WTO World Trade Organisation 


\section{TABLE OF CONTENTS}

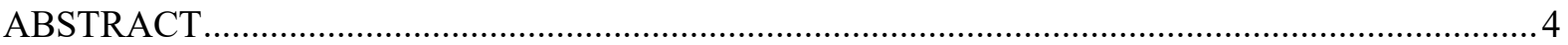

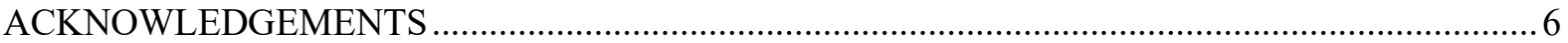

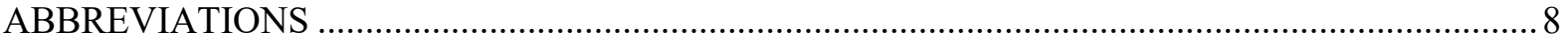

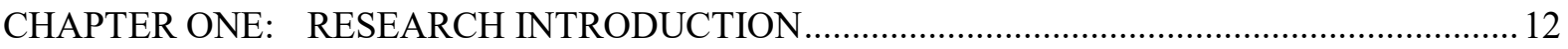

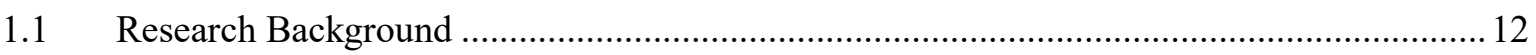

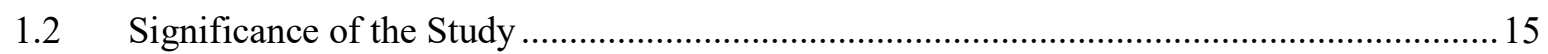

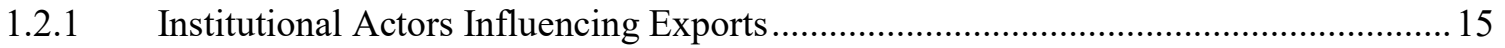

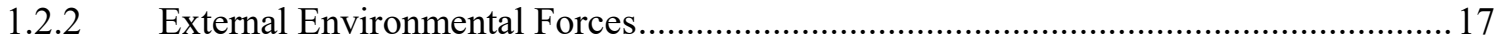

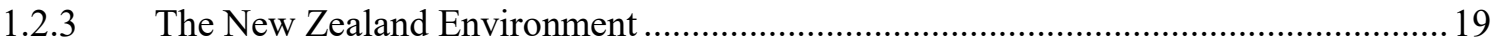

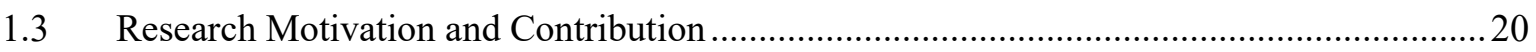

$1.4 \quad$ Literature on Authorised Economic Operators Programmes ...............................................2

1.4.1 Attributes of Authorised Economic Operators..............................................................25

1.4.2 Actors' Role in Authorised Economic Operator Programmes ........................................26

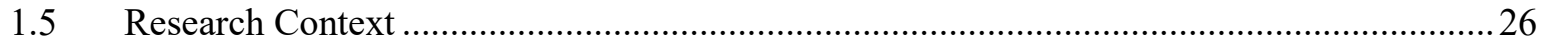

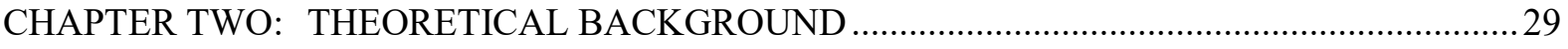

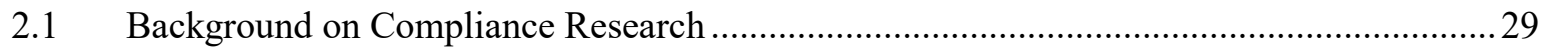

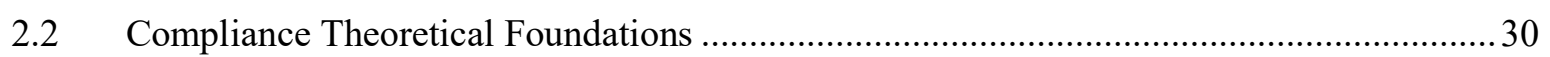

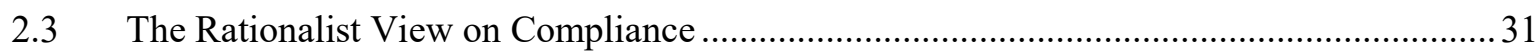

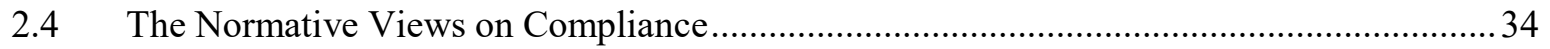

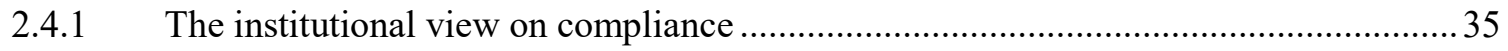

2.4.2 Accounting for Compliance Motivations...................................................................... 36

2.4.3 Accounting for the Nature of Regulations as Influencers on Compliance.....................39

2.4.4 Accounting for the Influence of the Regulatory Body on Compliance........................... 42

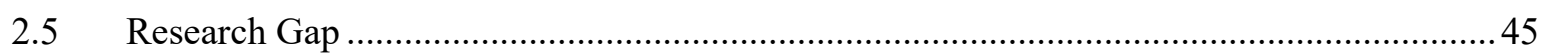

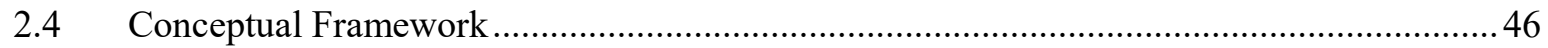

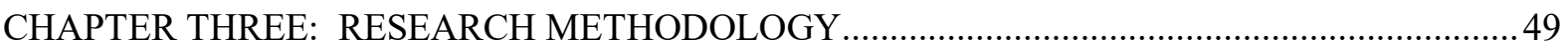

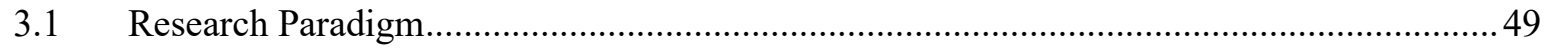

3.1.1 The Research Philosophy Applied in this Thesis .................................................... 50

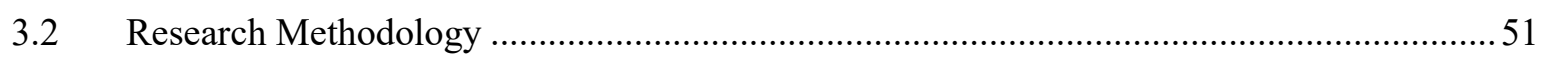

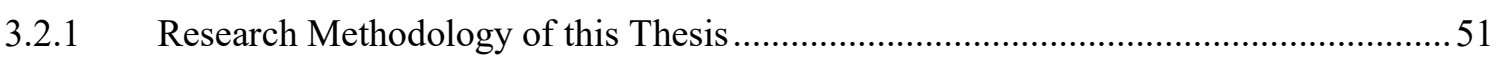

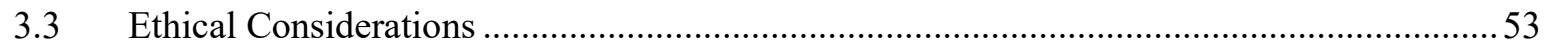

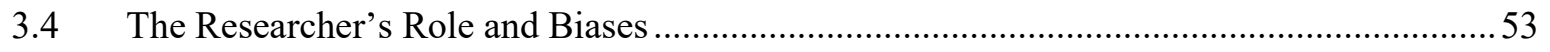

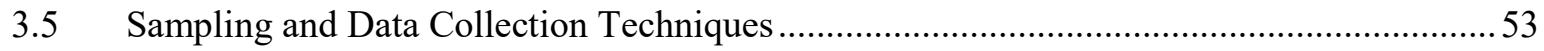

3.5.1 The Sampling and Data Collection Methods Applied in this Research ..........................55

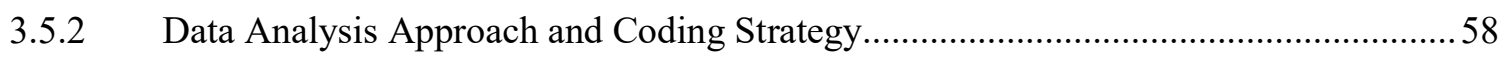




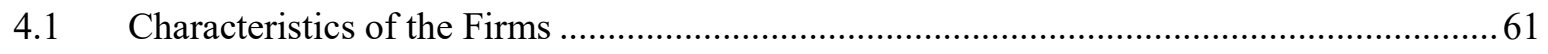

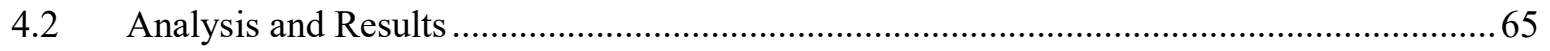

4.2.1 First Analysis - Identifying levels of compliance post-certification ..............................65

4.2.2 Second Analysis - Identifying compliance behaviour with specific best practices......69

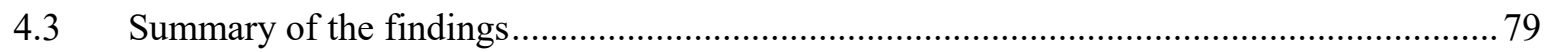

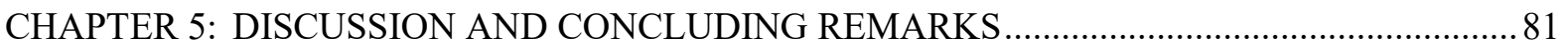

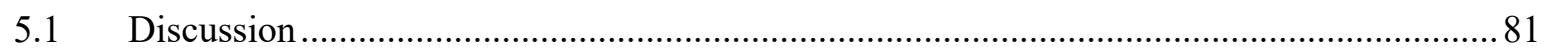

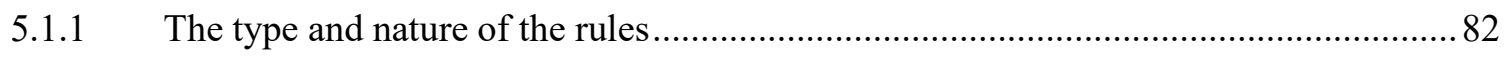

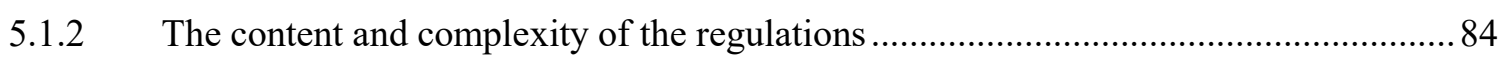

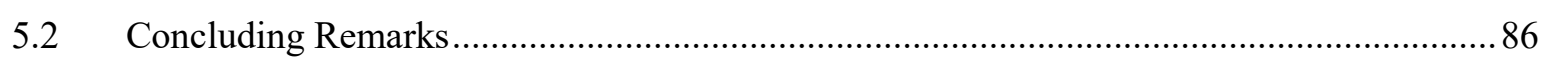

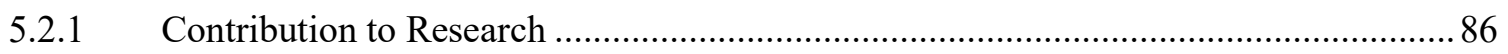

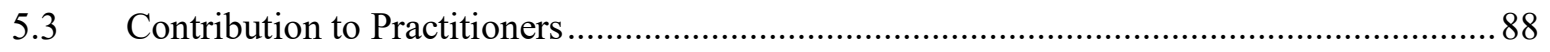

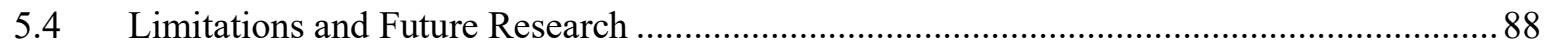

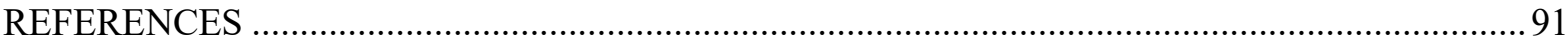

APPENDIX 1: New Zealand AEO Standards of Security and Required Best Practices ..................... 107

APPENDIX 2: Full Results by Best Practices among the Three Audit Periods (A1, A2 and A3) .....113

APPENDIX 3: Full Results Cohort of 25 Firms' three Audit Periods (T1, T2 and T3) ...................... 122

APPENDIX 4: Copy of Customs Fact Sheet Guide to Requirements of the Secure Export Scheme. 124 


\section{CHAPTER ONE：RESEARCH INTRODUCTION}

\subsection{Research Background}

The purpose of this research is to understand the compliance dynamics of approved Authorised Economic Operators (AEO) in the New Zealand context. Initiatives such as the AEO are the result of global efforts aiming to help the international trading community to secure global supply chains so that the movement of goods is smooth and efficient 1 . The AEO programme is an initiative of the World Customs Organisation (WCO) and its member countries. Its core philosophy is developing government to private partnerships for the safety of international trade and simplification of Customs procedures (Liu \& Tan, 2010). The AEO idea derives from modern models of production and distribution systems that deliver methods for improving the management and control of logistic structures (Campos, Morini \& Moraes, 2018; Pratama \& Everett, 2017). According to the WCO, the AEO programme's main objective is to provide a solution for the secure handling of internationally traded goods reinforced by a system of standards and best practices grounded in voluntary compliance, self-governance and reciprocal trust ${ }^{1}$. Until now, approximately 84 member countries of the WCO have implemented AEO programmes; this includes among others Australia, United States, Canada, China, Japan, and the European Union ${ }^{2}$. New Zealand has its own AEO programme called the Secure Export Scheme (SES).

Regardless of the country where the AEO programme has been implemented, firms that enter the programme are required to adopt and maintain security standards based on best practices to become trusted traders (Karlsson, 2017). The trusted trader status reassures countries' Customs administrations that firms have implemented the best practices and therefore are compliant with the security requirements. AEO programmes provide trusted traders with some advantages in their country and other countries where AEO status is recognised (Chang $\& \mathrm{Wu}, 2015)$. In this sense, firms can obtain from the programme advantages that relate to expedited trade facilitation, less Customs administrative burden and enhanced security of their cargo (Gutierrez \& Hintsa, 2006; Pratama et al., 2017).

\footnotetext{
${ }^{1}$ http://www.wcoomd.org/-/media/wco/public/global/pdf/topics/facilitation/instruments-and-tools/tools/safe-package/safe-framework-ofstandards.PDF?la=en

${ }^{2}$ http://www.wcoomd.org/-/media/wco/public/global/pdf/topics/facilitation/instruments-and-tools/tools/safe-package/aeocompendium.pdf?db=web
} 
There are mixed views about government to private partnerships like the AEO programme. Some scholars claim that these partnerships generate a "win-win" situation where governments offer international trade facilitation for safety of global supply chains and firms adopt rather strict standards of compliance in exchange for faster and disruption free international logistics (Liu et al., 2010; Cedilnik \& Ramsak, 2013). Others argue that programmes based on voluntary compliance and self-regulation produce efficiency but do so by placing responsibility on the firm to maintain the continuity of the adopted best practices (Christmann \& Taylor, 2006; Jamali, 2010). From a risk perspective, Karlsson (2017) argued that it is difficult for governments to manage all the transactions that involve international trade. Thus, systems that provide for voluntary compliance are a good way for government to allocate resources where they are needed. Opposite to this, is the thought that further delegating control tasks that generally have been conducted by government, might be risky as firms can take advantage of the delegated authority (Liu et al., 2010; Karlsson, 2017). Christmann and Taylor (2006) argue that voluntary compliance initiatives that rely on trust are effective as long as firms comply with the requirements (pg.863). Naturally this raises concerns as the effectiveness of the AEO standards can be compromised, lead to inefficiencies, and introduce risks to the supply chain of firms.

Existing research on voluntary compliance is rooted on the constructs of the compliance and institutional philosophies. While the institutional rationale places emphasis on institutional pressures, the compliance rationale underlines the involvement of different players influencing compliance. The institutional view illustrates that external pressures motivate firms to adopt similar ideas such as standards or best practices designed to produce efficiency in a specific area of the firm (Meyer \& Rowan, 1977; DiMaggio \& Powell, 1983; Scott, 1987; Lun, Wong, Lain \& Cheng, 2008). Research based on the institutional view has identified that firms respond to institutional pressures in different ways. For example, some firms are driven to gain legitimacy of influencing institutions, others conform to the pressures, others manipulate the pressures to their convenience and others avoid altogether (Scott, 2005; Boxenbaum \& Jonsson, 2008). Across the current knowledge on voluntary standards and best practices, a common occurrence is that some firms, after obtaining certifications, decouple some or all the adopted standards or best practices, thus becoming non-compliant with the requirements (Meyer et al., 1977; Christmann et al., 2006; Boiral, 2007; Boxenbaum et al., 2008; Jamali, 2010; Behnam \& MacLean, 2011). Literature has 
provided many reasons why firms decouple from practice. Some of these can involve factors inside the organisation, strategic responses, costs of compliance and, loosely coupled activities otherwise known as gap between means and ends among others (Boxenbaum et al., 2008; Behnam et al., 2011). The compliance view on the other hand, argue that compliance behaviour is driven by a number of factors arising from inside the organisation, and externally from the social and physical settings in which rules, standards and best practices are applied (Van Snellenberg \& Van de Peppel, 2002; Siddiki, Espinosa \& Heikkila, 2018). Literature on compliance has classified two broad approaches to study compliance behaviour namely the rationalist and the normative views. The rationalist view involves attitudes and motivations towards compliance based on decisions between economic costs versus benefits to comply or not comply. The normative view on the other hand accounts for behaviours, environmental factors, cooperation and assistance to comply (Van Snellenberg et al., 2002; Ettienne, 2011 Siddiki, Heikkila \& Espinosa, 2018). Different studies using different models based on these views have indicated that compliance behaviour is materialised at all levels including internal motives as well as external environment influencing compliance (Siddiki et al., 2018).

Organisational compliance behaviour has been studied from a myriad of disciplines and areas, ranging from industrial standards, policy, law and regulations, including voluntary standards (Foorthuis \& Bos, 2011; Siddiki et al., 2018). Literature based on the AEO best practices has mainly focused on adoption, usability and competitive advantage of the programmes (Chang et al., 2015; Laszuk \& Ryciuk, 2016; Pratama et al., 2017). Existing AEO literature lacks empirical evidence on the patterns of compliance among AEO certified firms. Thus, the purpose of this study is to contribute to the literature of compliance via empirically assessing the compliance behaviour of firms that have adopted AEO status. This research will investigate the compliance behaviour of the New Zealand exporters and their associated distribution parties that have adopted the Secure Export Scheme voluntary compliance programme to answer the following research question:

\section{What is the compliance behaviour of New Zealand firms that voluntarily adopted the Secure Export Scheme programme's best practices?}

As previously indicated research on compliance behaviour has shown that there are various elements affecting compliance behaviour. Given that the nature of compliance behaviour is 
complex as it involves internal motivations as well as the external environment in which governing bodies and their best practices interact with the subjects, it would be reasonable to explore these interactions with a range of variables. However, given the time constraints of this research it means that only some variables will be analyzed on the surface. Thus, this thesis will focus on analyzing the overall levels of compliance among firms to specifically indicate explicit non-compliant best practices as the behavioural output of this research.

\subsection{Significance of the Study}

This study is significant because different institutional actors influence and contribute to the economy and the development of international businesses trading goods in the global market place. This becomes more relevant when New Zealand exports in general make around thirty percent of the Gross Domestic Product4. Collaborations between the public and private sector are a reality in today's global landscape. It is important to note that not only institutional actors influence the dynamics of global markets but also external forces can influence via unpredicted events that can be detrimental for firms and the economy. Thus, collaborations such as the AEO programme can benefit both governments and businesses. As previously mentioned, these initiatives can prove beneficial in terms of trade facilitation and security of international cargo. Understanding how these actors and the external environment influence the international trade dynamics is important to foresee why this study is important. The following section explains in more detail about this.

\subsubsection{Institutional Actors Influencing Exports}

In the international trade setting, exporters are the key players influencing economic growth (Dean, Menguc \& Myers, 2000; Reuvid \& Sherlock, 2011; Hopkins, 2017). Exporters contribute to the aggregate demand of a country, generate employment and help to determine the balance of payments (Reuvid et al., 2011; Hopkins, 2017). For countries like New Zealand that have a small population base, currently estimated 4.9 million $^{3}$ trading goods across borders is an essential aspect of the New Zealand economy. In the year ended June 2018 New Zealand exports of goods (including services) was \$NZD79.8 billion ${ }^{4}$. New Zealand exports are primarily commodity-based products ranging from dairy, meat, logs,

\footnotetext{
${ }^{3}$ https://www.stats.govt.nz/indicators/population-of-nz

${ }^{4}$ https://www.stats.govt.nz/information-releases/goods-and-services-trade-by-country-year-ended-june-2018
} 
wood articles, fruit, electrical machinery, petroleum, aluminium articles, wine, and fish among others ${ }^{5}$. The main export destinations of New Zealand goods are Australia, China, the European Union, Japan and United States4. As demonstrated by these figures one can understand why exporting is indispensable in a small open economy like New Zealand.

However, exporters are not only involved in international trade transactions, they are also engaged with different actors involved in global supply chains that provide information and deliver export goods. Among others, exporters deal with third party manufacturing sites, Customs brokers, transport companies and freight forwarders (Williams, Lueg \& May, 2008). It is well known that global supply chains are multifaceted and challenging as all these actors are self-governing organizations (Christopher \& Peck, 2004; Williams et al., 2008). Thus exporters need to work with their supply chain to maximize information, align operating procedures and integrate systems to serve the end users (Togar, Simatupang and Sridharan, 2002; Christopher et al.,2004; Williams, et al., 2008). Apart from dealing with dynamic markets and interacting with their supply chains, exporters are regulated by Customs administrations that are in control of goods crossing borders. Regulators play an important role for risk management and trade facilitation; they are the developers of import and export legal requirements and initiatives that enhance the export industry (Dean et al., 2000; Togar et al., 2002; Swanson \& Smith, 2013). Figure 1 shows how a simple supply chain of an export firm looks like. In this context, cooperation between exporters, their supply chain and the regulators becomes an important aspect for international trade. At the institutional level, governments have used various initiatives to achieve cooperation of all actors and enhance global supply chains (Togar et al., 2002; Swanson et al., 2013). Initiatives such as the AEO programme are an example of this. These initiatives ensure procedures are aligned and international cargo is secured across the supply chain (Karlsson, 2017).

${ }^{5}$ https://www.nzte.govt.nz/investment-and-funding/investment-statistics 
Figure 1: Simple supply chain of an export firm

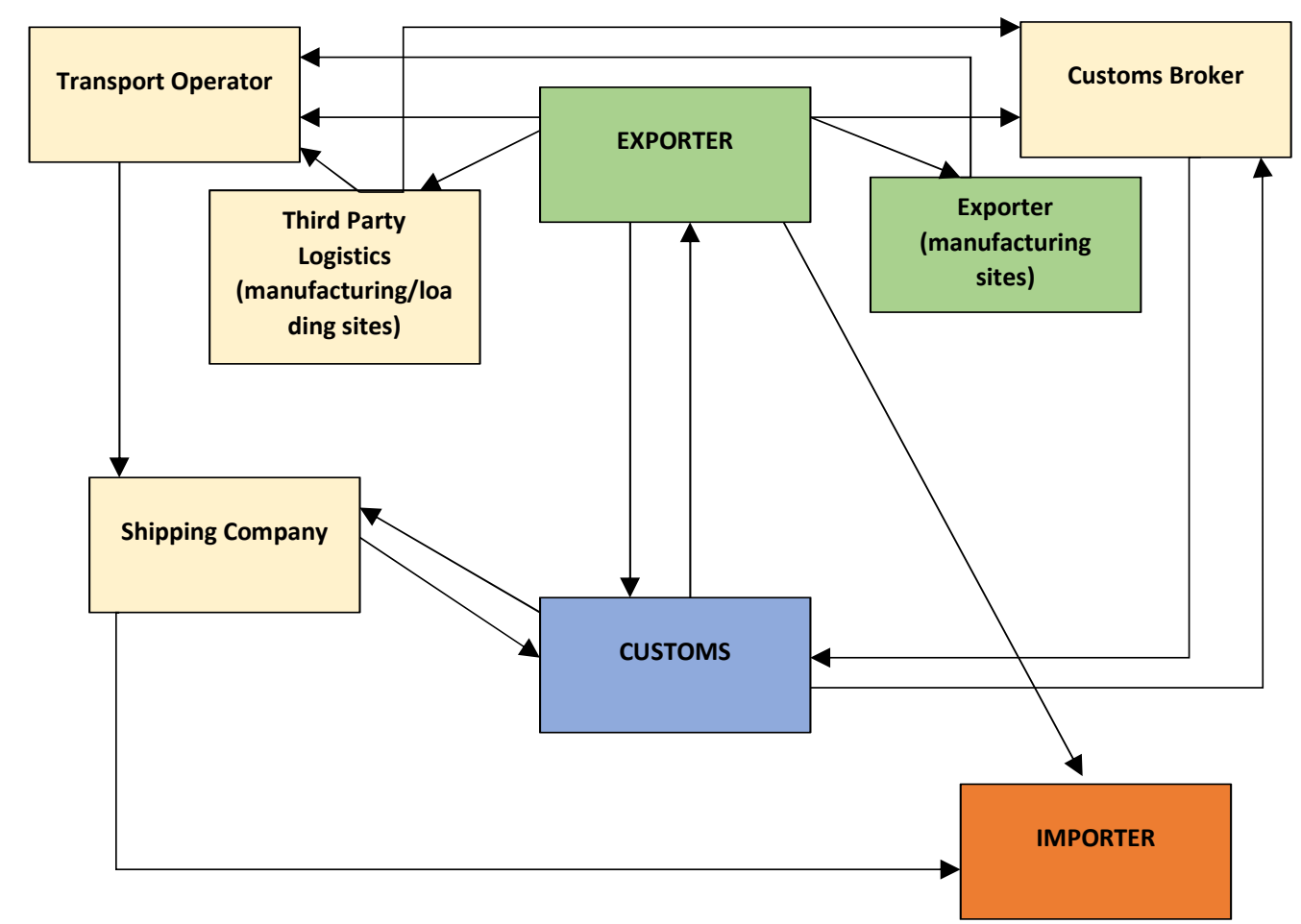

Source: modified from the works of Hervani, Helms and Sarkis (2005); Swanson and Smith (2013); Loh and Thai (2015); Sheu (2016)

\subsubsection{External Environmental Forces}

Why initiatives such as the Authorised Economic Operator (AEO) programme are important, why is it vital to harmonize procedures and enhance cooperation of these institutional actors? The answers lie in the environment where international trade occurs. Supply chains of export firms are vulnerable to external environmental risks such as socio-political unrest, terrorist attacks, cargo theft, cargo tampering, cyber-crime and industrial sabotage among others (Sheffi 2001; Juttner, Peck \& Christopher, 2003; Williams et al., 2008). External risks are capable of disrupting the flow of goods from reaching the end consumer as well as cost huge financial loses for firms and the economy of a country (Juttner et al. 2003; Burke, 2005). The 9/11 terrorist attack in the United States is the most notorious example of disruption to supply chains of global trading firms. Manufacturers of vehicle assembly parts experienced major delays because the United States government closed the borders (Sheffi, 2001; Juttner et al., 2003; Gutierrez et al., 2006). Cargo crossing between Canada and the United States normally took a few minutes but when the attacks occurred, it took approximately 20 hours (Nitsch \& Schumacher, 2004). Because of these delays, Ford and Toyota, for example, had to slow down their operations, as materials coming from overseas via road and air transport could not 
enter the country on time (Sheffi, 2001; Gutierrez et al., 2006). It is important to highlight that because of this event, many countries added to their existing programmes security measures around terrorism (Gutierrez et al., 2006). Thus, the World Customs Organisation's AEO programme was developed with the attempt to secure global supply chains and facilitate trade when incidents like this occur (Karlsson, 2017). In this regard, it is important that businesses ensure continuity when entering these programmes.

The 9/11 attacks were not an isolated case, terrorism and political conflicts continue to happen. The 2015 Paris terrorist attack resulted in tighter border controls that delayed cargo and accrued a cost for Belgian shippers of around \$USD3.5 million ${ }^{6}$. In 2016, a terrorist attack in Germany exploited the road transport system by hijacking a Polish cargo of steel beams that was destined to Germany resulting in goods not reaching the end consumer7. The Syria conflict is another example where continuous small terrorist attacks have forced Lebanese exporters to divert \$USD1 billion worth in goods that resulted in \$USD754 million loss in revenue for the Jordanian logistics industry6. According to the Supply Chain Intelligence Report (2016) the top ten countries that suffered from terrorist incidents in the supply chain of firms accounted for a total of $\$ 664$ billion worth of exports. Firms are not only affected by terrorism and political turmoil, cargo theft, smuggling and social unrest also affect supply chains of global trading firms. For instance, in 2016 Brazil had the highest rates of cargo theft with an increase of $36 \%$ causing delays for end users. Also, in South America, exists the issue of cocaine smuggling across borders which targets containerized cargo via road and sea7. In China, strikes in the logistics industry have increased four times from 2014 to 2016 thus delaying the delivery of goods to the ports and end users ${ }^{7}$. It is undeniable that unpredictable trade disruption will continue happening thus affecting global supply chains and international trade. Gutierrez and Hintsa (2006) said that organisations have always dealt with these issues but security programmes like the AEO help firms to avoid being the target or crime. Being prepared via enhancing the security of firms' supply chains and having access to trade facilitation becomes important for firms. Research until now has identified that firms that adopt certifications such as the AEO programme are better prepared in terms of security of their supply chains. In a study conducted by Voss and Williams (2013) located that firms belonging the C-TPAT programme in the United States outperform those that are

\footnotetext{
${ }^{6}$ https://www.mhlnews.com/global-supply-chain/supply-chain-experiencing-high-rate-terrorist-attacks\#close-olyticsmodal ${ }^{7}$ https://www.bsigroup.com/en-GB/about-bsi/media-centre/press-releases/2017/may/BSIs-Global-Supply-Chain-Intelligence-reportreveals-top-supply-chain-risks-in-2016/
} 
not part of the programme. The study located that these firms have improved their performance in security and resilience thus are better prepared for unforeseen trade disruption (Voss \& Williams, 2013). While this study is not concerned on the performance of the AEO programmes. It is important to stress why these programmes have been developed in the first place and what entering the programme requires from an organisation. Additionally is important to highlight that the study of AEO programmes is new. These programmes were developed in the early 2000s and empirical research in many aspects of the programmes still lack exploration (Bichou, 2010; Pratama et al., 2017)

\subsubsection{The New Zealand Environment}

While New Zealand is located in a unique geographical zone, it is not exempt to risks arising from the external environment. The World Economic Forum ranks cyberattacks as the second highest risk for businesses. In addition, data fraud or theft and failure of critical infrastructure are among the top ten risks globally and for the Asia Pacific zone8. Businesses trade internationally should be cautious about cyberattacks and see it as a major concern for critical infrastructure that includes among others businesses' sensitive information, automated transportation, technology, and building automation security systems. Businesses in New Zealand are not immune to these risks, neighbouring Australia for instance was the recipient of most of the cyberattacks in recent risk assessments ${ }^{8}$. Risks of this nature can cause financial damage if not at least disruption to the supply chain of the export industry. A key element of AEO programmes including the SES is that it focuses on securing the supply chain of firms that trade internationally (Chang-Bong, Chun \& Kwon, 2016). The programme requires firms to adapt internal processes to the standards of security and its best practices. By adapting to this secure best practices firms can develop degree of readiness and resilience when risks arise (Chang-Bong et al., 2016; Pratama et al., 2017; Karlsson, 2017). It is important to mention that New Zealand Customs is a member of the WCO. The WCO is the intergovernmental entity that in conjunction it its member countries developed the AEO programme1. More than $90 \%$ of the WCO member countries ratified the principles and standards for adoption under the AEO programme (Pratama et al., 2017; Karlsson, 2017). Further, the World Trade Organisation (WTO) in its new Trade Facilitation Agreement $(\mathrm{TFA})^{9}$ encourages its members to adopt international standards based on best practices to

\footnotetext{
${ }^{8}$ http://www3.weforum.org/docs/WEF_Regional_Risks_Doing_Business_report_2019.pdf

${ }^{9}$ The TFA is a major achievement of the WTO, approved by its 159 members. At the core of the TFA are articles that provide measures to help developing countries to the improve border management practices and elimination of red tape.
} 
secure and facilitate international trade (Widdowson, Blegen, Kashubsky \& Grainger, 2014). Thus, AEO programmes are growing in popularity with established programmes and more in the process of implementing one2.

\subsection{Research Motivation and Contribution}

The current global trade landscape relies on efficient and secure global supply networks were cooperation between the public sector and the private industry is key to improve the competitiveness of global traders (Haelterman, 2011; Chang-Bong et al., 2016). My research motivation studying the compliance behaviour of Authorised Economic Operators is twofold, as a Master student and as a practitioner. As a Master student the natural curiosity to understand the dynamics of cross-border businesses and governing agencies have led me to enquiry these relationships. My research interests are oriented to cross-border trade, in particular the export industry and requirements that export firms need to accomplish at the domestic and international level. As a practitioner during my time, liaising with AEO certified export firms, I experienced first-hand some instances of non-compliance from some firms. While my dealings were purely related on notifying concerns post-adoption, I internalised the whys of non-compliance, how it varies among firms, are there any patterns among firms, does it continue happening overtime? In my opinion, furthering the public sector's understanding of the compliance behaviour of New Zealand's AEO equivalents is crucial to foster and strengthen cooperative arrangements with the private industry. In the search for finding objective answers for the development of international trade Policy that affects international businesses engaging in cross border trade - the main purpose of this research is twofold:

To contribute to the existing knowledge on compliance and to the actors involved in voluntary compliance programmes by understanding the patterns of compliance among New Zealand exporters participating in Secure Export Scheme.

This research is important because it provides new insights that specifically apply to AEOs in New Zealand. Policy makers can use this research as a basis for improving current partnerships with the private industry to encourage continuity and compliance. As argued by Haelterman (2011) inadequate instructions from governing agencies are likely to result in 
scanty adoption of best practices. While accountability relies on the private sector, it is important that agencies governing the post-adoption of standards understand the challenges that compliance bring to businesses so processes and policies can be improved. This study also offers an insight to the New Zealand export sector and the risks that firms accrue when not fully understanding the main benefits and goals of these programmes. Countries that have adopted AEO programmes engage in mutual recognition agreements thus AEO status is recognised jointly (Chang et al., 2015). Consequently, firms holding an AEO status have a competitive advantage over those that select not to enter such programmes. A research conducted by Houe and Murphy (2018) indicated that AEOs do improve the competitive advantage and, by adopting these best practices, firms are able to reinforce internal processes and improve knowledge that leads to better relationships with customers and the governing agency. Thus, firms that ignore compliance are at risk of missing the competitive advantages that the AEO's best practices can bring. In this regard, this research has implications for both the New Zealand export sector and for other countries that have developed similar voluntary compliance programmes. For the academic field this research intends to contribute to the literature of AEO programmes and advance the current understanding of the compliance behaviour of firms that voluntarily adopt best practices. Empirical research on voluntary compliance of AEO programmes until now is limited. Thus, this thesis intends to contribute to academia by providing real accounts on compliance behaviour of firms that are part of an AEO programme and further the knowledge of the different actors influencing compliance.

\subsection{Literature on Authorised Economic Operators Programmes}

The World Customs Organisation's Authorise Economic Operator (AEO) programme is one of the most prominent initiatives advocating for public to private partnerships to secure international cargo and facilitate trade (Campos, et al., 2018; Pratama et al., 2017). However, this is not the first initiative focused on promoting such type of partnerships. Previous to the AEO inception, a number of countries developed similar programmes. Originally, these partnerships focused on initiatives promoting security of global supply chains against drug smuggling and cargo theft, loss and damage via risk management models (Gutierrez et al., 2006). Among others, the most notorious pioneers were Sweden, Canada and the Business Alliance for Secure Commerce (BASC). During the 80s, Sweden developed the first compliance programme "Stairway" later "StairSec" aiming at a partnership between Customs 
and the Swedish international trading community to improve quality and security (Peterson \& Treat, 2009; Karlsson, 2017). In the early 90s, the Canada Border Services Agency developed the Partners in Protection (PIP) programme (Gutierrez et al., 2006). A joint governmentindustry program was available for Canadian importers and exporters (Hart, 2010). The PIP programme was focused on detecting and preventing cross-border crime via enhanced security methods and improved compliance knowledge (Peterson, et al., 2009). Also, during the 90s, a group of Latin American countries formed the BASC programme to fight against smuggling of narcotics (Gutierrez, Hintsa, Wieser \& Hameri, 2007). The focus of the BASC was to facilitate international trade via the implementation of tight security standards around international businesses' supply chains (Gutierrez et al., 2007).

In 2001, the international trading community saw a complete shift to cargo security. Following the 9/11 terrorist attacks in United States a new security stand was placed and it included security of global supply chains against terrorism (Karlsson, 2017). The CustomsTrade Partnership Against Terrorism (C-TPAT) was created by United States through a joint government-industry partnership aiming for voluntary compliance of importers based on standards of security and trusted status (Melnyk, Ritchie \& Calantone, 2013; Ni, Melnyk, Ritchie \& Flynn, 2016). One important attribute that C-TPAT brought, was the trusted trader status that placed compliant firms with a low risk-status thus allowing preferential trade facilitation (Voss et al., 2013; Ni et al., 2015). In 2004, New Zealand developed the SES programme concerned with cargo security and facilitation of exports in New Zealand. Following the development of this programme, New Zealand and United States signed an agreement that mutually recognised the respective programmes (Peterson et al., 2009). Soon Sweden, Canada and BASC followed through and integrated security standards against terrorism into their programmes (Peterson et al., 2009).

Following these developments in 2005, the WCO and its member countries adopted a framework called the SAFE framework of standards and created the AEO programme (Gutierrez et al., 2006; Karlsson, 2017). The SAFE Framework is an instrument of the WCO that provides Customs administrations and businesses with systems, standards and best practices based on voluntary compliance, reciprocal trust1, Customs cooperation and public to private partnerships (Campos et al., 2018). The main role of the WCO and its SAFE Framework is to promote safe global trade, enhance trade facilitation and improve Customs operations among its member countries (Gutierrez et al., 2006; Karlsson, 2017). The WCO 
SAFE Framework covers different aspects of border administration. It has three pillars that aim to encourage:

1. Collaboration between Customs Administrations via the usage of harmonized standards to secure and facilitate global trade.

2. Partnerships between Customs and businesses to identify trusted global traders and supply benefits via AEO programmes.

3. Customs to other Government and Intergovernmental agencies cooperation to form partnerships at the national and international level1.

The AEO programme in pillar two involves the international trading community and is considered the core of all the pillars (Ireland, 2009; Campos et al., 2018). The AEO programme is a tool based on a set of Standards and best practices that Customs administrations adhere to and that businesses implement when entering these programmes. Table 1 summarises the key standards of security along with a description of the best practices. The WCO's AEO programme is the most structured tool as it harmonizes Customs procedures for security of global trade while ensuring trade facilitation (Campos et al., 2018). Since its creation, Customs authorities around the globe have adopted these standards and incorporated them into their voluntary programmes, the European Union, Australia, China, Singapore, Hong Kong, Korea, Taiwan, Chile and more have developed AEO programmes (Gutierrez et al., 2006; Peterson et al., 2009). Furthermore, those countries that have implemented secure supply chain programmes previous the WCO and its SAFE Framework for AEOs have evolved and incorporated the AEO security standards and best practices into their programmes (Gutierrez et al., 2006; Peterson et al., 2009). 
Table 1: Authorised Economic Operators' standards and best practices

\begin{tabular}{|c|c|}
\hline STANDARDS & BEST PRACTICES \\
\hline Business partner security & $\begin{array}{l}\text { Have adequate contractual procedures to ensure business partners } \\
\text { are trusted operators. }\end{array}$ \\
\hline $\begin{array}{l}\text { Cargo and conveyance } \\
\text { security }\end{array}$ & $\begin{array}{l}\text { Have adequate processes to safeguard the integrity of } \\
\text { international cargo, handling, storage and transportation. }\end{array}$ \\
\hline $\begin{array}{l}\text { Crisis management and } \\
\text { incident recovery }\end{array}$ & $\begin{array}{l}\text { Availability of adequate contingency plans against any form of } \\
\text { disruption. Thus operations may be impacted by an incident and } \\
\text { get degraded, but not fully interrupted. }\end{array}$ \\
\hline $\begin{array}{l}\text { Consultation, Cooperation and } \\
\text { communication }\end{array}$ & $\begin{array}{l}\text { Have a well-versed contact point person(s) responsible of } \\
\text { notifying Customs of any issues on compliance matters or other } \\
\text { matters that related to the AEO certification. }\end{array}$ \\
\hline $\begin{array}{l}\text { Education, training and threat } \\
\text { awareness }\end{array}$ & $\begin{array}{l}\text { Organisational readiness via processes to provide adequate } \\
\text { training to employees so that personnel are knowledgeable about } \\
\text { security requirements and the company's AEO status. }\end{array}$ \\
\hline $\begin{array}{l}\text { Information technology } \\
\text { security }\end{array}$ & $\begin{array}{l}\text { Have adequate technical security capabilities to protect } \\
\text { information from being leaked, processes for archiving electronic } \\
\text { records and security measures to protect computer systems } \\
\text { against loss of information. }\end{array}$ \\
\hline Personnel security & $\begin{array}{l}\text { Have adequate security procedures and employment policies to } \\
\text { ensure staff are trusted individuals. }\end{array}$ \\
\hline Security around sites & $\begin{array}{l}\text { Have adequate access controls around sites to preclude } \\
\text { unauthorised access to areas where international cargo, } \\
\text { documentation and information are kept and where operations are } \\
\text { being conducted. }\end{array}$ \\
\hline Self-quality assurance & $\begin{array}{l}\text { Have in place testing practices to ensure continuity of internal } \\
\text { processes, business partnerships and associated parties. }\end{array}$ \\
\hline
\end{tabular}

Source: Adapted from World Customs Organisation, Customs AEO Validator Guide, 2018 


\subsubsection{Attributes of Authorised Economic Operators}

As previously indicated, AEO programmes have three main functions; secure supply chains of global trading firms, facilitate global trade and form trusted partnerships between the public and private sectors. Furthermore, AEO programmes consist of a set of compliance standards of security in the form of best practices1. An AEO, as defined by the WCO is 'any of the parties that are involved in the movement of goods across borders, this can include among others, exporters, importers, manufacturers, carriers, third party logistics, freight forwarders, customs brokers and port companies 1 . Thus, AEO programmes present a number of attributes that are capable of benefiting not only international trading firms but also their supply chain partners. Sheffi (2001) indicated that the development and adoption of standards focused on securing global supply chains is important to generate resilience as firms could improve existing processes and internal policies. With resilient global supply chains, risk exposure can be minimised in the case of global disruptions that affect international trade (Christopher et al., 2004; Abe \& Ye, 2013). Another attribute of AEO programmes is that certified firms are given a trusted trader status, they are considered reliable firms that have implemented best practices and such receive preferential treatment by Customs administration (Houe \& Murphy, 2018). Preferential treatment by Customs authorities varies but generally involves less red tape at the border, faster cargo release, reduced fees and preferential processing in case of trade disruption (Widdowson et al., 2014; Chang-Bong et al., 2016). Okoboi and Kyanzi (2018) research on Uganda's AEO located that firms members of the AEO programme improved clearance time from 20 days to 3 days. Further, AEO programmes can be recognised mutually between countries, currently this is done by means of international agreements (Widdowson et al., 2014). New Zealand for instance has mutually recognised AEOs programmes with, Australia, Canada, China, Japan, United States, Korea, Hong Kong and Singapore ${ }^{10}$. Consequently, firms adopting the AEO status can have further benefits. One example of this is that firms can be considered internationally safe players and trusted business partners not only in their countries but also in those countries where mutual recognition exists (Widdowson et al., 2014; Houe et al., 2018).

\footnotetext{
${ }^{10} \mathrm{https}$ ://www.customs.govt.nz/business/export/mutual-recognition-arrangements/
} 


\subsubsection{Actors' Role in Authorised Economic Operator Programmes}

Countries developing their AEO programmes follow the guidance of the WCO SAFE Framework and include these standards and best practices into their programmes ${ }^{11}$. The role of each country is to ensure AEO firms are validated against these standards and that the best practices are implemented; this includes conducting post adoption assessments and monitoring11. It is important to emphasize that Customs administrations are responsible for regulating international trade therefore, these entities are in charge of validations and post adoption processes. AEO programmes require cooperative efforts and adherence based on reciprocal trust between the public and private sector to ensure security and trade facilitation (Campos et al., 2018). In this regard, Customs administrations seek to build a culture where companies voluntarily meet with AEO obligations. In order to achieve this, Customs administrations generally provide a number of benefits, such as, less bureaucratic processes and reduce border clearance time among others and firms compromise they can manage the safety of their supply chains (Liu et al., 2010; Cedilnik et al., 2013).

The firms' role is to fulfil the requirements of the AEO programme. This is generally done by completing applications that involve providing a self-assessment of the business operations, demonstrating historical compliance and financial solvency, showing businesses can selfmanage the security of their supply chain, and maintaining status as a legal business entity (Janowska-Bucka, 2008; Cedilnik et al., 2013). In addition, AEO programmes place the responsibility of secure supply chain practices on the certified firms. This means that in order to enhance the security of their supply chain, applicant firms are responsible for encouraging participation of their associated business partners (Janowska-Bucka, 2008). Thus, standards and best practices also need to be integrated into third party partners that will also enter contractual agreements for security and will be regulated against these.

\subsection{Research Context}

This study is based on assessing the compliance behaviour of New Zealand AEOs with the adopted standards of security. As previously indicated, the SES is aligned with the WCO SAFE Framework for AEO (Peter al., 2009). As compiled from the New Zealand Customs

\footnotetext{
${ }^{11}$ http://www.wcoomd.org/-/media/wco/public/global/pdf/topics/facilitation/instruments-and-tools/tools/safe-package/aeo-validatorguide.pdf?la=en
} 
website $^{12}$, export firms have the option to voluntarily enter the SES programme and adopt the secure best practices. To be certified as SES partner, firms need to demonstrate that they meet the criteria established by New Zealand Customs. This means that exporters have to prove that export goods are securely packaged and transported to the place of shipment without any form of interference. Firms entering the programme are required to present a self-assessment of their export operations in the form of a written security plan. This assessment details the firms' operating procedures that meet with the AEO standards of security. Firms are also required to present self-assessments made by sites operated by third parties and their selected transport operators ${ }^{13}$. Firms are required to update their assessments should operational changes that affect their procedures occur12. Since the SES programme covers the supply chain of exporters, firms entering the programme can select whether they will include third party logistics operators, such as, third party manufacturing sites and domestic transporters. When applicant firms are validated and meet the criteria, these obtain the SES certification and thus are given the trusted traders status. Under the Customs legislation, the trusted trader status can be reviewed at any time, Customs can revoke firms' from the programme and firms can voluntary withdraw from the programme ${ }^{14}$.

In exchange for adoption and compliance, New Zealand Customs provides the following benefits:

Reduced fees for export declarations

Ability to develop a secure supply chain for export operations

Minimal trade disruption when security alerts occur

Less Customs intervention at exit point

Access to less Customs intervention in countries where New Zealand has a mutual recognition agreement.

Ongoing advice and point of contact to ensure a secure supply chain is maintained and to provide assistance if certified firms have issues with countries where New Zealand has mutual recognition agreements.

\footnotetext{
12 https://www.customs.govt.nz/globalassets/documents/fact-sheets/fact-sheet-34-secure-exports-scheme.pdf

${ }^{13} \mathrm{https}$ ://www.customs.govt.nz/globalassets/documents/fact-sheets/fact-sheet-34a-secure-exports-scheme-security-plan.pdf

${ }^{14} \mathrm{http}: / /$ www.legislation.govt.nz/act/public/2018/0004/latest/DLM7040150.html?search=sw_096be8ed818fd78b_secure+export+scheme _25_se\&p=1
} 
$>$ Opportunity to develop business partnerships with overseas importers who are committed to AEO programmes ${ }^{15}$.

Additionally a research conducted by the New Zealand Institute of Economic Research showed that New Zealand's current Mutual Recognition Agreements of AEOs with other countries bring benefits for New Zealand's economy and for export firms. The research identified that the annual benefit for New Zealand is US\$370 million increase to GDP and that AEOs benefit from lower transit costs, reduced inspection times and lower costs of imports and certifications 10 .

To ensure that the security of the global supply chain of certified firms is maintained, New Zealand Customs conducts post-adoption audits in irregular time intervals. These audits assess the level of compliance against each standard and best practices. The audits are also conducted on certified firms' third party logistics providers that have been previously approved as secure sites and transport operators.

Based on the theoretical lenses of the theories of compliance, a conceptual model was developed. To answer the research question proposed in this study, it was decided to conduct a qualitative study based on longitudinal secondary data from audits conducted on SES partners. The SES was implemented in 2004 (Peterson et al., 2009) thus providing rich audit data on the performance of the SES partners over time. Currently there is over one hundred SES partners with over four hundred approved third party sites. For the purpose of this study, a sample of 103 companies' members of SES were selected. The study focused on audits of approved SES sites consisting of exporters' and their third party sites, transport operators were not included in this study. While transport operators have an important role is ensuring cargo transported domestically from factories to the Ports of export, the key element studied in this research are based on key security measures of export operations based on sites and not transport. Another reason for excluding transport operators is that the number of transport firms dedicated to export cargo is small thus audits on transport operators are not exclusively linked to a particular firm but to the transport operator itself.

${ }^{15}$ https://www.customs.govt.nz/business/export/secure-exports-scheme/ 


\section{CHAPTER TWO: THEORETICAL BACKGROUND}

This chapter outlines a general introduction to the literature on compliance behaviour, rules and the regulatory environment to highlight the possible areas of relevance to this study that can answer the research question. Second, the terms and concepts commonly used to explain compliance behaviour from different perspectives will be presented. Based on these key concepts of compliance behaviour, I will finally present the conceptual framework underpinning this thesis

\subsection{Background on Compliance Research}

Following years of research focused on the actions of governing bodies towards compliance, scholars gradually turned their attention to those who are subject to comply with rules. The reason is that compliance requirements for businesses have dramatically increased over the years, to include a wide range of fields, professions and practices (Kagan \& Scholz, 1980; Scholz, 1984; Braithwaite \& Makkai, 1991; Gunningham \& Kagan, 2005). It is undeniable that in today's institutional environment firms are highly regulated by rules, norms, policies and practices in which firms are required to report on their operational compliance with those rules (Sadiq, Governatori \& Namiri, 2007). Research based on firms' compliance behaviour, has been widely discussed by practitioners, policy makers and scholars (Gunningham et al., 2005; Sadiq et al., 2007; Foorthuis et al., 2011). Numerous academic studies have addressed the issue that compliance is a discouraging task for both businesses and governing bodies (Gunningham et al., 2005; Sadiq et al., 2007). There is evidence that business compliance costs affect the ability to comply however, this may not be the only reason for noncompliance and it may not apply to all businesses (Gunninham et al., 2005). Additionally there is evidence that governing bodies often lack of resources to regulate compliance and use self-monitoring mechanisms that allow them to focus on risk individuals and organisations. These self-monitoring mechanisms place the responsibility on firms to comply voluntarily with the rules, policies, standards and best practices (Christmann et al., 2006; Jamali, 2010; Liu et al., 2010; Karlsson, 2017). However, self-monitoring mechanisms have also proved the existence of non-compliance (Sadiq et al., 2007; Foorthuis et al., 2011). Research indicates that compliance behaviour is driven by numerous factors arising from organisational, social and physical settings in which the various regulations, policies, standards and best practices 
are applied (Van Snellenberg et al., 2002; Siddiki et al., 2018). Thus, compliance behaviour can therefore be explained from numerous perspectives. These include, economic (i.e. concerning decisions motivated by financial inducements), reputation and status (i.e. concerning to decisions motivated by acceptance of others), and social (i.e. concerning to decisions motivated by conformity based on understanding of the requirements) (Fairman $\&$ Yapp, 2005).

\subsection{Compliance Theoretical Foundations}

What is compliance? The Cambridge dictionary defines compliance as 'the act of obeying an order, rule or request ${ }^{\prime 16}$. To put it simply, compliance can mean following the rules. Literature (e.g.,) however, explains compliance from different perspectives. Literature has widely used the concept that compliance arises when individuals accept the conditions imposed by governing bodies after measuring the outcomes of getting rewards or gaining approval against penalties or judgment (Kelman, 1958; Lange 1999; Gelderman, Ghijsen \& Brugman, 2006). These concepts are based on rational views and imply that when it comes to the individual's view on compliance, they have a rational choice whether or not to comply and this choice usually involves attitudes and motivations. This means that individuals have a way to process and act on the signals that rules and governing bodies present in the environment (Lindenberg \& Steg, 2007; Etienne, 2011; Siddiki et al., 2018). Early studies based on the rational perspective indicated that organisations measure the utility of compliance to put it simple businesses measure the costs versus the benefits of complying. Early studies, considered that an individual would avoid complying with rules when the penalty was perceived as low value (Kelman, 1958). These studies, for example, explained compliance as a persuaded behaviour associated with pressured conducts in that individuals' conform to specifications dictated by others because of rewards or fear of punishment (Kelman, 1958; Lange , 1999; Lindenberg et al., 2007). Because of these views, models to enhance compliance were based on deterrence and enforcement strategies. These were often based on persuasion to bring organisations into accepting the rules made by the governing bodies (Hawkins, 1994). However, a fundamental belief of compliance is that, there is connection among those who hold the power and those that are liable to that power (Etzioni,

\footnotetext{
${ }^{16} \mathrm{https} / / /$ dictionary.cambridge.org/dictionary/english/compliance
} 
1961). Hence, over time studies attempted to describe compliance at a deeper level to account for connections, such as, behaviours, motivations and goals towards the rules and the regulating processes that governing bodies partake (Hopkins, 1994; Etienne, 2011). Compliance explained from the behavioural response of the individual that is regulated, includes normative views. Thus, newer studies have defined compliance as the individual's behavioural response and the acknowledgement that there is a rule guiding (Etienne, 2011; Siddiki et al., 2018). Scholars argue that understanding compliance is complex because it involves behaviours, rules and the regulating environment. As a result, compliance has been studied from different perspectives and fields, providing a wide range of models that cover different assumptions. Literature has classified two broad approaches to compliance, namely the rationalist and normative views. The rationalist views focus on calculations of costs versus benefits, which aligns with early deterrence models and the normative views account for behaviours, environmental factors, cooperation and assistance (Foorthuis et al., 2011; Etienne, 2011). Scholars have further discussed these views and proposed various models to study compliance. Scholars have also proposed that rules from governing bodies persuade behaviour and that compliance should be referred as the behaviour of the regulated when conforming to the rules (Yuk1, 1989; Hopkins, 1994; Lange, 1999). Since behavioural responses towards rules and the regulating process are an important component, scholars have suggested that not everyone will respond to the rules in the same way. Organisations react in different ways when presented with new rules created by various institutional bodies thus the nature of the rules formulated would also have an effect on compliance (Hopkins, 1994; Siddiki et al., 2018). Lastly, rules are not made on their own; higher bodies are responsible for the development and monitoring of the rules. Scholars have discussed that how regulating bodies signal enforcement and how this would have an effect on the organisation's involvement with compliance (Hopkins, 1994; Lunemburg, 2012).

\subsection{The Rationalist View on Compliance}

Rationalist views on compliance are associated with the early deterrence models. Deterrence perspectives on compliance date back as early as 1600 s to 1700 s; this thinking is based on regulatory studies, mostly from theories of rational choice, planned behaviour and criminology (Sutinen \& Kuperan, 1999; Foorthuis et al., 2011). The rationalist view on compliance generally took into account conformance behaviours associated with punishment 
and, social and economic influences as a form to persuade and attain compliance. These views see individuals' and organisations' compliance as planned behaviour based on motives, such as, gains, moral obligations and fears, and automatic compliance based on habits and routine (Etienne, 2011; Siddiki et al., 2018). Models based on the rationalist view focused on developing strategies for governing bodies to encourage compliance and discourage noncompliance (Sutinen et al., 1999).

A notable contribution was made by Kelman (1958), who proposed that compliance arises from individuals' assessments between pros and cons of complying or non-complying with rules. He brought the view of social influences on individuals' behaviour, implying that to achieve a positive outcome individuals would accept the influence of a governing body either to obtain a reward or approval or simply to avoid sanctions. His perspective discusses the way individuals modify their behaviour to meet with the demands of the social environment. Kelman (1958) described social influence as a request and individuals' behaviour as anything from peer pressure, socialisation, compliance, persuasion and so on. From this, he identified three types of social influences:

$>$ Compliance; individuals or social actors accept the influence might not necessarily agree with the content of the request.

Identification; people accept the influence because it comes from a respected source.

$>$ Internalization; people accept and believe in the content of the request and the influence.

From the perspective of criminology, deterrence models focused on severity of sanctions for achieving compliance. Becker (1968) proposed a framework to understand criminal activity arguing that individuals break the rules based on value maximisation. In this sense, Becker suggested that if breaking the rules exceeds the utility of acting according to the rules, then individuals are likely to act unlawfully. Based on this, he proposed that individuals' decision to comply or not-comply is based upon two main factors: the chance of being caught noncompliant and the severity of the punishment. Becker's model did not go deeper analysing the individuals' reasoning and the degree of punishment however; his framework gave rise to seeking the understanding of compliance behaviour (Sutinen et al., 1999; Mendoza, Dekker \& Wielhouwer, 2016). 
Compliance theory as such was born from the work of Etzioni $(1961,1997)$, referring to it as a set of systems used by governing bodies to influence organisations to comply with rules. Etzioni's work adopted social theories, institutional dynamics and formal organisations to understand the structure of organisational compliance. In his work, he emphasized the analysis of the relationship between the power exerted by the governing bodies and the level of participation of organisations subject to that power. Etzioni (1961) identified three types of powers used by governing bodies to shape behaviour towards compliance - coercive, economic, and normative. In this regard, governing bodies would control using: coercive power to inflict fear, economic power to reward via incentives and normative power via symbolic rewards. He also identified that individuals can be categorised by the type participation - alienated, calculative, and moral. In his view, these types of participations ranged from negative to positive. Thus, alienated participation relates to individuals negatively disengaged, calculative participation relates individuals that assess the benefits and, moral relates to individuals that positively participate in all circumstances. Power and participation are said to correlate, for example, using coercive power to shape behaviour can cause rejection on alienated organisations (Etzioni, 1961). Etzioni's model has been one of the most widely used frameworks in deterrence views on compliance. However, the model has a shortfall; it is based on a macro-organisational idea divided in two dimensions, the governing bodies and organisations. The model focuses on how to influence compliance on individuals and organisations but does not look deep into other motivational aspects that arise from the rules and the environment that surrounds these (Hirsch, 197; Penley \& Gould, 1988).

Compliance deriving from early deterrence models is largely based on strategies aiming to persuade conformance or to develop tools based on dissuasion to reinforce compliance. These views looked at the act of conforming to the rules rather than the ability individuals have to conform to the rules. These views indicate that compliance occurs when individuals or organisations accept the rules proposed by a higher body after calculating the effects of gaining rewards or approval against punishment and judgement (Fairman et al., 2005; Gelderman et al., 2006). Hence, most of the empirical research conducted did not explain the underlying behaviour and indicated that individuals not always behave the expected way according to the level of punishment (Hopkins, 1994; Van Snellenberg et al., 2002; Locke, Amengual \& Mangla, 2009). For example, research found that deterrence models using low 
punishment not always resulted in non-compliance. What is more, perceptions on punishment contrasted among individuals and the rules (Sutinen et al., 1999; Van Snellenberg et al., 2002; Locke et al., 2009; Siddiki et al., 2018). The early deterrence view on compliance also was focused at individual level of regulatory compliance and did not fully focus at the organisational or firm level thus leaving many questions answered (Locke et al., 2009; Siddiki et al., 2018).

\subsection{The Normative Views on Compliance}

Normative views on compliance challenged the rational economic assumptions that refer to the probability of being caught versus punishment, and brought newer ideas for the analysis of compliance (Beaton-Wells, 2015). Theorists noted that compliance is multifaceted and that enriched models were necessary to understand compliance behaviour of individuals or organisations (Sutinen et al., 1999; Beaton-Wells, 2015). Further studies on compliance behaviour have indicated that compliance is not entirely self-manifested; in many cases, the wider environment provides signals via the development of rules and governing mechanisms that affect individuals' and organisations' ability to comply (Van Snellenberg \& et al., 2002; Beaton-Wells, 2015). One of the main attributes of the normative view is that it takes on the rational view and extends the scope to account for multifaceted behavioural motivations, environmental influences and mechanisms that define compliance (Sutinen et al., 1999; Etienne, 2010; Beaton-Wells, 2015). Normative views on compliance extend to integrate other theoretical lenses and perspectives, such as, institutional, social, psychological, economic, behavioural, organisational structures and more (Sutinen et al., 1999; Foorthius et al., 2011; Beaton-Wells, 2015). In this regard, the focus of normative views is not to ensure compliance using models based on punishment but rather use models that enhance cooperation and commitment. Thus, the normative view accounts for the wide range of rules that organisations currently face and proposes improved models to understand compliance behaviour. These models are normally based on the relationship between governing bodies and those who are subject to rules, policies, standards and best practices (Etienne, 2010; Foorthius et al., 2011; Etienne, 2011). 


\subsubsection{The institutional view on compliance}

Recent studies on compliance borrow key insights from the neo institutional philosophy. From an institutional perspective, compliance has been linked to accountability studies based on organisational legitimacy, with emphasis on societal beliefs and institutional pressures (Behnam \& et al., 2011; Hernes \& Erdvik, 2014). The neo institutional view analyses organisational behaviour by paying close attention to the institutional environment in which organisations' interact. Key to this is the notion that organisations are social structures that deal with external pressures arising from new regulations, standards and practices that come from a broader institutional environment (Meyer et al., 1977). In this regard, regulatory compliance from the neo institutional view assumes the role of legitimacy of the new regulations or standards in determining compliance decisions (Sutinen et al., 1999; Jamali, 2010; Siddiki et al., 2018). The main argument of the neo institutional view is that organisations adopt and comply with new rules or standards because they are under pressure from the wider business environment in which they interact (Meyer et al., 1977; DiMaggio et al., 1983; Scott, 2005). Three recognised forces put pressure on organisations: coercive, mimetic and normative. Coercive pressure relates to the power of the governing body by means of laws, regulations and policies; mimetic pressure typifies an organisational response to competition and, normative pressure embodies norms and values that are deeply rooted in an organisation (DiMaggio et al., 1983; Scott, 1995). Evidence of this has been presented in research and identified some firms adopt new regulations because of a fad without a full commitment to integrate, others do it for obtaining economic benefits and others for loyalty (Boxenbaum et al., 2008; Behnam et al., 2011). The neo institutional view argues that organisations pressured to incorporate rules or standards based on external pressures, often following the organisational adaptation process face the dilemma of decoupling from practise. Decoupling is the term used in the neo institutional view to explain disengagement with the new adopted rules or standards (Meyer et al., 1977; Boxenbaum et al., 2008). Westphal and Zajac (2001) and, Bromley and Powell (2012) suggested that frequently, organisations overlook the implementation process and do not take into consideration the effects that new rules or standards would cause to the organisation when implementing them. Two types of decoupling have been widely identified; these are based on inconsistences between policy and practice, and means and ends. Bromley and Powell (2012) described inconsistencies between policy and practice occur when regulations, standards or best practices are adopted as a ritual i.e. detached from daily routines. Similarly, they described 
inconsistencies between means and ends occur when regulations, standards or best practices are implemented but are inaccurately tied to the organisation's activities. Scholars have explained decoupling from different angles, some say that it is the result of strategic actions, misalignment of policy and practices or decentralised individuals' decisions (Westphal \& Zajac, 2001; Bromley et al., 2012; Hernes et al., 2014).

Scholars have argued that analysing compliance from the neo institutional perspective has advantages and disadvantages. On one side, neo-institutionalism recognizes the different dimensions of choice that individuals have. For instance, individuals are intelligent and capable of interpreting, judging and reacting around situations (Etienne, 2010). On the other hand, some scholars have argued that using neo-institutional perspective is only useful for deducing conclusions but does not predict behaviour (Etienne, 2010). Scholars noted that the focus of the neo-institutional view is to explain how the institutional field affects intraorganisational change based on external pressures. Consequently decoupling is the action resulting from the process of organisational change, which by means of empirical research demonstrates whether a firm is compliant or not. In this regard, the analysis of decoupling does not fully explain the underlying factors towards compliance because neoinstitutionalism ignores the problem of actor's behaviour towards conflicting rules (Schuman, 1995; Etienne, 2010). In today's current business environment organisations are surrounded by a vast number of rules and norms from a variety of sources, some are compulsory (i.e. mandated by law) and others are voluntary norms that governing bodies develop for various reasons. Governing bodies are part of the institutional surroundings in which firms interact and as such have influence over organisations and place pressures when developing new laws or norms. These factors are explained in the subsequent sections.

\subsubsection{Accounting for Compliance Motivations}

Academics recognise that motives play an essential part in explaining compliance behaviour. Significant body of research in this area demonstrated that the reasons for complying can be diverse and that, at times individuals and organisations can be driven concurrently by a mixture of motives (Nielsen \& Parker, 2012; Beaton-Wells, 2015). They argued that individuals and firms interacting with the larger institutional setting do not function without knowledge. More often, individuals and firms make choices based on motives or get involved 
out of concerns (Nielsen et al., 2012). Scholars argue that while some individuals by nature comply with rules or procedures and can go beyond compliance, others have different attitudes and motivations towards compliance (Etienne, 2011; Nielsen et al., 2012). Understanding the behavioural aspects combined with the motives behind compliance has been subject of extant research. Up until now, a vast number of scholars have researched and theorised about the factors that motivate compliance behaviour (Kelman, 1958; Becker, 1968; Etzioni, 1961; Sutinen et al., 1999; Van Snellemberg et al., 2002; Gelderman,et al., 2006; Lindenberg et al., 2007; Etienne, 2011). Scholars add that understanding compliance behaviour is a complex task because individuals' and organisations' behaviours are diverse (Etienne, 2011; Nielsen et al., 2012). Some of these behaviours may be automatic the result of spontaneous past learning values, or planned the result of premeditated pursuits or goals coupled with the pressures of a social environment (Etienne, 2011). In this regard, normative views on compliance borrow insights from the institutional and deterrence perspectives to account for underlying factors at the individual and intra-organisational level. This includes viewing motives from theories of scientific management, human and neo-human relations.

Attitudes and motivations towards compliance have a set foundation based on the studies of Lindenberg and Steg (2007), Etienne (2011), Nielsen and Parker (2012), and Aurigmea and Panko (2012) who suggest that there are multiple motivations for individuals or groups to decide whether to be compliant or not with the rules, policies standards or best practices placed by governing bodies. These scholars have used a well-known typology that distinguishes three factors that influence compliance. These factors have been supported through models and research referred to social, economic and normative motives for compliance:

$>$ Social motives for compliance refer to an organisation's commitment in attaining the endorsement and respect of others. In this regard, organisation's behaviour is seeking to be socially accepted by business partners, clients, governing bodies, the public and so on. Strategies based on reputation, such as, be part of an élite group or self-image work well to enhance compliance (Braithwaite et al, 1991; Nielsen \& Parker, 2008).

$>$ Economic motives for compliance refers to an organisation's commitment in taking full advantage of economic or quantifiable returns. Economically driven organisations tend to behave in a rational way to obtain greater financial results. Strategies based on 
deterrence models with formal economic sanctions and informal reputational sanctions tend to work well to enhance compliance from these firms (Bardach \& Kagan, 2002; Robinson \& Darley, 2004; Nielsen et al., 2008).

Normative motives for compliance refers to an organisation's voluntary commitment in complying with the rules. This is considered as the most solid form of compliance behaviour as it involves moral judgement about the elements of the rules, policies, standards or best practices. Organisation's behaviour is based on the belief that acting according to the law would help the firm know its moral perceptions on following the right path. In other words individuals or organisations that are normatively driven to comply do it because they trust the governing bodies and the whole institution of rules and standards (Tyler \& Darley, 1999; Nielsen et al., 2008).

Research using these three types of motivations has provided insightful empirical results on compliance behaviour. Sutinen and Kuperan (1999) proposed a testable model that involved intrinsic and extrinsic motivations for compliance. Intrinsic motivations for compliance apply to circumstances where individuals' actions derive from enjoyment, volition and benefits. Whereas extrinsic motivations for compliance apply to situations where individuals are persuaded to do things. They argued that the presumption individuals approach compliance by weighing economic gains versus sanctions does not represent the full picture. They integrated, to their research framework, social and normative views from the institutional perspective. Their testable model uncovered that individuals' perception of legitimacy of the governing bodies' rules, policies or standards would affect the decision to comply. Many of the interviewees in their research presented normative motivations towards compliance regardless of the penalties. This implied that perception of legitimacy is constructed into the purpose of the rule and not on severity of the penalties (Sutinen et al., 1999).

Nielsen and Parker (2012) shared a similar view, utilising the typology of social, economic and normative organisational motives to test compliance behaviour. Their research confirmed that organisations have multiple motives for compliance reflecting each of these typologies. In addition, they noted that the different motivations of an organisation help to identify three main groups to which organisations can be labelled. Thus, they proposed to label these groups as social citizens, good citizens and dissidents. In a study conducted by Siddiki, Espinosa and Heikkila (2018) they focused on motivations based on deterrence models of 
compliance. In their view, normative and social influences affect compliance behaviour. Their typology to study compliance motivation was based on shame and guilt, fear of social disapproval and fear of sanctions that individuals experience from not complying. The research found that more organisations are worried about social disapproval and guilt as enablers of compliance but little emphasis was assigned to financial sanctions. Moreover, compliance behaviour was identified to materialise at different stages, at the individual, organisational and social level (Siddiki et al., 2018).

\subsubsection{Accounting for the Nature of Regulations as Influencers on Compliance}

Regulations have always been around us, from a young age we are exposed to authority figures that direct what we are allowed to do or what we are not. When we grow up, we face same circumstances but in structured settings, such as, as individuals representing organisations that are guided by rules from the wider institutional environment (Siddiki, Espinosa \& Heikkila, 2018). In the institutional environment, regulations are in the form of legal requirements, policy goals or standards created to promote best practices, insert reporting frameworks and meet regulatory needs (Gilbert, Rasche \& Waddock, 2011; Rasche, 2012). Regulations exist as a response to failures and risks on the economic environment, to control harmful corporate activities or to provide firms with ways of improving performance (Hopkins, 1994; Hobbs, 2010). Literature recognizes two types of regulations, those that are mandatory and those that are voluntary (Hobbs, 2010; Ni et al., 2016).

Mandatory regulations are characterised by an element of rulemaking. These regulations are dictated by statute of law, they carry a legal obligation on organisations on what is ought to be done and what is not. Thus placing an obligation on organisations to comply with the requirements of the rule itself (Gilbert et al., 2011. For example, international trading firms that are subject to technical regulations, such as, mandatory food safety requirements and labelling requirements for allergens must comply with this requirement in order to be able to export products offshore (Liu, 2009; Hobbs, 2010). Other mandatory regulations place an emphasis on self-monitoring mechanisms intended to impose compulsory code of conducts, such as, labour rights or environmental protection (Locke, Amengual \& Mangala, 2009).

Voluntary regulations on the other hand, differ from mandatory rules in that they are characterised by a discretionary or voluntary nature. In this regard, individuals and organisations choose to adopt the regulation (Scholz, 1984; LIU, 2009). The intent of 
voluntary regulations is to create among organisations a culture of voluntary compliance. They are characterised by creating standards and best practices that can enhance productivity, increase revenue, protect from harm and increase the social responsibility of firms (Hobbs, 2010; Rasche, 2012; Siddiki et al., 2018). Voluntary regulations have proliferated to resolve the issues presented in current environments (i.e. enhancing security of export cargo). They are growing in number and spanning a variety of fields; today we see more and more voluntary initiatives not only adopted by businesses but also by governments (Rasche, 2012; Reinecke, Manning \& Hagen, 2012). For example, the International Organisation for Standardization (ISO) and its quality manufacturing standards. These standards aim on maximising production and developing quality products of a firm (Siddiki et al., 2018). Other voluntary regulations are created with a multipurpose intention to protect or help the economy, the public and businesses from external environmental risks (Liu, 2009; Ni et al., 2016). With the advancement of globalisation of markets, we see a myriad of voluntary initiatives based on standards and best practices applied to international trade, many of these standards overlap (Liu, 2009). Classic examples of these are the protection of supply chains via supply chain security programmes such as the Authorised Economic Operator programmes and the Container Security Initiative. These two initiatives have the same aim securing global and many requirements are the same for both programmes (Liu, 2009; Ni, et al., 2016; Karlsson, 2017). While voluntary regulations are not compulsory and firms are free to adopt them, they can in practice become compulsory. Scholars have added that when standards become popular the institutional environment itself would pressure firms to adopt the regulations and maintain compliance (Liu, 2009; Hobbs, 2010). Other types of standards or best practices are voluntary in nature but they come with a binding agreement stipulated in legislation that place certain obligations on organisations. For example, the Secure Export Scheme, is a voluntary initiative that requires to follow certain processes and conditions that New Zealand exporters need to follow during and post application process ${ }^{17}$. One of the major difficulties that voluntary regulations pose to regulating bodies is that when these are adopted for the purpose of legitimacy rather than improving efficiencies or competitiveness, the likelihood of non-compliance is increased (Behnam et al., 2011). This goes back to the institutional views on compliance behaviour and relates to some organisations adopting

\footnotetext{
${ }^{17}$ http://www.legislation.govt.nz/act/public/2018/0004/latest/whole.html\#DLM7040150
} 
voluntary standards and best practises without a real commitment for implementation (Boxenbaum et al., 2008; Behnam et al., 2011).

Literature recognizes that compliance, and non-compliance behaviour is associated with the rules themselves, their content, complexity and requirements (Scholz, 1984; Van Snellenberg et al., 2002; Gelderman et al., 2006). Empirical research has identified that regulations in general, be they compulsory or voluntary are capable of producing an impact or influence on compliance behaviour. There is empirical evidence of compliance and non-compliance behaviour with both, mandatory and voluntary regulations' requirments (Scholz, 1984; Gelderman, Ghijsen \& Schoonen, 2010; Hernes et al., 2014). In a study conducted by Hernes and Erdvik (2014) found that the written content of the regulations affected compliance behaviour. A good number of organisations were unsatisfied that the regulations guidelines were not sufficiently detailed to understand the exact requirements. The lack of detail on the written guidelines created a potential for misinterpretation as organisations made their own judgements. This subsequently affected their ability to comply. In this regard scholars add that when compliance with regulations comes into the balance it is believed that the intended objective of the particular rule may shape behaviour (Edelman, 1992; Scholz, 1984; Hopkins, 1994; Van Snellenberg et al., 2002; Locke et al., 2009; Etienne, 2011). There is evidence of this, studying compliance behaviour with law; Edelman (1992) found that extensive regulations that had vague principles allowed firms with a window to set their own interpretation of the regulation thus affecting compliance. Scholars for example have added that regulations that lack clarity, that have complicated structures with highly technical language, and provide little guidance on how implementing or following the rules, are problematic (Scholz, 1984; Edelman 1992; Behnam et al., 2011; O’Neill, 2014). Similarly, Van Snellenberg and Van De Peppel (2002), found in their research that non-compliance behaviour was largely unintentional because individuals did not understand the content of the rules. They also found, to a smaller degree, that intentional non-compliance behaviour was related to resistance to the rules, lack of expertise from the regulator and economic opportunism from the organisations. Gelderman, Ghijsen and Brugman (2006) observed that individuals' understanding of the rules had a correlation to compliance behaviour supported these findings.

The acknowledgement that the rules' content, complexity and requirements influence compliance behaviour is based on the internal interpretation that individuals and 
organisations place when acquiring information about the rules (Behnam et al., 2011; Foorthuis et al., 2011; O’Neill, 2014). In this regard, when individuals and organisations assess the new regulations, they internalise and interpret information in different ways. If information about the regulation is complex individuals and organisations will assign their meaning thus increasing the chances of misunderstanding (Behnam et al., 2011; Foorthuis et al., 2011; O’Neill, 2014). According to Scholz (1984), some rules are designed clearly because they intend to address less complex issues. These type of rules stipulate what the objective and the expected outcome is and, how enforcement procedures are achieved in different scenarios. Individuals and organisations should not have difficulties in understanding these regulations because they are not ambiguous. However, regulations that intend to resolve complex issues are more problematic, this especially applies to regulations that are focused on resolving issues around businesses processes. These types of regulations are ambiguous; they normally cover many aspects concerning a single issue. Scholars suggest that regulations that present complex procedures normally are difficult for businesses to implement. Businesses find them restrictive, time consuming and costly (Scholz, 1984; Gelderman, Ghijsen \& Schoonen, 2010; Hernes et al., 2014). Scholars agree that when rules are perceived as producing inefficiencies for businesses, they yield a negative impact on compliance (Gelderman et al., 2006).

\subsubsection{Accounting for the Influence of the Regulatory Body on Compliance}

Modern literature recognizes that governing bodies play an important role in shaping compliance behaviour. Van Snellenberg and Van De Peppel (2002) suggested that compliance and non-compliance behaviour is associated with the rules themselves as well as the way governing bodies regulate the rules. Furthermore, scholars have argued that the way governing bodies use regulatory mechanisms trigger signals that can also influence compliance behaviour. Thus, modern models should account for the actors that influence and demand compliance from others (Fairman et al., 2005; Etienne, 2011; Foorthuis et al., 2011; O’Neill, 2014; Gray \& Silbey, 2014).

There are two reasons why regulatory bodies are an important part for studying compliance behaviour. Firstly, in many settings, especially in public policy, the regulatory bodies are the promoters and developers of laws, rules, standards or best practices (Sutinen et al., 1999; Lunenburg, 2012). For years, regulatory bodies have been known for using different mechanisms to influence compliance of individuals and firms. In this regard, scholars add 
that regulatory bodies create rules with the intention of shaping behaviour, however the attempt of moulding behaviour alone causes reactions from individuals and organisations (Smith, 1999; Hopkins, 1994; Van Snellenberg et al., 2002). Secondly, regulatory bodies are also in charge of exercising governance mechanisms, monitoring and maintaining compliance. They have first-hand view of what is the intended outcome of particular rules, thus enabling them to use different methods to ensure those who adopt the regulations maintain compliance. The methods used by the regulatory bodies are known for signalling influences that can affect compliance behaviour (Reinecke, Manning, \& von Hagen, 2012; Foorthuis et al., 2011; O’Neill, 2014; Gray et al., 2014).

Baldwin and Black (2008) stated that the monitoring and enforcing of compliance is usually problematic because the organisational setting includes the engagement of various governing bodies and organisations whose roles and obligations can clash. For example, compliance requirements by various regulatory bodies may pressure organisations as they face multiple regulations at the same time. Another example are compliance requirements that involve various processes inside an organisation. In this regard, organisations are in charge of ensuring compliance of various decentralised units that are located in different geographical zones. They also added that at times regulatory bodies lack specific enforcement objectives and have to rely on self-monitoring thus increasing the chances of non-compliance behaviour. This is particularly the case of voluntary regulations where organisations, after adopting new regulations, are left with the role of maintaining compliance (Baldwin and Black, 2008). In this regard, monitoring mechanisms via well-defined enforcement strategies plays an important role to influence individuals and organisations towards compliance. Scholars have also argued that, frequently, regulatory bodies approach governance of regulations in a safe manner called "soft law". This is especially true to those rules that are voluntarily adopted (Hopkins, 1994; Mason, 2011; Etienne, 2011). However, self-monitoring mechanisms coupled with "soft law" approach is likely to signal organisations to take advantage of this and adopt the proposed regulations without full commitment (Hopkins, 1994; Baldwin et al., 2008; Etienne, 2011). For example, voluntary regulations that require adopting organisations to self-monitor their processes open the door to pick and choose compliance when it is convenient (i.e. at the time until the regulator monitors) (Muldford, 1978; Van Snellenberg et al., 2002; Scheffer and Kaeb, 2011). Other aspect for example is the sanctions inflicted by regulatory bodies when organisations are not compliant. Scholars have argued that in many 
instances sanctions are counterbalanced with economic gains and, that organisations are likely to measure the outcome of a sanction against risk of violation (Mulford, 1978; Van Snellenberg et al., 2002; Fairman et al., 2005; Scheffer et al., 2011). For instance, if sanctions are small and economic gains are higher, organisations may be compelled to infringe the adopted regulations (Van Snellenberg et al., 2002).

Lastly, research identified that regulatory bodies in the role of monitoring are one of the factors that influence failure in compliance (Sutinen et al., 1999). As indicated earlier in this chapter, monitoring mechanisms are normally based on deterrence models. Governing bodies use these mechanisms to influence compliance. Thus, going back to the initial deterrence views on compliance that classified the three types of power employed (coercive, economic and normative), will play an important role in influencing compliance behaviour postadoption of the rules, policies, standards or best practices (Etzioni, 1961). Furthermore, Lunenburg and Ornstein (2012) suggested that the type of enforcement and power the governing body applies affect the behaviour and involvement of organisations with the rules. In their view, in order to obtain compliance cooperation, regulatory bodies need to approach effective strategies that align with the individual or organisational direction and motivations. Modern literature agrees that the way regulatory bodies employ governing mechanisms is perceived by organisations or individuals and that this is likely to shape their behaviour towards the regulatory body and rules thus creating a reaction be either hostility or cooperation (Scholz, 1984; Fairman et al., 2005; Lunenburg and Ornstein, 2012). In this regard, modern studies shifted to cooperation rather than sanctioning. This especially applies to voluntary regulations that aim to shape behaviour without imposing harsh penalties on non-compliance. Cooperative arrangements include tactics that link to behavioural response based on motivations. For instance regulatory bodies in order to improve voluntary compliance offer, financial rewards, reduce compliance costs, monitor only when issues arise, and concentrate only on risk from individuals or organisations (Scholz, 1984; Foorthuis et al., 2011). In today's modern regulatory environment the use of alternative methods is common. Scholars add that effective regulatory mechanisms for voluntary compliance should be solid enough to distinguish those individuals and organisations that do not comply with rules. Scholz $(1984,1991)$ stated that when governing bodies create regulatory mechanisms that are solid, provide enhanced cooperation and can easily detect non-compliance would leave organisation with little motivation default the requirements. 


\subsection{Research Gap}

Literature on compliance behaviour offers a large number of explanations around issues relating to enforcement and behaviour. However, the focus has been oriented to individuals and the consequences that actions deriving from enforcement and behaviours lead to the organisations. Additionally compliance behaviour has been studied from numerous disciplines and areas, ranging from regulations based on legal and policy studies and industrial standards including voluntary standards (Foorthuis \& Bos, 2011; Siddiki, 2018). While there are numerous studies that have addressed compliance behaviour on a range of rules, standards and best practices from different fields. To my knowledge compliance behaviour, specifically speaking from the Authorised Economic Operator (AEO) programmes is limited. As indicated in Chapter one most of the literature on AEOs has mainly focused on adoption, usability and competitive advantage of the programmes (Chang et al., 2015; Laszuk et al., 2016; Pratama et al., 2017). While there are numerous studies that have addressed compliance behaviour on a range of rules and standards from different fields. To my knowledge compliance behaviour, specifically speaking from the AEO programmes is limited.

A preliminary search on ABI/INFORM Global database using key words present in the title and abstract, such as, "compliance behaviour", 'standards conformance', "standards" and 'best practices" resulted in over eight hundred thousand articles. However, when narrowing down to key words, such as, "supply chain security" and "compliance behaviour" the results were much smaller resulting in over twenty thousand articles. Further searches using key words "Authorised Economic Operators" and "compliance" resulted in fourteen results and "Secure Export Scheme" and "compliance" resulted in zero. When using the same range of key words in other journal databases such as Elsevier Open Access Journals, Wiley Online Library and JSTOR Journal Storage obtained similar results in some cases less items were located. A google scholar search using the same range of key words provided comparable results. However, when using key words "secure export scheme" and "compliance" it resulted in one submitted $\mathrm{PhD}$ paper. This paper addressed compliance behaviour from an information security perspective of Customs stakeholders (Shafiu, 2015). As literature on AEOs is an emerging field and research focused on compliance behaviour of these is limited we can conclude that there is a gap in the literature. This particularly applies to compliance behaviour towards the adopted standards of security with its best practices of AEO 
programmes. Thus, this thesis is novel as it intends to provide accounts of compliance patterns among the export firms that are part of the Secure Export Scheme. This will help to further the understanding of compliance behaviour when standards, best practices are adopted by organisations.

\subsection{Conceptual Framework}

Based on the literature review, scholars agree that individuals and organisations are normally driven by three distinct motives or goals that relate to economic gains, social pressures and normative beliefs (Van Snellenberg et al., 2002; Lindenberg et al., 2007; Locke et al., 2007; Etienne, 2011; Nielsen et al., 2012; Siddiki et al., 2018). However, these motivations or goals are affected at different stages by a common denominator being the governing bodies and their regulations. The content of the regulations, how governing bodies interact with the external environment and signal regulatory mechanisms can cause an impact on individuals' and organisations' motives thus affecting compliance behaviour (Etzioni, 1961; Van Snellenberg et al., 2002; Lindenberg et al., 2007; Locke et al., 2007; Etienne, 2011; Nielsen et al., 2012; Siddiki et al., 2018). The conceptual framework of this research is inspired by these ideas and illustrates a number of correlated studies from the review of literature on compliance theory. Figure two below presents a diagram depicting the theoretical framework of this study. 


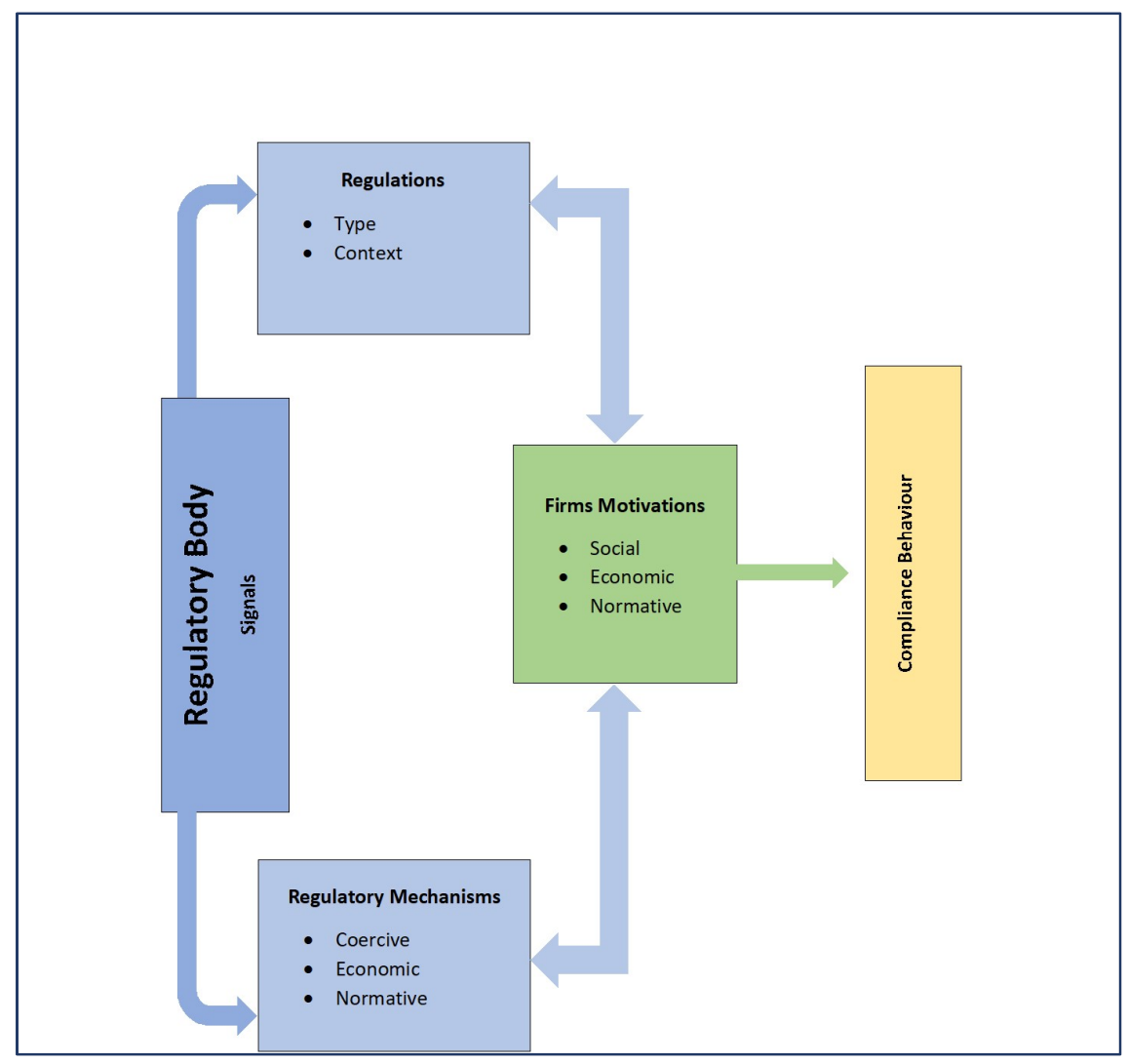

Source: Adapted from the works of Etzioni (1961);Van Snellenberg and Van de Peppel (2002); Lindenberg and Steg (2007); Locke, Amangual and Mangla (2009); Etienne (2011; Nielsen and Parker (2012); Siddiki, Espinosa and Heikkila (2018)

The central idea of the conceptual framework in Figure two above is that compliance behaviour of firms can be influenced by external signals arising from the rules and the monitoring mechanisms that governing bodies develop and implement. I borrowed a wellknown typology that assumes three intra-organisational factors - social, economic and normative influence compliance behaviour of organisations (Lindenberg et al., 2007; Etienne, 2011; Nielsen et al., 2012; Aurigmea \& Panko, 2012). While organisations have their own motivations and goals, they also face influences from the external regulatory environment. The reason for this is that governing bodies play a major role in structuring and shaping the decision making process of organisations and affecting internal motivations (Etienne et al., 2010). Evidence of this can be located from the institutional setting where firms are pressured by the external environment to adopt new regulations, practices, innovations or standards (DiMaggio et al., 1983; Hopkins, 1994; Lange, 1999). Compliance as such and for the purpose of this study is defined as the organisational behavioural response and the 
acknowledgement that there is a rule guiding (Etienne, 2011; Siddiki et al., 2018). The conceptual framework proposed in this study assumes organisations have acknowledged and adopted the new regulations. Thus, regulations as a variable for influencing compliance behaviour is viable. Literature normally classifies regulations in two strings, mandatory and voluntary. Furthermore, literature states that mandatory regulations place a legal obligation on firms whereas voluntary regulations are discretionary and firms choose whether they want to adopt them (Scholz, 1984; Liu, 2009; Gilbert et al., 2011). While this study focuses on measuring voluntary regulations only, it is important to make clear that there is a distinction in regulations type. The conceptual framework also proposes that following adoption, regulations signal organisations on different requirements. Literature has acknowledged that the content of the rules, their complexity and requirements can affect compliance behaviour (Scholz, 1984; Van Snellenberg et al., 2002; Gelderman, et al., 2006). Thus, the framework proposes that social, economic and normative motives for compliance are influenced by the content of rules. Lastly, the role governing bodies in enforcing compliance behaviour via regulatory mechanisms mirrors rational views on compliance behaviour. Modern models on compliance behaviour account for mechanisms, such as, coercive, economic and normative power applied by governing bodies in an attempt to enhance compliance. These same methods are said to signal different strategies that if not applied correctly can trigger the social, economic and normative motive for compliance of firms (Scholz, 1984; Fairman et al., 2005; Lunenburg and Ornstein, 2012). 


\section{CHAPTER THREE: RESEARCH METHODOLOGY}

The purpose of this research is to contribute to the current knowledge on compliance behaviour with an empirical assessment of the New Zealand exports firms that voluntarily adopted the best practices of the Secure Export Scheme to answer the question - What is the compliance behaviour of New Zealand firms that voluntarily adopted the Secure Export Scheme programme's best practices? This chapter presents an overview of the research paradigms. This is followed by presenting the philosophy applied, the research methodology employed to collect data and how the sampling and data collection approaches were designed. The chapter closes with ethics implications and addresses potential bias.

\subsection{Research Paradigm}

Research paradigm is important for researchers because it involves knowledge and where it comes from. Strictly speaking, from a research perspective knowledge is valuable as it helps us to find the meaning of things, express opinions and find answers to questions - like the research question presented in this thesis. There are a number of ways in which we gain knowledge, for example, through personal experiences, observation, assumptions or overgeneralisation (Blackstone, 2018). Kuhn $(1962,2012)$ introduced the term paradigm and said that all research fields are characterised by similar sets of beliefs systems that are used to address a research question. In this sense, the most important aspect of enhancing our knowledge in a research setting is to use reliable research methods and structured systems to interpret information (Kuhn, 2012; Antwi \& Hamza, 2015). A research paradigm is therefore, a systematic way of how a researcher see things and, how via different beliefs attempts to find answers to research questions. Key to this is adopting a philosophical position on viewing the research. Thus, in approaching a research methodology, concepts such as, ontology and epistemology are considered by researchers (Killam, 2013, Antwi et al., 2015).

In research ontological inquiries relate to what a researcher believes is the source of reality and what is known about it (Lincoln \& Guda, 2011; Killam, 2013; Antwi et al., 2015). There are two broad philosophical positions within ontology, positivist and interpretive. The positivist research refers to the belief that there is one reality and it does not change. Using objective measurements, such as, scientific methods or experiment to present empirical findings reveals reality. Thus, research of this nature can be generalised and is quantifiable 
also known as quantitative studies (Lincoln et al., 2011; Antwi et al., 2015). An interpretive research on the other hand refers to the belief that our social constructs and interactions shape reality and as a consequence there are multiple versions of the reality. In this sense, reality is subjective and depends on the interpretation or meaning we attach to it. Thus, research of this nature is of a qualitative nature (Lincoln et al., 2011; Antwi et al., 2015; Blackstone, 2018).

Epistemological beliefs refer to how we uncover the truth. It involves the relationship the researcher has with obtaining knowledge and whether the source of that knowledge should be in an objective or subjective way (Lincoln et al., 2011). The objective position contributes to ontological positivist beliefs. To uncover the truth researchers apply a neutral approach with minimal influence on the information that is gathered. Researchers guided by this idea look from the outside to obtain objective measurements and observations (Lincoln et al., 2011; Killman, 2013; Antwi et al., 2015). The subjective position contributes to ontological interpretive beliefs. It stresses the understanding and meaning of behaviours, situations and experiences from interacting, observing, analysing or conducting case studies. Researchers guided by this idea prefer an insider interpretation of the phenomenon to obtain in-depth understanding (Killman, 2013; Antwi et al., 2015).

\subsubsection{The Research Philosophy Applied in this Thesis}

The purpose of this research is to examine the patterns of compliance of export firms that voluntarily adopted the Secure Export Scheme's best practices. Within compliance research different strategies have been utilised to collect and analyse information. However as highlighted in the previous Chapter 2, research based on the Authorised Economic Operators (AEO) has mostly been oriented to adoption and competitive advantage of the programmes (Chang et al., 2015; Laszuk et al., 2016). Because research on the compliance of AEO is an emerging field and lack of empirical findings, a qualitative approach is more appropriate as it allows for exploring. Additionally, as mentioned in Chapter 2, understanding compliance behaviour is complex because it involves internal motivations as well as other external influences that affect the motivations of individuals or organisations (Foorthuis et al., 2011; Etienne, 2011). The conceptual framework proposed in this thesis focuses on analysing aspects, such as, motivations of the firms and signals that regulating bodies present towards the rules' requirements and post-adoption monitoring procedures. While the proposed conceptual framework will not look every aspect in detail, it is important to stress that, its focus is to understand the relationship between the firms and the regulating bodies to 
comprehend the patterns of compliance. In view of this, the philosophy adopted in this research is based on interpretive enquiries supported by subjective views.

Thus, this research is of a qualitative nature as it is based on the social constructs between the export firms and the governing body that is in charge of regulating the Secure Export Scheme best practices. This research will interpret the views of auditors that transcribed their findings in documents. This will involve the immersion in the data to conduct document analysis, interpret results and observe patterns among the subjects of study.

\subsection{Research Methodology}

Methodology in research refers to the use of systematic ways to obtain and analyse knowledge. It is said that methodology, ontology and epistemology are interconnected and appropriate systematic use of them would properly shape and guide to the next set of beliefs and enquiries (Lincoln et al., 2011; Killman, 2013, Blackstone, 2018). Therefore, the methodology is the technique and action plan that researchers use to direct the whole study. It is argued that a research methodology is not the same as a research method. A methodology refers to the researcher's rationale about the research strategy that will be adopted to conduct the research. Whereas a research method relates to the technique, a researcher uses to collect information (Llewellyn, 1993). Which approach is selected depends on the nature of the study and enquiries around ontology and epistemology. (Kuada, 2009; Antwi et al., 2015). These concepts are the basis for forming a strategy that can help advance the purpose of a research and design the methodology in which information is collected.

\subsubsection{Research Methodology of this Thesis}

As previously indicated the nature of this research is qualitative as it intends to interpret the findings of others. Qualitative research methods explore and advance understanding of a problem or topic. It involves the interpretation of subjective meanings primarily from communication processes and interactions; narrative of collective environments, circumstances and actions; and theory building via finding outlines and relations in the data (Fossey, Harvey, McDemott \& Davidson, 2002). Within qualitative research methods, various perspectives and approaches are used to acquire in-depth knowledge from the data (Bronson \& David, 2012). There is a range of methodologies within research methods that researchers use, these include but are not limited to, experimental, manipulative, general 
qualitative, grounded theory, phenomenology, hermeneutical, dialectical approaches (Bronson et al., 2012; Kuada, 2009). For the purpose of this research, I refer to hermeneutics as the most appropriate methodology. Hermeneutic refers to interpretation, making sense of written manuscripts that signal a meaning (Llewellyn, 1993; Noorderhaven, 2000).

Traditionally the hermeneutics methodology involved the interpretation of religious, literature and philosophical texts. Today, modern hermeneutics extends to all modern methods of communication (Noorderhaven, 2000). As a methodology hermeneutic seeks to make sense of a social context that one is detached from. Thus, its central position refers to distance between the subject that interprets and the object of interpretation (Noorderhaven, 2000). In this sense, understanding as in the individual's ability to intellectually, translate actions, words, written material and other is key to the utilisation of this methodology (Vieira \& De Queiroz, 2017).

This thesis seeks to understand the patterns of compliance behaviour of a specific group of firms. Compliance behaviour lies within the individual who via his or her own motivations makes the decision to comply or not with the rules. However, the conceptual framework proposed in this thesis signposts that the governing body and its regulations affect motivations and this will subsequently cause an effect on compliance behaviour. In an institutional context, the behaviour lies within the organisation that intrinsically involves a number of individuals. Compliance usually involves something that is needed to be complied with. In the case of this thesis, compliance is towards the standards of security that require the implementation of best practices. These standards and best practices are signals explained in written and verbal form. Consequently, individuals within the organisation will interpret, make sense and act upon the written standards and best practices, as well as, any other interaction they may have with a governing body. The governing body on the other hand monitors and conduct audits on organisations to measure compliance with the standards and best practices. Those individuals that conduct the audits will also interpret and made sense of the various interactions they have with the organisations. Outcomes of the audits are later transcribed in documents for others to also interpret and make sense of it. All of these interaction are described in the hermeneutics concept. Additionally, in this social context, distance between the subject that interprets and the object that is interpreted exists as one is independent from the other (Llewellyn, 1993; Noorderhaven, 2000). Thus, the application of hermeneutics seems appropriate to conduct this study. 


\subsection{Ethical Considerations}

The data collection process of this thesis required special permissions given that firms' data was likely to contain sensitive information. In this regard, this thesis follows the guidelines of the Human Ethics Committee of Victoria University of Wellington. Prior to collecting data, ethics approval was sought to maintain the integrity of the work and the prestige of the university. A Privacy Threshold Assessment (PTA) was presented to the New Zealand Customs proposing the research. The PTA was approved in principle provided the research was confidential and firms were kept anonymous. Since the researcher is a current employee of New Zealand Customs, the handling of data collection was executed within the organisations' computerised system and followed the requirements of the Information and Privacy team. Due to conducting this research within New Zealand Customs computerised system, there were no significant ethical or privacy risks.

\subsection{The Researcher's Role and Biases}

The researcher's role in the study took into consideration own personal knowledge regarding the subjects of study. As discussed earlier the researcher's motivation to conduct this study emerged from practical experience notifying some firms on non-compliance. For this purpose the researcher took into consideration own biases and preconceptions and used bracketing standpoint to analyse the data. With this, the researcher avoided those already existing knowledge to interfere with the data analysis. In this regard the researcher reflected that the already insight knowledge about the SES programme was limited to a small number of firms that the researcher interacted with. Thus the overall levels of compliance with the best practices requested in the SES programme were unknown by the researcher. While the researcher considered levels of compliance to conduct the study it was for the sole purpose of understanding underpinning factors that influence compliance behaviour. Because of this the researcher decided to make an evaluation for both compliant best practices versus noncompliant ones.

\subsection{Sampling and Data Collection Techniques}

The appropriateness of the participants and adequacy of the source of information are the main guidance when applying sampling technique in qualitative research (Marshall, 1996; 
Fossey et al., 2002). In this regard, qualitative research places and emphasis on identifying participants that can provide accurate evidence and that the source of information addresses the research query (Fossey et al., 2002; Marschan-Piekkari \& Welch, 2004). In designing the sampling methodology, I took into consideration these recommendations. The proposed theoretical framework of this study uses compliance theory to understand the patterns of compliance behaviour of exports firms with the adopted standards and best practices of the AEO programme in New Zealand. To provide accurate accounts on patterns of compliance it is best to consider participants that have already been assessed against this. Therefore, the participants of this study include those that have previously been subjected to monitoring processes by the governing entity.

The type of data and how it is gathered is other consideration that researchers need to account for. However, qualitative research is characterised for being flexible with data gathering. Thus, researchers can explore various sources of information (Fossey et al., 2002). Traditionally researchers use interviews, surveys and observation. However, there is also the inclusion of collecting data from written material, images and so on (Fossey et al., 2002; Antwi et al., 2015). The central theme of this research is exploring compliance patterns of firms that are already part of the AEO programme in New Zealand. While conducting interviews or surveys would bring closeness to the subjects of research. I believe it would limit the research to obtain only the perceptions of the firms and not how firms are actually performing against compliance. In view of this, an alternative is to explore written documents, such as, audits that firms have been subjected to, since they entered the programme. Audits are conducted by the entity that regulates firms and contains rich information about compliance behaviour and patterns over time.

When collecting the sample, non-probability sampling techniques are preferred over probability. This is because non-probability techniques are subjective in nature and focused on the characteristics of the sample and the aim of the study (Etikan, Musa \& Alkassim, 2016). Within non-probability sampling technique, researchers have a number of strategies that can apply to select the sample. The most common strategies are convenience and purposive sampling (Etikan et al., 2016). Convenience sampling technique allows the researcher to select subjects of study that are easily accessible, available and convenient (Marshall, 1996; Etikan et al., 2016). Purposive sampling technique in the contrary, allows researchers deliberately select subjects that best fit the qualities to answer the research 
question and can provide rich quality information (Marshall, 1996; Etikan et al., 2016). In deciding the research strategy, I took into consideration time, resources, availability and richness of the data. I concluded to use purposive sampling technique for reasons explained in the next paragraphs.

\subsubsection{The Sampling and Data Collection Methods Applied in this Research}

The sample of this research involves export firms that are part of the Secure Export Scheme (SES). Export firms are audited in segments from the moment they enter the programme. The objective of monitoring is to test measure each best practice and record whether it is compliant with the prescribed requirements. Therefore, this research uses secondary data in the form of audits performed over time. Data on audits ranges from 2005 to 2018. During this period, approximately 1000 plus audits have been completed, documented and reported. Auditors collect insights about compliance and record their opinions and results in the reports. This type of information provides the researcher with the opportunity to evaluate compliance patterns over time. Additionally this data offers an ideal setting for obtaining insights that are valuable for the proposed conceptual framework. As previously explained in Chapter 1, an AEO programme involves the firms and any other third party logistic (TPL) sites that export firms contract to perform export operations on their behalf (Janowska-Bucka, 2008). Thus, this research will also include to some extent audits conducted on TPL's. In choosing the data collection strategy, I conducted a preliminary assessment to evaluate the type of data available and identify any constraints. I identified and considered the following limitations that:

One limitation was the decision whether to interpret over 1000 audit reports or reduce the sample size. Audit reports are in written format and examination of the reports is achieved by checking one by one to collect insights. It would be extremely time consuming to assess each audit report. In addition to this, the availability of resources to collect the data were limited. Given the nature of the data and privacy regulations around business information. I obtained as a current employee permission to collect data within Customs computerised system only. This limited the pool of resources to assess the data, for example, I could not use NVIVO to assess the documents. This left me with the option to use excel spread sheets to collect and analyse information, which again is time consuming to do. However, one of the characteristics of qualitative research method is that it is centred on obtaining sufficient data that describe the phenomena and answer the research query (Fossey et al., 2002). Thus, in 
terms of sample size qualitative research could involve smaller samples as long as they contain adequate data (Marshall, 1996; Fossey et al., 2002). In this regard, reducing the sample size was feasible to conduct this study and minimise the limitations described above.

Second limitation was around audits, Customs selects each year a sample of firms and their TPL sites for audits. This causes an effect on the sequence of the audits per year as different firms are audited each year. Normally longitudinal approach measures change on a two chronological range that involves time and a subject (Garret, 2007). Longitudinal approach considers time as a continuum and differences between subjects. When differences between time and subjects are identified it is recommendable to form cohorts at a specific time (Garrett, 2007). Cohort in longitudinal approach is defined as group of individuals that experience the same situation in a time-period (Garret, 2007). In this regard, this research can form cohorts based on the audit period rather than the year the firms were audited. For example, a cohort of firms and sites that were audited for the first time, a cohort of firms that were audited for the second time and so on.

Third limitation was concerned with the audits executed on Third Party Logistic (TPL) approved sites. I identified that many of these contracted TPL approved sites were shared among industries thus audits on a TPL were likely to overlap. Referring back to convenience sampling strategy that allows the use of purposive sampling technique helps. Deliberate selection of the subjects can help to avoid this issue as well as to ensure that audits from cohorts are spread and represent the sample population. Purposive sampling technique would help to ensure that the audit of a specific TPL selected under one SES firm was not the same for other SES firm. The preliminary assessment helped to re-evaluate the sample and data collection resulting in the following outcome:

$>$ Collected audit data and available demographics of 103 export firms that have been audited between 2005 and 2018 .

I selected one audit per firm in a given year. For example, those firms that had only one site I selected the one available audit. Those firms that had no sites a contracts to TPLs I purposively selected a TPL that was audited. Those firms that had multiple self-owned sites I randomly selected one audit. Those firms that had multiple selfowned sites and TPLs I purposively selected one audit. 
Data collected was at irregular time intervals, this is due to the nature of audits, which occur in groups each year. Because of this, the sample appears as time-period with different sample sizes and somewhat independent observations. This resulting in the ability to conduct exploratory analysis to discover patterns of systematic variation across groups of firms in a year interval.

$>$ The audits collected were divided into three groups that could be followed over time. Table two below shows how the groups of audits were organised. A1 group represents the first time the 103 firms had an audit. Out of the 103 firms, 68 had an audit for the second time, these are represented by A2 group. Out the 68 firms, 25 firms had an audit for the third time, these are represented by A3 group. Additionally the 25 firms audited for the third time could be traced back to follow their specific progress over time.

Table 2: Audits samples over time

\begin{tabular}{|l|c||}
\hline Audit Period & No of firms audited \\
\hline \hline A1 = First audit period & $\mathrm{n}=103$ \\
\hline \hline A2 = Second audit period & $\mathrm{n}=68$ \\
\hline \hline $\begin{array}{l}\text { A3 = Third audit period } \\
\text { (T1, T2, T3) }\end{array}$ & $\mathrm{n}=25$ \\
\hline \hline Grand Total & $\mathbf{1 9 6}$ \\
\hline
\end{tabular}

In addition to gathering data from the audits, I also used open source data to obtain information about the standards of security and required best practices and legal documents requiring compliance. The focus is on the audits of the sample selected where the unit of analysis are whether the firm is compliant or non-compliant. The compliance aspect is on the best practices that firms are require to implement. Therefore, mapped audits results with open source information relating to the 67 best practices (Appendix 1 contains a summary of the 67 best practices chosen for this research). This data is publically available in the Customs website. From the public Customs website, I collected open source data of the benefits the SES programme proposes, as well as, obligations and regulatory requirements. Legislative requirements are in the form of law under the Customs and Excise Act 2018. This 
information is publically available in the New Zealand Parliamentary Counsel Office website. Some company demographics were also collected from the export firms' individual websites and the New Zealand Companies Register.

\subsubsection{Data Analysis Approach and Coding StrategyThis study builds on unobtrusive} research of audit documents using a directive approach of qualitative content analysis to analyse data. Qualitative content analysis is a system that provides understanding of a phenomenon via the subjective interpretation of the substance of the text data (Vieira \& Queiroz, 2017). Qualitative content analysis primarily focuses on the interpretation and meaning of the text data. It is a technique used to conduct systematic analysis and narrative of text data based on human interaction (Hsieh \& Shannon, 2005; Vieira et al., 2017). Important features of qualitative content analysis is that it uses organized structures to categorise text data using themes and concepts to create codes and frames thus providing greater flexibility for analysis (Vieira et al., 2017). Researchers commonly use traditional, directed and summative data coding methods to conduct content analysis. The traditional method of coding is applied when literature and theory on a particular issue is limited. Researchers code categories directly from the text data thus allowing gaining new insights (Vieira et al., 2017). The directed method of coding applies when literature and theory exists but there is not sufficient research on the issue. Researchers using the directed approach develop conceptual frameworks to help them identify key variables and concepts (Vieira et al., 2017). The summative approach of coding applies when researchers want to understand the usage of words, messages or content. Researchers using this method use key words, counting and comparing (Vieira et al., 2017). The directive approach of qualitative content analysis is appropriate for the purpose of this research as it provides the means to use a method that best suits this study. As previously mentioned this research intends to analyse text data from audit reports and other material to understand patterns of compliance among firms. This study uses a conceptual framework to gain key insights from the existing literature and theory surrounding the compliance behaviour phenomenon.

The data coding involved a number of phases to prepare the data, familiarise with the content of audits and other open source material, extract the unit of analysis, develop coding scheme, develop a method to anonymise subject, assess and re-assess consistency of the coding, collate all coded data to assess findings. The following is a summary of the steps followed: 
1. Familiarisation with the content of audits and external material was executed to gain insights into the data and to identify which variables could be used for this study. This involved reading all sampled audits and other sources to relate to the conceptual framework.

2. For the purpose of this research, 67 standard's best practices were identified as the main stratum. These were extracted, mapped and categorised in excel sheets for each firm to later collect compliance and non-compliance instances from the audit reports.

3. A procedure of systematic coding was developed to anonymise firms. This coding system allowed the researcher to trace back firms and audits were data was identified as missing.

4. Each audit report was analysed separately to identify compliance and noncompliance. The audit reports clearly identified compliance and non-compliance linked to a particular best practice. This information was collected in numerous excel sheets (103) pertaining to each firm. Codes were assigned for compliance $=1$ and non-compliance $=0$. These codes were assigned to each of the 67 best practices. The information was categorised by the year the audit was conducted to identify the first, second and third audits that the firms were subjected to. The raw data was re-assessed to identify gaps and missed information. Because each excel sheet followed a systematic coding system any gap on information was easily traced back.

5. All the data collected on each firm was later collated in a single excel document. I applied filters to this document to identify each audit period. I subsequently created excel sheets for each audit period sample for analysis.

6. Firms' demographic information were available was extracted from the audit reports as well as from a variety of open source data. The information of each firm was collated in an excel sheet. Codes around demographics were used to further deidentify firms. Thus firms were clustered by industries and company size in terms of number of employees.

7. A frame was developed to categorise legislative and standards' best practices requirements. This frame categorises each standards by the contextual meaning that is 
based on the conceptual framework. This frame was utilised separately to draw conclusions during the analysis process. 


\section{CHAPTER FOUR: DATA ANALYSIS AND RESULTS}

As previously indicated, the purpose of this thesis is to understand the patterns of compliance of export firms that have voluntarily adopted the best practices of the Secure Export Scheme (SES). This Chapter presents the results from the analysis conducted on the audits. In the context of the research question, the findings indicate that the compliance behaviour of export firms varies. While overall, the firms present high levels of compliance the analysis detected that there are specific best practices that the firms are struggling to achieve. The first part of this Chapter commences with an overview of the characteristics of the sample selected for analysis. The second part presents a detailed analysis divided into two stages to understand the levels of compliance and the identification of the specific non-compliant 'best practices'.

\subsection{Characteristics of the Firms}

Before discussing the empirical results of this analysis, it is important to describe the characteristics of the export firms that formed the data set of this study. The results of this study are based on the analysis of one hundred and ninety six audits from a range of sites distributed among 103 export firms that are part of the SES. Most of the characteristics of the export firms have been derived from the audit reports. However, some information has also been collected from external publicly available sources. It is important to note that some of the information collected may not represent the actual figures of the firms and some variations can be expected. For example, during the analysis of the audits it was identified that firms go through various changes, such as, incorporating or closing new sites including Third Party Logistic (TPL) sites and changes around transport operators, in-house declarants and Customs brokers. All these changes affect some of the figures presented in the firms' characteristic as each data information was retrieved at the point when the audit was conducted and might not be current.

The 103 export firms belong to a range of industries depicted in Table three below, these proportions are representative of New Zealand firms as per the Australian and New Zealand Standard Industrial Classification (ANZSIC). Food and beverage industry covers $35 \%$ of the exporters in this sample; this is followed by agriculture produce accounting for $20.4 \%$ and wood and paper exporters with $17.5 \%$ of the exporters in this sample. While each industry may have different requirements over manufacturing processes, when it comes to the SES 
programme, the same security requirements are expected from firms regardless of the industry they belong to. In terms of company size this analysis adapted to the recommendations established by the Organisation for Economic Cooperation and Development (OECD) to categorise firms' size. According to the OECD a common categorisation is by the number of people employed by firms. Thus small firms normally employ between 1 to 50 staff (this includes micro-businesses), medium sized firms employ between 51 to 250 staff and large firms employ 251 and more staff ${ }^{18}$. Exporters belonging to the SES are well spread in terms of business size. The analysis showed that $31 \%$ of the sampled exporters correspond to small firms, 33\% to medium sized firms and 36\% to large firms. The organisational type of firms varied from local established exporters, multinational corporations, subsidiaries and affiliates. Local New Zealand exporters represented the majority, with $60 \%$ of the sampled firms. Multinational corporations both, New Zealand based and foreign established in New Zealand accounted for $15 \%$ of the sample. New Zealand subsidiaries accounted for $23 \%$ and affiliates for $2 \%$ of the sampled exporters.

Other characteristics observed related to sites ownership, control over transport operators and control over export declarations. It was identified that $23 \%$ of the sampled export firms did not own manufacturing operations - thus contracting services to TPL. The remaining 77\% export firms self-owned between 1 to 29 sites. However, firms contracting export operations to TPL businesses accounted for $58 \%$ of the sampled exporters. The remaining $43 \%$ of the sampled exporters did not contract TPL sites. TPL contracted sites per firm ranged between 1 to 109 sites. The analysis of ownership of sites and contracting services to TPL businesses identified that some firms having self-owned sites still contract export operations to TLP sites. Another characteristic identified from the sampled export firms was whether the firms had control over transport operators or not. The analysis identified that $86 \%$ of the export firms had direct arrangements with domestic transport operators thus having full control. The remaining $14 \%$ of the firms delegated domestic transport arrangements to third party logistics businesses to deal with. Firms also were characterised by arrangements on how export declarations were submitted with Customs. The analysis identified that $53 \%$ of the exporters had in-house declarants directly submitting export declarations. While a $42 \%$ of the exporters had contracted the services of a Customs broker to conduct this work. A small number of

\footnotetext{
${ }^{18} \mathrm{https} / / /$ data.oecd.org/entrepreneur/enterprises-by-business-size.htm
} 
firms accounting for $6 \%$ had both in-house declarant and Customs brokers to conduct this task.

\section{Table 3: Firms characteristics}

$\mathrm{n}=103$

Sampled audits 196

Industry Characteristics:

$\begin{array}{ll}\text { Agriculture produce } & 20 \%\end{array}$

$\begin{array}{ll}\text { Food and beverage } & 35 \%\end{array}$

Machinery and equipment $\quad 9 \%$

Textile, leather, clothing and footwear $\quad 12 \%$

$\begin{array}{ll}\text { Wood and paper } & 17 \%\end{array}$

$\begin{array}{ll}\text { Other manufactured products } & 7 \%\end{array}$

\section{Company Size:}

$\begin{array}{ll}\text { Small } & 31 \%\end{array}$

$\begin{array}{ll}\text { Medium } & 33 \%\end{array}$

$\begin{array}{ll}\text { Large } & 36 \%\end{array}$

\section{Organisational Type:}

$\begin{array}{ll}\mathrm{MNC} & 15 \%\end{array}$

$\begin{array}{ll}\text { Local exporter } & 60 \%\end{array}$

$\begin{array}{ll}\text { Subsidiary } & 23 \%\end{array}$

$\begin{array}{ll}\text { Affiliate } & 2 \%\end{array}$

\section{Sites Ownership:}

$\begin{array}{ll}\text { Exporters owned zero sites } & 23 \%\end{array}$

$\begin{array}{ll}1-29 \text { self-owned sites } & 77 \%\end{array}$

$1-109$ contracted to third party logistics (TPL) $\quad 58 \%$

Exporters don't contract third party logistics $\quad 42 \%$

\section{Control Over Transport Operators:}

Controlled by the SES firm $\quad 86 \%$

Not controlled by the SES firm $\quad 14 \%$

\section{Control over export declarations:}

$\begin{array}{ll}\text { In house declarant } & 53 \%\end{array}$

External Customs broker $\quad 41 \%$

$\begin{array}{ll}\text { Both in-house declarant and Customs brokers } & 6 \%\end{array}$ 
Firms' length of time in the SES programme ranges from three to fifteen years. As depicted in Figure 3 below, the majority of the firms (sixty-two) have more than 10 years in the SES. Thirty firms have between 10 to 6 years and eleven firms have less than 6 years in the programme. This indicates that a large number of SES firms are experienced with the programme's requirements.

Figure 3: Firms' Length of time in the Secure Export Scheme

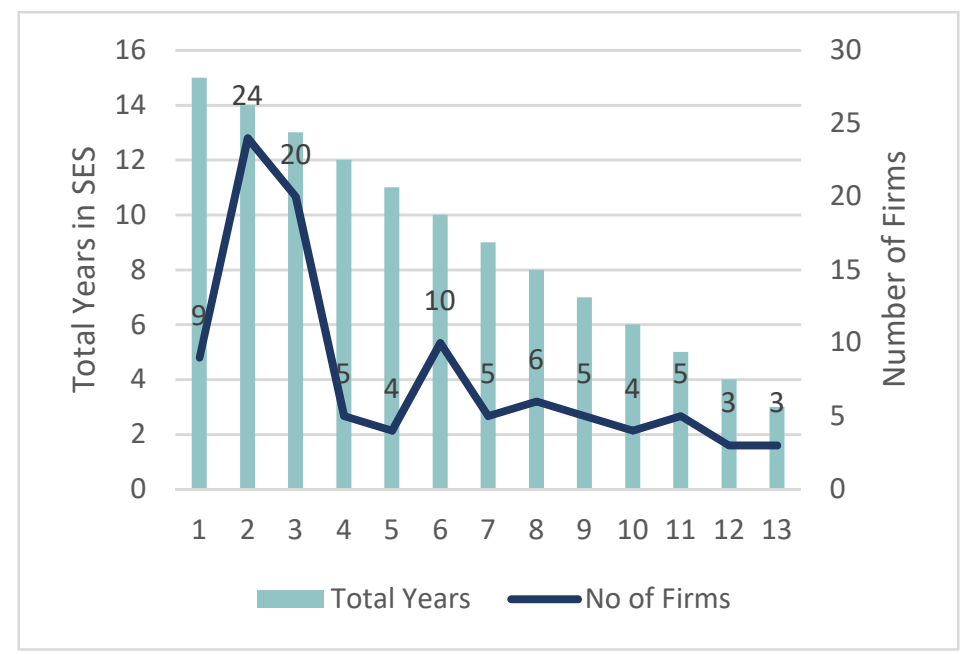

The frequency of audits varied among firms, these are conducted in time intervals from 2005 to 2018. Every year a number of firms and their third party logistic sites (TPL) are selected for audit. As depicted in Figure 4 below, while all 103-export firms were subject to a first audit, it was identified that subsequent audits varied. The samples corresponding to the second and third audit became smaller with 68 and 25 respectively. The decrease in sampled audits per firm varied for two reasons. First, the preliminary analysis explained in the previous Chapter 3 indicated that TPL sites are shared among businesses in the same industry. Second, firms subject to second audits are selected depending on previous audits findings and how often a firm has been audited in previous times. 


\section{Figure 4: Firms' Frequency of audits}

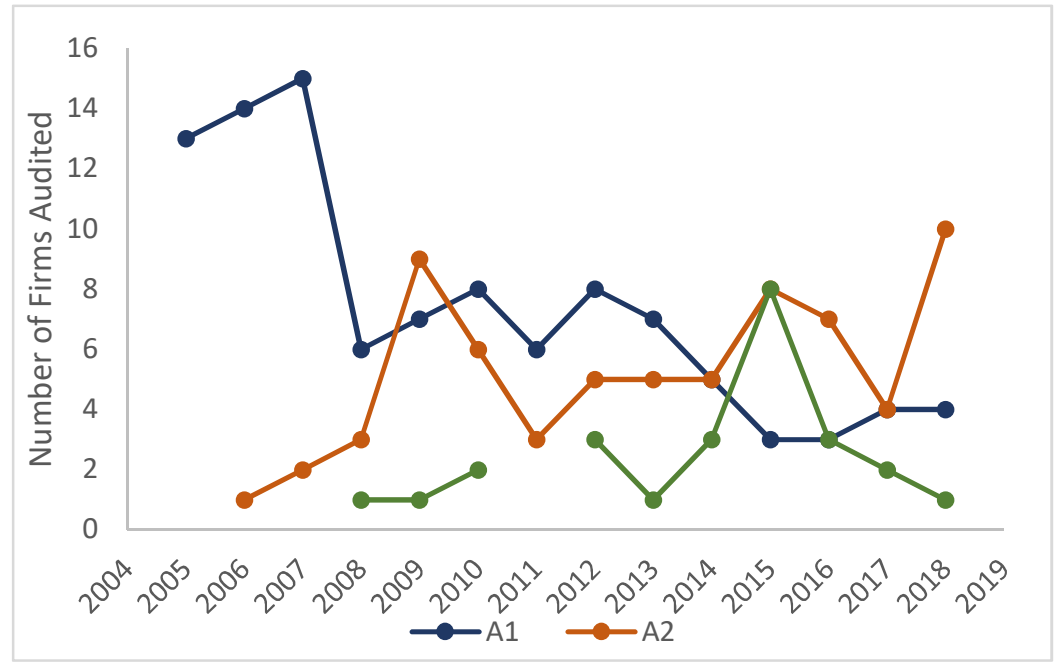

\subsection{Analysis and Results}

This thesis seeks to answer to the following research question - What is the compliance behaviour of New Zealand firms that voluntarily adopted the Secure Export Scheme programme's best practices? Thus, compliance behaviour towards the best practices is the focal point of this research. To answer the research question this analysis was divided in two stages. The first stage was focused on understanding the levels of compliance postcertification. This consisted on exploring all the audit data to identify the degrees of compliance post-certification from the first audits to the third audits that these firms received. The three samples of audits (A1, A2 and A3) that were described in the previous Chapter form part of this analysis. The second part of the analysis consisted of identifying specific compliance behaviour with the best practices. For this analysis a cohort of firms ( 25 firms) that were audited consecutively (i.e. three times) was selected (T1, T2 and T3). Given the number of best practices (67) and time constraints, this part of the analysis narrowed down to select only best practices that presented maximum compliance and the higher degrees of noncompliance. The results of all the analyses are presented using descriptive statistics.

\subsubsection{First Analysis - Identifying levels of compliance post-certification}

The first analysis was conducted to identify compliance levels among firms. Table 4 below summarises the findings (full results by best practice among the three audit periods is located in Appendix 2). This analysis included the audits conducted on the 103 export firms. For each 
sampled firm I collected the audit of one site from their first audit until their third audit. The total of audits examined were 196. These were divided into three periods, the audit period one (A1) covered all the 103 SES firms, this is the first audit that these firms were subjected to upon being certified in the SES programme. The audit period two (A2) covered 68 firms having their second audit. The audit period three (A3) covered 25 firms having their third audit. The data collected on compliance was based on counts of violations attributed to each of the 67 best practices of the SES. Compliance received a score of zero " 0 " and noncompliance received a score of one " 1 ". A fully compliant site received 67 scores corresponding to $100 \%$ compliance with all 67 SES best practices. Calculations used simple statistics. To calculate the total average rate of compliance firms were grouped by the number of best practices that these were compliant with. In the first line, commencing with the first audit period A1, 6 out of the 103 firms were compliant with all the 67 best practices $((6 / 103) * 100=6 \%$ round up). The total average compliance rate was the sum of each line in column $\overline{\mathrm{x}}$. Alternatively the calculation in the dataset is represented by the (sum of all the compliant best practices per audit period) / (Total number of firms x Total number of best practices) x 100. The average number of compliant best practices was calculated using a weighted factor. The weighting factor corresponds to the (sum of (number of firms $x$ number of specific best practices compliant) / total number of firms). As per the first line in Table 4 below, the weighted factor corresponds to (A1 6 x CBP $67=W F$ 402). The sum of each weighted factor in column $W F$ was divided by the total number of firms in the specific sample $(6,388 / 103=62)$.

Table 4: Compliance with Secure Export Scheme's best practices among firms

\begin{tabular}{|c||c|c|c|c|c|c|c|c|c|c|c||}
\hline $\begin{array}{c}\text { A1 } \\
(\mathbf{n}=\mathbf{1 0 3})\end{array}$ & $\mathbf{C B P}$ & $\mathbf{W F}$ & $\overline{\mathbf{x}}$ & $\begin{array}{c}\mathbf{A 2} \\
(\mathbf{n}=\mathbf{6 8})\end{array}$ & $\mathbf{C B P}$ & $\mathbf{W F}$ & $\overline{\mathbf{x}}$ & $\begin{array}{c}\text { A3 } \\
(\mathbf{n}=\mathbf{2 5})\end{array}$ & $\mathbf{C B P}$ & $\mathbf{W F}$ & $\overline{\mathbf{x}}$ \\
\hline 6 & 67 & 402 & $6 \%$ & 7 & 67 & 469 & $10 \%$ & 1 & 67 & 67 & $4 \%$ \\
\hline \hline 12 & 66 & 792 & $11 \%$ & 7 & 66 & 462 & $10 \%$ & 4 & 66 & 264 & $16 \%$ \\
\hline \hline 15 & 65 & 975 & $14 \%$ & 8 & 65 & 520 & $11 \%$ & 3 & 65 & 195 & $12 \%$ \\
\hline 15 & 64 & 960 & $14 \%$ & 8 & 64 & 512 & $11 \%$ & 3 & 64 & 192 & $11 \%$ \\
\hline \hline 6 & 63 & 378 & $5 \%$ & 13 & 63 & 819 & $18 \%$ & 4 & 63 & 252 & $15 \%$ \\
\hline 12 & 62 & 744 & $11 \%$ & 6 & 62 & 372 & $8 \%$ & 5 & 62 & 310 & $19 \%$ \\
\hline
\end{tabular}




\begin{tabular}{|c|c|c|c|c|c|c|c|c|c|c|c|}
\hline 11 & 61 & 671 & $10 \%$ & 4 & 61 & 244 & $5 \%$ & 1 & 61 & 61 & $4 \%$ \\
\hline$\overline{55}$ & 80 & 300 & $4 \%$ & 3 & $\overline{60}$ & 180 & $4 \%$ & $\overline{1}$ & 60 & 60 & $4 \%$ \\
\hline 3 & 59 & 177 & $3 \%$ & 2 & 59 & 118 & $3 \%$ & 1 & 59 & 59 & $4 \%$ \\
\hline 4 & 258 & 232 & $3 \%$ & 4 & 58 & 232 & $5 \%$ & 1 & 255 & 55 & $3 \%$ \\
\hline 4 & 57 & 228 & $3 \%$ & 3 & $\overline{57}$ & 171 & $4 \%$ & 1 & 43 & 43 & $3 \%$ \\
\hline 5 & 56 & 280 & $4 \%$ & 2 & 56 & 112 & $2 \%$ & - & - & - & - \\
\hline 1 & 54 & $\begin{array}{ll}54 \\
\end{array}$ & $1 \%$ & 1 & $\overline{55}$ & 55 & $1 \%$ & - & - & - & - \\
\hline 1 & 53 & 53 & $1 \%$ & - & - & - & - & - & - & - & - \\
\hline 1 & 51 & 51 & $1 \%$ & - & - & - & - & - & - & - & - \\
\hline 1 & 48 & 48 & $1 \%$ & - & - & - & - & - & - & - & - \\
\hline 1 & 43 & 43 & $1 \%$ & - & - & - & - & - & - & - & - \\
\hline \multicolumn{4}{|c|}{ Total average rate of compliance } & \multicolumn{2}{|c|}{ A1 93\% } & & \multicolumn{2}{|c|}{ A2 94\% } & \multicolumn{3}{|c|}{ A3 93\% } \\
\hline \multicolumn{4}{|c|}{$\begin{array}{l}\text { Average number of compliant } \\
\text { best practices }\end{array}$} & \multicolumn{2}{|c|}{ A1 62 } & & \multicolumn{2}{|c|}{ A2 63} & \multicolumn{3}{|c|}{$\mathbf{A 3} 62$} \\
\hline
\end{tabular}

(x: Average Compliance Rate, CBP: Compliant Best Practices, WF: Weighted Factor, A1, A2 and A3: Audit Periods; $n=103, n=68$ and $n=25$ : sample size per audit period)

Overall, high degrees of compliance were located among the SES firms. In the first audit period A1, the average rate of compliance was $93 \%$. This means that on average firms were compliant with 62 best practices. In the second audit period A2, the average rate of compliance increased one percent (94\%) thus increasing the average compliance of the best practices to 63 out of the 67 . The third audit period A3 presented same results as A1 with a rate of $93 \%$ compliance and an average of 62 compliant best practices out of the 67 . Further analysis indicated that full compliance was identified in a small number of firms. For example from the 103 firms that received their first audit, only six firms were fully compliant with all the 67 best practices (100\% compliance). The remaining of the firms presented different degrees of compliance ranging from 43 to 66 compliant best practices. As depicted in the summary Table 4 above, twelve firms were compliant with 66 out of the 67 best practices. Other fifteen firms were compliant with 65 and 64 best practices respectively. At 
the lower end, it was located that one firm was compliant with 43 out of the 67 best practices. The 68 firms that were audited for the second time presented similar results. Within this group achievement of the best practices ranged from 55 the minimum to 67 the maximum. At the higher end, 7 out the 68 firms were fully compliant with all the best practices $(100 \%$ compliance). These were followed by 7 firms that were compliant with 66 best practices out of the required 67. From there the compliance with best practices started dropping by one best practice. The minimum achievement was 55 out of the 67 best practices which is an increase from the minimum located in the in the first audit period. Lastly, the 25 firms that were audited for a third time presented different characteristic. In this audit period, only one firm was fully compliant with all the 67 best practices (100\% compliance). The remaining of the firms presented different degrees of achievement of the SES best practices ranging from 43 the minimum to 66 at the upper end. Figures $5 \mathrm{a}, \mathrm{b}$ and $\mathrm{c}$ below show a visual representation of these findings. It can be observed in the figures that the higher levels of compliance are spread to the left. The outlier firms can distinctively noticed on the right hand side of the graphs were compliance starts dropping by small number of firms.

\section{Figure 5a, b and c: Visual representation of firms' compliance levels post-certification}
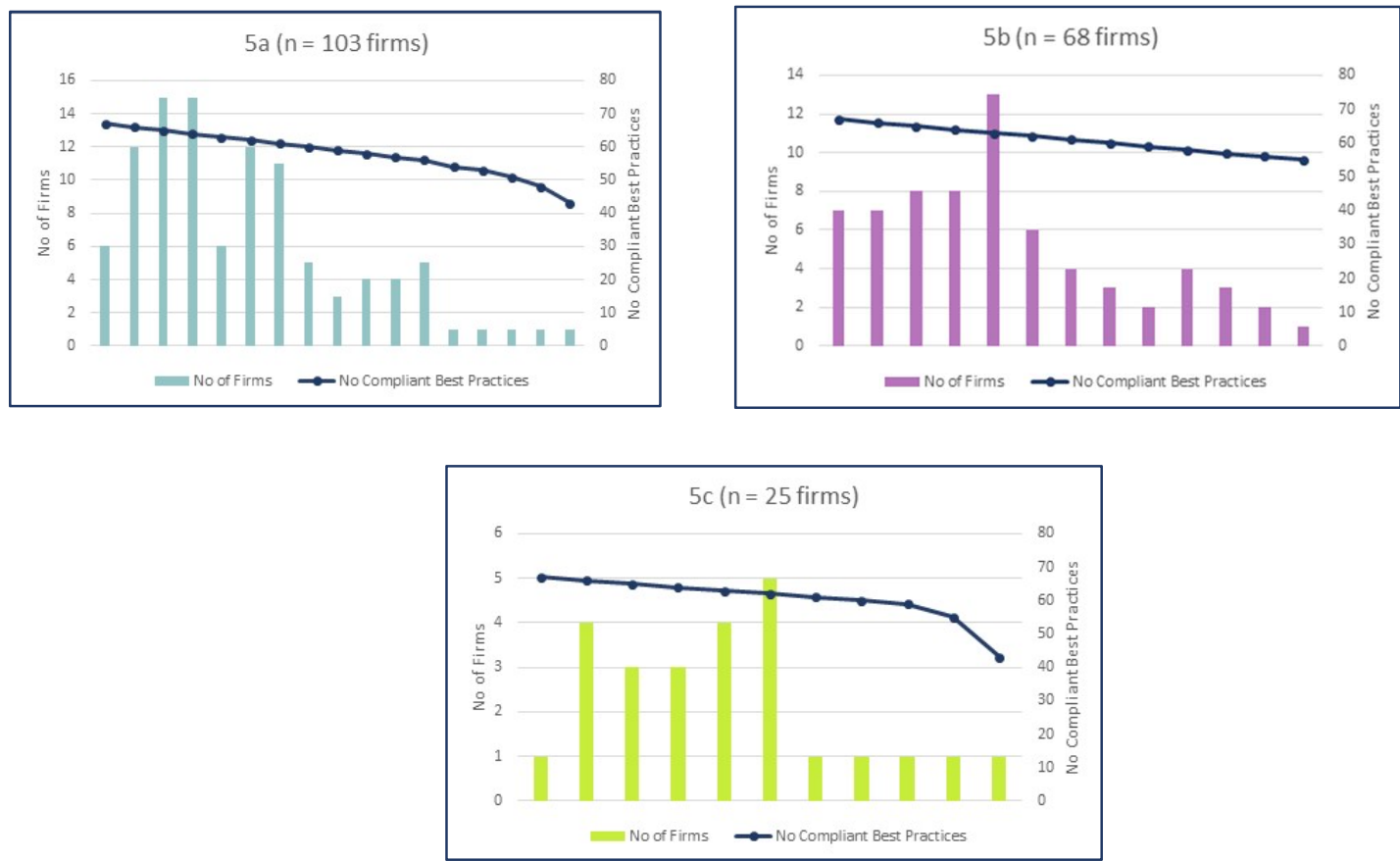

\subsubsection{Discussion of the first analysis findings}

Overall firms have been achieving high degrees of compliance. Compliance of the SES firms is high post-certification, with an average compliance rate of $93 \%$ in audit period $1,94 \%$ in 
audit period 2 and 93\% in audit period 3. As depicted in the Figures 4a, c and c and in Table 4 compliance varies among firms, while the majority of the firms are at the upper end, some outliers can be identified. These outliers appear to be the ones that have the lower compliance rate of the best practices. The findings also indicate that it does not matter how small or big the sample is, the same patterns of compliance are presented with each sample. However, this sole analysis does not answer the research question presented in this thesis. At this point, what is known is that compliance is high because a large number of firms have achieved high degrees of compliance with a large number of best practices and that this is presented over time.

When going back and looking at the samples, maximum fulfilment of all the 67 best practices is only presented in small number of firms in each of the audit periods. In audit period 1 six firms fulfilled all the 67 best practices, in audit period 2 seven firms achieved this and in audit period 3 one firm achieved maximum fulfilment. When looking at the data from this perspective it can be observed that a large number of firms across all samples had one or more best practices non-compliant. These figures indicate that there are some best practices that are unfulfilled by a good number of firms. Analysing those best practices that are compliant in full against those that default could indicate specific compliance behaviour of the firms. The second analysis focused on identifying those specific best practices, thus setting the path to understand certain behaviours among firms.

\subsubsection{Second Analysis - Identifying compliance behaviour with specific best practices}

The previous analysis provided insights on the overall compliance of the SES firms with the best practices. The analysis carried out in this section placed attention on firms' compliance by best practice to identify specific compliance behaviour. This analysis was divided into three phases, the first phase focused on analysing compliance and non-compliance among the SES firms. The second phase focused on placing attention to the best practices to observe specific compliance behaviour. The third phase conducted an interpretive analysis of a group of best practices to understand and discuss compliance behaviour in relation to the conceptual framework proposed in this thesis. For these analyses the cohort of 25 firms was selected as these firms were consistently audited over time. This sample entailed three consecutive audits from the first time firms were audited until their third audit (T1, T2 and T3). 


\subsubsection{Phase one analysis - compliance and non-compliance behaviour among the SES firms}

As expected, this cohort presented high levels of compliance over time. As depicted in Table 5 below, the average rate of compliance for this group was estimated at $93 \%$ and the average non-compliance rate was 7\%. This pattern was presented across all the audit periods of this group (T1, T2 and T3). Same as the previous analysis this cohort showed that on average 62 best practices are compliant. While the compliance figures are not significantly low, this analysis identified that non-compliance was consistent -averaging 5 best practices in each audit period. The analysis also showed that full achievement of all the 67 best practices was only attributed to small number of firms. For example, in their first and second audits (T1, T2) only two firms achieved full compliance of all 67 best practices. In their third audit (T3) full achievement of all the best practices was reduced to only one firm. This points out that the remaining of the firms had one or more best practices non-compliant. Hence implying there were different degrees of compliance among the SES firms. In this regard we can say that within the same cohort of firms, compliance behaviour does not change over time and that certain best practices are likely to be influencing firms not to reach the maximum fulfilment of compliance. In order to understand this, the second phase analysis focused on the best practices as per se to observe any specific patterns among the best practices and is explained in the next sub-section.

Same method as previous analysis was utilised to calculate the total average rate of compliance and non-compliance. First firms were grouped according to the number of best practices that these were compliant and non-compliant with. For example in the first line for the time period T1, 2 out of the 25 firms were compliant with all the 67 best practices $\left((2 / 25)^{*} 100=8 \%\right)$. Since these firms are fully compliant with all the best practices there are zero non-compliant ones therefore the average rate for these is calculated as $\left((0 / 25)^{*} 100=\right.$ $0 \%$ ). The total average compliance and non-compliance rate was calculated as the sum of each line in columns $\overline{\mathrm{x}}$ for the specific period (T1, T2 and T3). Alternatively the calculation in the dataset is represented by the (sum of all the compliant best practices per audit period) / (Total number of firms x Total number of best practices) x 100 and the (sum of all noncompliant best practices per audit period) / (Total number of firms x Total number of best practices) x 100. The average number of compliant and non-compliant best practices was calculated using weighted factor. As per the first line in Table 5 below, weighted factor for 
compliant best practices in the first time period (T1) corresponds to $(\mathrm{T} 1$ firms 2 x CBP $67=$ WF 134). The weighting factor corresponds to the (sum of (number of firms $\mathrm{x}$ number of specific best practices compliant) / total number of firms). The sum of each weighted factor in the column $W F$ was divided by the total number of firms in the specific sample $(1,555 / 25$ $=62.2)$. The same formulas were used to calculate the non-compliant best practices.

Table 5: Compliance and non-compliance with Secure Export Scheme best practices among firms

\begin{tabular}{|c|c|c|c|c|c|c|}
\hline $\begin{array}{c}\text { T1 } \\
\text { firms }\end{array}$ & CBP & $W F$ & $\overline{\mathbf{x}}$ & NCBP & $W F$ & $\overline{\overline{\mathbf{x}}}$ \\
\hline 2 & 67 & 134 & $8 \%$ & 0 & 0 & $0 \%$ \\
\hline 3 & 66 & 198 & $12 \%$ & 1 & 3 & $0 \%$ \\
\hline 4 & 65 & 260 & $16 \%$ & 2 & 8 & $\overline{00 \%}$ \\
\hline 1 & 64 & 64 & $4 \%$ & 3 & 3 & $\overline{0 \%}$ \\
\hline 3 & 63 & 189 & $11 \%$ & $\overline{4}$ & 12 & $1 \%$ \\
\hline 1 & 62 & 62 & $4 \%$ & 5 & 5 & $0 \%$ \\
\hline 4 & 61 & 244 & $15 \%$ & $\overline{66}$ & 24 & $1 \%$ \\
\hline 3 & 60 & 180 & $11 \%$ & 7 & 21 & $1 \%$ \\
\hline$\overline{11}$ & $\overline{58}$ & 58 & $3 \%$ & 9 & 9 & $1 \%$ \\
\hline 1 & 57 & 57 & $3 \%$ & 10 & 10 & $1 \%$ \\
\hline 1 & 56 & 256 & $3 \%$ & 11 & 11 & $1 \%$ \\
\hline 1 & 53 & 53 & $3 \%$ & 14 & 14 & $1 \%$ \\
\hline $\begin{array}{l}\text { T2 } \\
\text { firms }\end{array}$ & CBP & WF & $\overline{\overline{\mathbf{x}}}$ & NCBP & $\overline{W F}$ & $\overline{\overline{\mathbf{x}}}$ \\
\hline 2 & 67 & 134 & $8 \%$ & 0 & 0 & $0 \%$ \\
\hline 1 & 66 & 66 & $4 \%$ & 1 & 1 & $0 \%$ \\
\hline 3 & 65 & 195 & $12 \%$ & 2 & 6 & $0 \%$ \\
\hline 3 & 64 & 192 & $11 \%$ & 3 & 9 & $1 \%$ \\
\hline 6 & 63 & 378 & $23 \%$ & 4 & 24 & $1 \%$ \\
\hline 2 & 62 & 124 & $7 \%$ & 5 & 10 & $1 \%$ \\
\hline 2 & 61 & 122 & $7 \%$ & 6 & 12 & $1 \%$ \\
\hline 1 & 60 & 60 & $4 \%$ & 7 & 7 & $0 \%$ \\
\hline
\end{tabular}




\begin{tabular}{|c|c|c|c|c|c|c|}
\hline 3 & 58 & 174 & $10 \%$ & 9 & 27 & $2 \%$ \\
\hline 1 & 56 & 56 & $3 \%$ & 11 & 11 & $1 \%$ \\
\hline 1 & 55 & 55 & $3 \%$ & 12 & 12 & $1 \%$ \\
\hline $\begin{array}{c}\text { T3 } \\
\text { firms }\end{array}$ & CBP & WF & $\overline{\overline{\mathbf{x}}}$ & NCBP & $W F$ & $\overline{\overline{\mathbf{x}}}$ \\
\hline 1 & 67 & 67 & $4 \%$ & 0 & 0 & $0 \%$ \\
\hline 4 & 66 & 264 & $16 \%$ & 1 & 4 & $0 \%$ \\
\hline 3 & 65 & 195 & $12 \%$ & 2 & 6 & $0 \%$ \\
\hline 3 & 64 & 192 & $11 \%$ & 3 & 9 & $1 \%$ \\
\hline 4 & 63 & 252 & $15 \%$ & 4 & 16 & $1 \%$ \\
\hline 5 & 62 & 310 & $19 \%$ & 5 & 25 & $1 \%$ \\
\hline 1 & 61 & 61 & $4 \%$ & 6 & 6 & $0 \%$ \\
\hline 1 & 60 & 60 & $4 \%$ & 7 & 7 & $0 \%$ \\
\hline 1 & 59 & 59 & $4 \%$ & 8 & 8 & $0 \%$ \\
\hline 1 & 55 & 55 & $3 \%$ & 12 & 12 & $1 \%$ \\
\hline 1 & 43 & 43 & $3 \%$ & 24 & 24 & $1 \%$ \\
\hline \multicolumn{3}{|c|}{ Total average rate of compliance } & T1 93\% & \multicolumn{2}{|c|}{ T2 $93 \%$} & T3 93\% \\
\hline \multicolumn{3}{|c|}{ Total average non-compliance rate } & T1 7\% & \multicolumn{2}{|c|}{ T2 7\% } & T3 7\% \\
\hline \multicolumn{3}{|c|}{ Average compliant best practices } & T1 62 & \multicolumn{2}{|c|}{ T2 62} & T3 62 \\
\hline \multicolumn{3}{|c|}{$\begin{array}{l}\text { Average non-compliant bets } \\
\text { practices }\end{array}$} & T15 & \multicolumn{2}{|c|}{ T25 } & T35 \\
\hline
\end{tabular}

(x): Average Compliance Rate, CBP: Compliant Best Practices, NCP: Non-Compliant Best Practices, WF:

Weighted Factor, T1,t2 and T3: Time period firms were audited)

\subsubsection{Phase two analysis - identification of compliance and non-compliance patterns of the SES best practices}

This phase of the analysis considered the degrees of compliance and non-compliance against each best practice over time. The focus was on obtaining patterns of both, compliance and non-compliance that are presented across the three audit periods (T1, T2 and T3). Given the number of best practices (67) this analysis was concentrated only on the maximum compliance rate and higher rates of non-compliance with the specific best practices. The results of the analysis are summarised in a table in Appendix 3. From the analysis, the data showed that 13 best practices were fully compliant over the three audit periods by all the 
firms (100\% compliance by all firms). The remaining of the best practices presented different degrees of compliance and non-compliance. Among all the best practices that presented various degrees of non-compliance the data showed that for a small number of outliers. This can be seen in Figure 6 below, were those specific best practices start raising from $20 \%$ up to $56 \%$. These best practices where consistently non-compliant over the three audit periods and maintained similar rate over time. A number of these non-compliant best practices among some of the fully compliant were selected for further qualitative analysis and interpretation. The following sub-section draws conclusions of these.

Figure 6: Firms non-compliance with specific best practices - Cohort of 25 firms followed over time

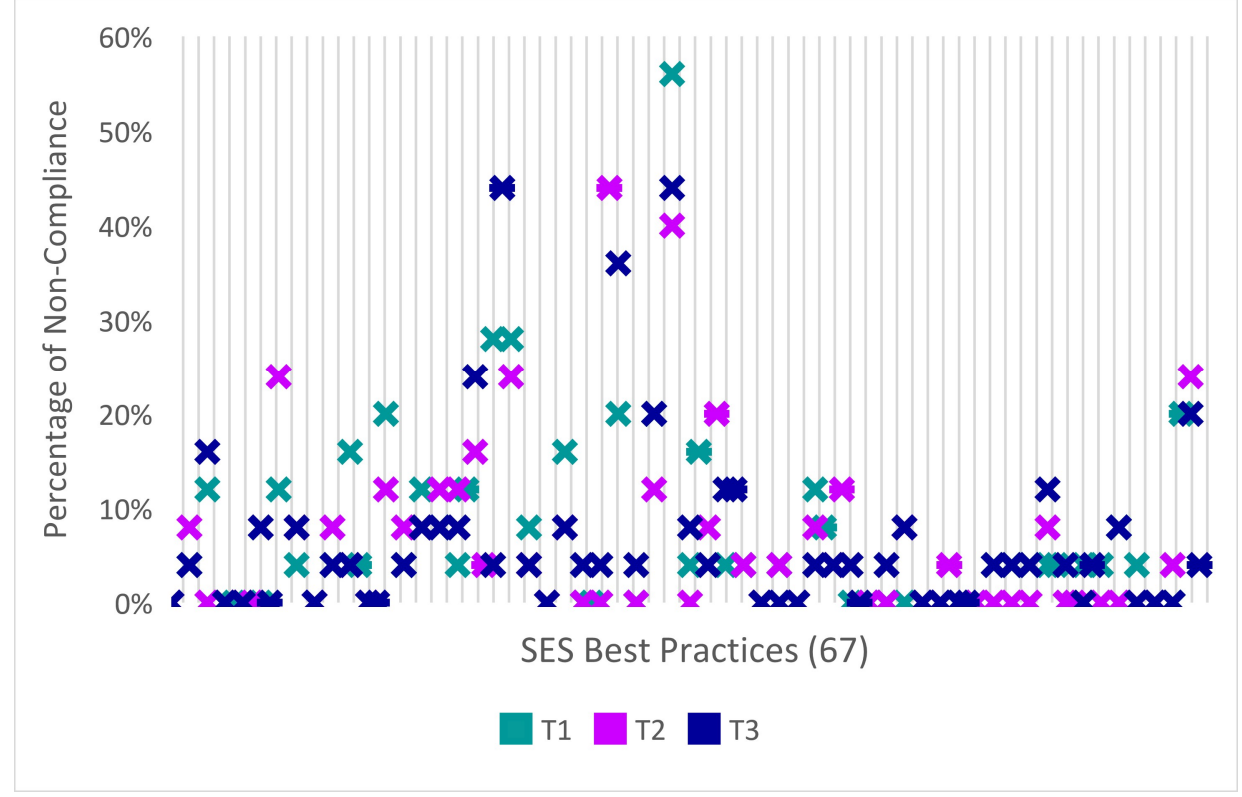

\subsubsection{Phase three analysis - Description, analysis and interpretation of the best} practices

As indicated in the previous section, the analysis showed that certain best practices were fully compliant across time by all firms. Whereas others presented high degrees of non-compliance by a good number of firms. This stage focused on making sense of those specific best practices understand the exact content and requirements and, how complex these are for firms. Given time constraints, for the purpose of this analysis, the researcher selected only four fully compliant best practices and four best practices that presented the highest degrees of non-compliance. Each of these selected best practices are explained using a publically 
available extract from Customs that indicates the explicit requirement. Appendix 4 contains a copy of the document Customs Fact Sheet 34A. The selected best practices were further analysed to understand their type, nature and content.

In summary, the analysis showed that the type and nature of the selected best practices indicate mixed signs. By analysing, the Customs website one can see that on the surface the SES programme is voluntary as firms enter the programme on their own will. However entering the programme requires from firms to meet certain requirements. A number of the passages collected from the Customs website indicate that there are obligations placed on firms. The phrases "make a written commitment...", “is underwritten by legislation”, "you must demonstrate...", “...must detail..."12 clearly indicate that while firms are free to enter or exit the SES, once they are in the programme requirements kick in. The SES programme is underwritten by legislation, while the legislation does not explain in detail the best practices it does indicate the aspects and requirements of securing of export goods and conditions imposed on those who enter the programme14. Therefore, it can be argued that all the SES best practices are of a compulsory nature once firms enter the programme. Arguably, the SES programme is voluntary and one would expect that there would be some form of flexibility on the application of the best practices. However, one particular best practice (archival of export documentation) was different to the rest of sampled ones.

\section{Best practice 39 - Archival of export documentation}

This best practice that was compliant by all firms across all the audit periods. The requirements is that export firms need to retain export documentation for a prescribed period of 7 years. The excerpt from Customs states the following:

\section{..... Confirm that export documentation archives are retained in hard copy or electronic} format for seven years.

Further analysis located that this requirement is part of the Customs and Excise Act 2018 specifically Section 354, it requires individuals and organisations dealing with Customs to keep records of import and export activities for up to 7 years ${ }^{19}$. This is not the only piece of legislation that demands businesses to keep records for a prescribed period. In general, all

\footnotetext{
${ }_{3}^{19} \mathrm{http}: / /$ www.legislation.govt.nz/act/public/2018/0004/latest/DLM7039809.html?search=sw_096be8ed8192f7da_7+years_25_se\&p=3\&sr=6 3
} 
New Zealand's registered businesses are required to keep records for up to 7 years. This is stated under the Goods and Services Tax Act 1985, specifically under Section $75^{20}$. Therefore, it can be argued that while this best practice is part of a voluntary programme, the main nature of this practice is compulsory by law and consequently there is not flexibility around it.

The best practices of the SES present other interesting features; these are referenced to the Authorised Economic Operator (AEO) standards of security that was developed by the World Customs Organisation. However the AEO standards are referenced to the International Organisation for Standardisation (ISO) and its ISO standards (primarily ISO 9001:2015, section 6)11. As previously discussed in chapter two, rules and policies are growing in scope and a vast number of standards and best practices are presented for businesses to implement (Boiral, 2001; Boiral, 2007; Rasche, 2012; Reinecke et al., 2012). It has been discussed by scholars that because of the large number of standards and best practices, including the numerous programmes these tend to overlap (Boiral, 2001; Liu, 2009; Ni, et al., 2016; Karlsson, 2017). Examples of these involve ISO standards that are embedded on business operations and other secure supply chain initiatives like the Container Security Initiative (Bpiral, 2001; Liu, 2009; Ni, et al., 2016; Karlsson, 2017). Arguably, one could ask is it good or bad that best practices overlap? Is it good or bad that there are different programmes with very similar requirements? Perhaps we could say yes it is good that they overlap because this ensures compliance. However, we do not know for certain if this can affect other areas of the firms or if conflicting programmes with similar requirements may push firms to seek opportunism. Interestingly from the best practices selected in this section, three of them were fully compliant by all the firms (best practices 4,5 and 7) the other four best practices were not compliant. The three compliant best practices are described and analysed below:

\section{Best practice 4 - Documentation to identify goods to be loaded in export containers}

All firms presented full compliance (100\%) across all the audit periods. This best practice require firms to have as a minimum processes and documents in place to ensure products that are loaded into export containers are recorded. The excerpt from Customs specifies the following:

\footnotetext{
${ }^{20} \mathrm{http}: / /$ www.legislation.govt.nz/act/public/1985/0141/latest/DLM85281.html?search=sw_096be8ed8191d6ed_\%22keeping+of+records\%22 $25 \_$se\&p $=1 \& \mathrm{sr}=1$
} 
Describe the controls or procedures used to ensure that goods are properly marked, weighed, counted and subsequently documented in packing lists, invoices, shipping and Customs documentation prior to loading. Include the following:List the documentation used to identify products to be loaded eg, packing/pick list and/or tally sheet

\section{Best practice 5 - Reconciliation of goods to be loaded in export containers}

Same as the previous best practice, all firms across all audits were compliant with this requirement. This best practice requires firms to have as a minimum processes in place to be able to identify and reconcile the export goods that are loaded into containers. In other words firms should have proper identification of the goods, for example, labels, marks and other. The excerpt from Customs states the following:

Describe the controls or procedures used to ensure that goods are properly marked, weighed, counted and subsequently documented in packing lists, invoices, shipping and Customs documentation prior to loading. Include the following: The checks that are in place to verify the goods have been properly marked, weighed, counted and reconciled

\section{Best practice 7 - Procedures for detecting errors with products}

Lastly, best practice 7 was also compliant by all firms across all the audits periods. The best practice required firms having processes in place to detect and report errors with documents and products. The excerpt from Customs stated the following:

Describe the controls or procedures used to ensure that goods are properly marked, weighed, counted and subsequently documented in packing lists, invoices, shipping and Customs documentation prior to loading. Include the following:The procedures for the reporting of errors in documentation or with product lines

The best practices described above $(4,5$ and 7$)$ have some interesting features. They all relate to quality controls on manufacturing and logistics operations that are part of the ISO standards (9001:2015) regarding quality management systems. In this regard, it can be argued that these best practices are critical for firms' successful operations therefore embedded in the daily practices. Literature discussed that some standards or best practices aim the maximisation and quality of production of firms and firms are more inclined to comply with them (Siddiki et al., 2018). What is more some are critical for achieving outcomes that are 
relevant for firms' operations therefore when implemented it is very difficult for firms to dislodge (Melnyk et al., 2013). One would expect that controls on manufacturing and logistics processes such as the ability to reconcile the movement of goods, reconcile stock and purchase orders, processes in place to reject or return goods and detection of errors are of great importance for firms. Therefore, these best practices may have been already part of the business operations and implemented via other standards requirements.

The remaining non-compliant best practices selected for further analysis $(22,29,30$ and 33) while the requirements are also referred to the ISO standards; these do not appear to fall within firms' critical operations. Therefore, we could say that these best practices have to do with firms' motivations and the signals from the governing bodies. The written content of these regulations is aligned with interpretation of the requirements and how these are presented in written documents. Literature has discussed that the content and complexity of the written requirements are said to motivate compliance behaviour. Regulations that are too ambiguous, extensive, lack detail and are highly technical can affect the compliance behaviour of firms (Edelman, 1992; Scholz, 1984; Hopkins, 1994; Van Snellenberg et al., 2002; Locke et al., 2009; Etienne, 2011). The four selected non-complaint best practices are described and analysed below:

\section{Best practice 22 - Seals register}

This best practice requires firms to have records of the usage of approved seals that are applied in export containers. The minimum requirement is to have procedures that specify how the approved Customs seals are received, used and accounted by the firm. Firms are required to have a register to record seals' usage. The following excerpt from Customs requires firms to specify the following:

Describe the register (in manual or electronic format), that will be maintained and secured to record the seal number, date of receipt, date of usage and use (eg, transferred to another party, container number the seal has been applied to, or if damaged and destroyed). The SES partner must take physical possession of the Customs-approved seal/marking/substance or device and reconcile the seal numbers at the time of receipt before distribution to their approved secure sites. 
The best practice above seems not difficult to achieve however, one can observe that there are two elements to it. The first element is recording information of seals usage every time one is used and the second element is reconciling all the seals numbers and previous delivery to other sites. We could argue that this requirement can be interpreted by firms as extensive, as it appears the firms are in charge of delivering seals to all the sites.

\section{Best practice 29 - Customs contact number}

This best practice requires firms is have New Zealand Customs contact numbers displayed around the approved site. The specific requirement in the Customs text is:

\section{Identify the locations where Customs contact numbers will be prominently displayed}

Regarding best practice 29 the requirement of displaying Customs contact numbers appears to be a simple task. However, the best practice can be considered ambiguous as it does not provide enough detail as to what is the purpose for displaying contact numbers. Because of this same ambiguity firms might feel the requirement can be avoided or not noticed.

\section{Best practice 30 - Quality assurance controls}

This best practice requires firms to have documented quality control practices, such as, periodic reconciliations of the seals to identify lost or missing seals, that security practices around keeping seals is safe and compliance with container loading procedures are maintained. The excerpt from Customs specified the following:

The documented quality control measures in place that regularly verify that the company procedures are complied with. The following SES procedures must be subject to quality control measures and the results recorded:

- Seal register maintenance including regular stock reconciliations to identify missing/lost seals

- Security practices for Customs-approved seals is being maintained

- Compliance with container loading procedures

- Keys/access cards register maintained

- Transport operator sign off practices at the time of collection of approved packages 
- 7/8 secure package inspection sign off practices

When reading the written requirements of this best practice it can be observed that it is extensive. Quality assurance controls are required for several tasks which can be seen as a greater effort for firms. Interestingly seal register controls and container loading processes again in this list. Additionally it can be argued that conducting quality assurance would also require technical expertise from the firms.

\section{Best practice 33 - Post clearance checks on export entries}

This is the best practice among the audited firms were non-compliance detection was the highest. This best practice relates to the Self-quality assurance. It is described as "documented quality assurance procedures to verify the accuracy of export declarations" lodged into the Customs' computerised system by either the firms' in-house declarant or their contracted Customs broker. In other words as a minimum firms should conduct and record periodic audits on export declarations to detect any error in the data. From the audits a good number of firms were failing to achieve this requirement, between $40 \%$ and $56 \%$ of the firms were non-compliant with it. The excerpt from Customs specifies the following:

The quality assurance procedures for post clearance checks on export entries (including entries lodged by your Customs brokers) to confirm accuracy of the declaration made to Customs. eg, shipping details, tariff classification, description of goods, FOB value, SES details

Best practice 33 can be considered technical, as firms are required to conduct quality assurance checks on export entries submitted by their brokers or in-house declarants. This would require firms to assign an individual to conduct these checks however, that individual should have the technical expertise to be able to conduct the checks.

\subsection{Summary of the findings}

This chapter presented the results from the analysis conducted on 196 audits of SES firms that have voluntary entered and adopted the best practices of the SES programme. The audits were conducted in stages from the moment the firms entered the SES programme until current. The analysis collected in total three audit periods to account for firms that have 
recently entered the programme. A systematic approach was adopted to conduct various analyses. In the first stage of the analysis, the researcher examined the compliance levels among firms. The results indicated that overall there are high levels of compliance with SES best practices averaging 62 best practices out of 67 . This pattern was consistent among the different audit periods. The analysis concluded that compliance post-certification is high (between 93\% and 94\%) over time. However, the analysis also located that small number of SES firms only attained full achievement of all the 67 best practices. This mean that the majority of the firms had one or more best practices non-compliant.

The second stage of the analysis examined a cohort of firms to see whether there were distinctive patterns that would indicate compliance and non-compliance behaviour with specific best practices. In this analysis, the researcher first scanned the levels of compliance and non-compliance among the firms. The analysis found that both compliance and noncompliance does not change over time. The selected sample maintained over time the same high rate of compliance at $93 \%$ and low rate of non-compliance at $7 \%$. By comparison, these results were the same as the overall analysis of all the audits in the first stage. While these results are very positive, the researcher again found that a small number of firms only reached full achievement of all best practices. This indicated that the majority of the sampled firms had one or more non-compliant best practices. The researcher then looked at the degrees of both compliance and non-compliance by best practice. In this analysis the focus was on patterns that would indicate specific behaviour towards the best practices. The analysis clearly showed the different levels of compliance among the three-audit period. The outliers were visibly identified from the rest of the best practices. These findings led the researcher to identify the specific best practices that appear across all the audits fully complaint and moderate to highly non-compliant. The following Chapter 5 presents a discussion of these results in relation the conceptual framework proposed in Chapter 2 and provides recommendations for future research. 


\section{CHAPTER 5: DISCUSSION AND CONCLUDING REMARKS}

The previous Chapter 4 provided the results of the analysis conducted on the 196 audits of 103 firms that are part of the SES programme. This chapter will first discuss those results in relation to the conceptual framework that was proposed in Chapter 2. The second part of this chapter will discuss the implications for policy makers, academia and the export industry. The chapter concludes with recommendations and recommendations for potential future research.

\subsection{Discussion}

In chapter 2, this thesis developed a conceptual framework explaining the potential influences on the compliance behaviour of organisations. This conceptual framework aims advance the current knowledge base on compliance behaviour to answer the research question - What is the compliance behaviour of New Zealand firms that voluntarily adopted the Secure Export Scheme programme's best practices? In summary, the conceptual framework proposed in this thesis suggests that to assess compliance behaviour one should account for all the players that lead some form of influence on compliance. This includes organisations that are subject to regulations, the regulating bodies and its interaction with organisations and the rules themselves. Vast literature has agreed that organisations are driven by three key motives that relate to economic, social and normative pursues (Van Snellenberg et al., 2002; Lindenberg et al., 2007; Locke et al., 2007; Etienne, 2011; Nielsen et al., 2012; Siddiki et al., 2018). In an ideal setting, organisations would only be driven by these motives and would make decisions around compliance based on these. However, literature on compliance behaviour suggests that there is more to it, external influences from governing bodies and their requirements put pressure on organisations' motives (Lindenberg et al., 2007; Etienne, 2011; Nielsen et al., 2012). The monitoring mechanisms applied by governing bodies affect those internal motivations. Additionally the type, content, complexity and requirements of the regulations also influence on those internal motives of the firms thus affecting compliance behaviour (Scholz, 1984; Van Snellenberg et al., 2002; Gelderman, et al., 2006). In this thesis, the researcher will discuss the findings of the previous chapter in relation to the type, content and complexity of the regulations to answer the research question. 


\subsubsection{The type and nature of the rules}

The conceptual framework is based on the signals that the governing body present when rules and policies that require the adoption of standards, codes of practice and best practices are presented to organisations to adopt. In summary the type and nature of regulations indicates whether the rules and policies are mandatory or voluntary (Hobbs, 2010; Melnyk et al., 2013; Ni et al., 2016,). While mandatory regulations and policies' main characteristic is that they are based on statute of law, voluntary regulations in the contrary are of a discretionary nature (Gilbert et al., 2011; Scholz, 1984; Liu, 2009). Empirical evidence indicates that compliance and non-compliance behaviour has been encountered on both mandatory and voluntary rules and policies (Scholz, 1984; Gelderman et al., 2010; Hernes et al., 2014). The results of this research mirror these findings.

Based on the findings in the previous chapter a number of fully compliant best practices were selected. The researcher located that best practice 39 "Archival of Export Documentation" is a particular case of a mandatory requirement. This best practice requires SES firms to keep export documentation for a period of 7 years. The researcher located two pieces of legislation that impose this requirement on firms. The Customs and Excise Act 2018 and the Goods and Services Tax Act 1985. Therefore, regardless of the nature of the firms this practice is required to be fulfilled by all registered firms in New Zealand. In this regard, we could assume that SES firms have already implemented this practice even before they joined the SES programme. Thus, the requirement has already been accepted as matter of law and not as the implementation of a best endeavour. Literature on compliance motivations of firms explains that three driving forces influence attitudes towards compliance, social, economic and normative motivations (Nielsen et al., 2008 Etienne, 2011). The most solid form of compliance is presented in normative motives. As explained by scholars firms driven by normative motives, trust the institutions and the regulations (Tyler et al., 2000; Nielsen et al., 2008). This rationale may explain why this particular best practice was fully compliant by all the firms across all the audit periods. There is a chance that this best practice is embedded in a business context.

The remaining of the best practices selected in the previous chapter presented both full compliance and high degrees of non-compliance. These best practices are also considered of a compulsory nature as when entering the programme firms are required by law to follow 
secure practices. However, the nature of the programme is voluntary and in this regard mixed signs from the requirements and the governing body can lead firms to see the programme's requirements as "soft law". As previously discussed in chapter two, scholars have argued that governing bodies use governance mechanisms that require self-assurance processes thus enabling firms to take advantage of this (Hopkins, 1994; Mason, 2011; Etienne, 2011). It is important to note that this aspect is not taken into account however is important to note the importance of it. Additionally the majority of the best practices within the Authorised Economic Operators are referenced to the International Organisation for Standards (ISO standards). However not all best practices behaved the same way, some of these were fully compliant by all the firms in the selected cohort whereas others were not. In this part, we focus on the fully compliant best practices. The findings located the following best practices linked to ISO standards:

\section{Referenced to ISO 9001:2015, section 6}

Best practice 4 "documents to identify goods to be loaded in export containers" Best practice 5 "reconciliation of goods to be loaded in export containers" Best practice 7 "Processes for detecting errors with products' line"

An interesting aspect of these best practices is that they appear to be critical for firms operations because the main requirement referred to quality controls over manufacturing and logistics. One would expect that the manufacturing and logistics processes of a firm would be critical for achieving optimal results to ensure that goods loaded into export containers are properly marked thus firms would have the ability to trace back when errors or issues arise. In this regard, these best practices induce the internal motivations of firms to comply. As previously mentioned, motivations can be either social, economic or normative. While social motivations place an importance on gaining the approval of social networks, economic motivations are centred on economic gains and normative motivations relate the acceptance of the rule as such (Braithwaite et al., 1991; Nielsen et al., 2008). When looking at it from this perspective, one can argue that these best practices align with the economic motives of firms as there is an element of controls to ensure optimal processes. Optimal processes present a competitive advantage on firms. 


\subsubsection{The content and complexity of the regulations}

Scholars have argued that rules and policies that involve standards and best practices can at times be ambiguous, extensive, complicated and technical. In this regard, the content and complexity of the requirements is said by a number of scholar to affect compliance behaviour (Scholz, 1984; Van Snellenberg et al., 2002; Geldermanet al., 2006). The selected regulations that presented high degrees of non-compliance are discussed based on this view.

Best practice 22 required firms to have a seal register in a prescribed form and reconcile all the seals before distribution to other sites. In this regard, this best practice appears to be extensive in terms of the requirements. One can argue that while developing a mere seal register is an easy task on the other hand reconciling each seal might require greater efforts "The SES partner must take physical possession of the Customs-approved seal/marking/substance or device and reconcile the seal numbers at the time of receipt before distribution to their approved secure sites". Considering that firms order seals on batches of " $x$ " quantity may require time to reconcile each of them to collect the seal number, be in charge of distributing seals to other sites and ensure these are accounted for in the various sites that firms have. Previous empirical findings suggest that regulations that are extensive in terms of requirements would affect compliance behaviour (Edelman, 1992; Scholz, 1984; Hopkins, 1994; Van Snellenberg et al., 2002; Locke et al., 2009). Thus, it can be argued that this requirement can affect economic motivations of a firm. The whole process of reconciling seals every time these are used and maintaining a register may require greater efforts that the firm may have not had implemented or catered for in the past. For example, having a dedicated person conducting the administrative work on distributing and reconciling seals in the register. Current personnel might not agree to conduct this task as it was stated in their initial contract.

Best practice 29 required firms to display Customs' contact numbers. While this is a very simplistic process to follow, this same simplicity may have caused a large number of firms to be not compliant with it over time. This best practice mirror the scholarly discussions around regulations that do not provide sufficient information and are somehow vague on what is the intended purpose of the requirement (Edelman, 1992; Scholz, 1984; Hopkins, 1994). Assuming that firms follow only the requirements in the written documents placed in the Customs website, we could argue that the regulation does not state why it is important to 
place Customs contact numbers around the site. Arguably, there is purpose for it but unless firms are not explained what the intended purpose is, firms might interpret this as a requirement that is not critical.

Best practice 30 required firms to implement quality assurance controls. It presented high levels of non-compliance. The requirements of this best practice were rather extensive. Quality assurance controls covered a range of areas from security controls, controls over all the type of registers and documentation. Overall, the requirement relates to be in control of all the Secure Export Scheme's requirements. Apart of presenting extensive requirements for a singular best practice, the best practice itself lacked of details in terms of what was the precise requirement for each of the different aspects covering the practice. Additionally the quality assurance requirement itself is a highly technical requirement. Therefore, it can be argued that unless firms have the knowledge and expertise to be able to implement and conduct quality assurance controls it might cause some form resistance or trial and error to be able to effectively implement this. This best practice appears to have all the elements described in the literature. The requirement is extensive, does not provide sufficient details on how to approach the extensive requirements and of a technical nature. Because of this, we could argue that firms' motivation to comply with this best practice may be related to greater efforts. Technical and extensive regulations may cause an effect on economic motivations as the firm will have to ensure technical expertise and dedicated staff can complete this task. Having dedicated staff to achieve this specific requirement may increase the compliance costs of firms and as a result, firms may avoid complying with the requirement.

Lastly, best practice 33 required firms to conduct post-clearance checks on export entries. This best practice among all of them was the one that presented the highest degrees of noncompliance overtime. The written requirement of this best practice was very clear in that firms needed to conduct quality checks upon post-clearance of exports namely conduct periodic audits on export declarations. While the content's requirements is clear and the task is not extensive it can be argued that in order to conduct periodic audits firms must need to have the technical expertise to do so. To achieve this task, first knowledge of export declarations and quality assurance controls needs to be developed. Again, this best practice appears to induce economic motivations of firms. For example, if a firm outsources export declarations to a Customs broker, this means that the firm does not have the technical expertise to be able to verify the work completed by a broker. In this regard, the firm may 
seek to obtain the technical expertise however, obtaining technical expertise will increase the compliance costs of the firm. Because of this, firms may utilise existing resources that lack the knowledge. This can create non-compliance, as the internal resource is not in a technical capacity to achieve the intended outcome of the best practice.

\subsection{Concluding Remarks}

The objective of this thesis was to further the knowledge on the compliance behaviour of firms that voluntary enter programmes like the Secure Export Scheme (SES). With the help of the literature review and the findings pulled from the previous chapter, some concluding remarks will firstly summarise the core findings of this thesis and the contribution to research. This will be followed by providing some insights for key stakeholders. Lastly, this thesis closes with limitations of the study and some recommendations for possible future research.

\subsubsection{Contribution to Research}

As previously discussed in chapter 1, the SES programme is based on the Authorised Economic Operator's (AEO) initiative of the World Customs Organisation (WCO). The main purpose of the AEO initiative is to secure the supply chain of globally trading firms against cargo theft, tampering and unexpected events. Until now a large number of countries have adopted implemented domestically AEO programmes. The New Zealand Secure Export Scheme (SES) is one of the pioneer countries that adopted the AEO standards of security and its best practices. The SES among other benefits aims to help New Zealand exporters to secure their export supply chain. To date there is limited empirical research dedicated to understand the compliance behaviour of the firms that adopt these type of programmes. To the knowledge of the researcher, this study is the first attempt that focuses on analysing firms that are part of this programme to understand their patterns of compliance over time. Using a conceptual framework that is founded on the different views of the theory of compliance the researcher found significant insights into the compliance behaviour of the SES firms. These insights led to answer the research question proposed in this thesis:

What is the compliance behaviour of New Zealand firms that voluntarily adopted the Secure Export Scheme programme's best practices? 
To sum up, the findings indicate that the compliance behaviour of export firms that voluntarily have adopted the Secure Export Scheme (SES) best practices varies among firms. While the majority of the SES firms present high degrees of compliance with the best practices of the secure supply chain programme, this compliance is not absolute. The research revealed that a large number of firms had one or more best practices non-compliant.

Furthermore, distinctive patterns of non-compliance with specific best practices were located during the analysis. As literature on compliance behaviour of firms suggests, the written content and complexity of the regulations and it requirements is one of the factors that affect the compliance of firms. This research demonstrates that this view apply to the SES firms. The research located that those best practices that were non-compliant by large number of firms had issues regarding the written content of the requirements. For example, one of the regulations had requirements that were vague without sufficient information, other three had requirements that involved extensive tasks and required technical knowledge to be able to achieve them. Empirical research have identified these aspects, were firms felt discontent of vague written requirements and confused with extensive regulations thus applying own interpretation (Edelman, 1992; Hernes et al, 2014). The problem with regulations of this nature is that it opens the windows for misinterpretation leading firms to non-compliance (Edelman 1992; Behnam et al., 2011; O’Neill, 2014).

Lastly, his research highlights the importance of understanding non-compliance behaviour as a focus of study. As discussed in previous chapters, literature acknowledges that studying compliance behaviour is a complex task. The researcher can corroborate this, there a number of ways on approaching the study of compliance behaviour. These include but are not limited to enforcement mechanisms, governing bodies' signals and intra-organisational needs. The conceptual framework proposed in this study integrates all these perspectives. While the final stage of the analysis focused on compliance of the best practices based on the written requirements, it shows that these are potentially linked to firms' motivations. Firms' motivations are affected not only by governing bodies but also by other stakeholders. For example, the global logistics management also have influences on firms; they are at the centre of the cost-competitiveness of international business transactions. Providing logistics solutions for delivery of products to external markets. 


\subsection{Contribution to Practitioners}

This study highlight implications for policy makers and developers of standards and best practices like the AEO and the SES in New Zealand's case. The results indicate that the way written requirements are presented require interpretation from those who are implementing them. If requirements are vague, extensive, complex and technical firms are likely to avoid or place their own interpretation to it. The risks of this is that firms would either go the extra mile or would go a completely opposite direction leading to non-compliance. The intended purpose of AEO initiatives is the effective use of the best practices to assure both the governing body and firms that the supply chain is ultimately secure. In this regard, it is important for governing bodies to look into this and further explore ways on improving the written requirements to help firms to improve their compliance. For example, the governing body could implement ongoing communication with key stakeholders to improve the description of best practices. The governing body could also provide explicit objectives for each requirement and, where requirements overlap with other form of standards harmonise procedures. Lastly encouraging compliance as a mean of mutual collaboration for the improvement of both trade facilitation and security of the supply chains via conducting outreach programmes could also enhance firms' compliance.

This study also highlights implications for the export industry. While the study finds that overall there are high degrees of compliance among the SES firms, this compliance is not absolute for all. The research located that only a small number of firms were fully compliant with all the 67 best practices. This indicated that a large number of firms had issues with one or more best practices. These findings should not be taken lightly as the effectiveness of securing an export supply chain depends on the proper implementation of the best practices. Requirements such as self-assurance are integrated in the SES best practices. This raises the question whether export firms have interpreted them wrong, are in purpose or are accidentally non-compliant or lack the expertise in conducting self-assurance. Either way self-assurance processes are important for monitoring the internal development of the best practices.

\subsection{Limitations and Future Research}

While this research has drawn important insights about the patterns of compliance behaviour of the SES firms and provided an overview of these patterns, some limitations have been 
identified. Arguably, these same limitations can lead to further research on compliance behaviour of firms and to strengthen the views and findings of this present study. Firstly, it is considered that the main limitation is that this research explored the compliance behaviour of the SES firms through the angle of the written requirements regarding the best practices only. Primarily the analysis involved the interpretation of the written documents. In this regard, this involve the interpretation that the researcher assigns to those written documents and not the interpretation that firms assign to it. In view of this, it is recommended to extend this research based on the propositions presented in the discussion section. It is important to obtain the views of firms when presented with written requirements. After all, the firms are the ones that need to implement the best practices therefore their views are highly important. This especially applies for practitioners drafting these requirements, as it would help them to understand how firms interpret, implement and pursue compliance.

The second limitation is that this research did not explore in detail the other aspects of the proposed conceptual framework. For example, the motivations of the firms were briefly taken into consideration and presented as assumptions. For the same reasons discussed in the previous paragraphs, only firms can provide insightful meanings about how the best practices' requirements affect their compliance. The governing mechanisms imposed by Customs (i.e. the governing bodies) were also not included. Literature account these as influencers on compliance behaviour. In the case of the SES, Customs manages the programme and the development of regulations. Further research could explore these areas on a post-adoption setting. Exploring the views of firms against the governing mechanisms can help to understand the aspect of collaboration and self-assurance that is required from initiatives like the AEO and SES programme. This research also did not take into account corporate restructuration. During the analysis of the characteristics of the firms, identified that over time firms go through various changes. For example, changes to personnel specifically management, changes to the number of contracted Third Party Logistics sites, opening or closing manufacturing sites, to mention the most notorious. Corporate restructuring could also affect compliance behaviour and further research could take into account these changes.

Lastly, the analysis of this research did not take into account whether the results were affected by other variables, such as, firms' size, industry type, control over third parties and, usage of brokers or in-house declarants. It would be interesting to observe if variations 
regarding these variables show different patterns on the compliance of the SES. For example investigating the effects of having third party logistics, how the operations of these affect the overall compliance when there is not centralised operations. Measuring this against firms that fully run self-owned sites for instance. The same can be applied to transport operators and how these affect the security requirements around signing documents and ensuring the security of cargo to the point of delivering cargo to the ports. Another string of research can be focused on in-house declarants and Customs brokers' inputs in securing the information and integrity of the export declarations. How large multinational corporations operate the requirements of the SES against Small and Medium domestic export firms. The study could also measure industry type and specific ISO standards alignment with the SES best practices. How all these characteristics of the firms would affect the ability to comply can provide greater insights to firms' compliance behaviour. 


\section{REFERENCES}

Abbott, K. W., \& Snidal, D. (2009). The governance triangle: regulatory standards institutions and the shadow of the state. The politics of global regulation, 44 .

Abe, M., \& Ye, L. (2013). Building resilient supply chains against natural disasters: The cases of Japan and Thailand. Global Business Review, 14(4), 567-586.

Ananchotikul, N., Kouwenberg, R., \& Phunnarungsi, V. (2010). Do Firms Decouple Corporate Governance Policy and Practice? European Financial Management, 16(5), 712737.

Antwi, S. K., \& Hamza, K. (2015). Qualitative and quantitative research paradigms in business research: A philosophical reflection. European journal of business and management, 7(3), 217-225.

Aurigemma, S., \& Panko, R. (2012, January). A composite framework for behavioral compliance with information security policies. In 2012 45th Hawaii International Conference on System Sciences (pp. 3248-3257). IEEE.

Autry, C. W., \& Bobbitt, L. M. (2008). Supply chain security orientation: conceptual development and a proposed framework. The International Journal of Logistics Management, 19(1), pp. $42-64$

Baldwin, R., \& Black, J. (2008). Really responsive regulation. The modern law review, 71(1), 59-94.

Bavorova, M., Fietz, A. V., \& Hirschauer, N. (2017). Does disclosure of food inspections affect business compliance? The case of Berlin, Germany. British Food Journal, 119(1), 143-163.

Beaton-Wells, C. (2015). Substance and process in competition law and enforcement. Why we should care if it's not fair. In Procedural Fairness in Competition Proceedings. Edward Elgar Publishing.

Beck, N. (2005). Technical Efficiency or Adaptation to Institutionalized Expectations? The Adoption of ISO 9000 Standards in the German Mechanical Engineering Industry. Organization Studies,26(6), 841-866.

Becker, G. S. (1968). Crime and punishment: An economic approach. In The economic dimensions of crime (pp. 13-68). Palgrave Macmillan, London.

Behnam, M., \& MacLean, T. L. (2011). Where is the accountability in international accountability standards?: A decoupling perspective. Business Ethics Quarterly, 21(1), 4572 .

Bell, E., \& Bryman, A. (2007). The ethics of management research: an exploratory content analysis. British journal of management, 18(1), 63-77. 
Benefits of the secure export scheme. (12 June 2012). Customs.govt.nz. Retrieved 31 May 2016, from

http://www.customs.govt.nz/features/ses/sesbenefits/Pages/default.aspx/NoAuthor

Bichou, K. (2010). Risk-based cost assessment of maritime and port security. In Security and Environmental Sustainability of Multimodal Transport (pp. 183-211). Springer, Dordrecht.

Blackhurst, J., Ekwall, D., Martens, B. J., Chang, H. L., \& Wu, J. G. (2015). Exploring company ability to meet supply chain security validation criteria. International Journal of Physical Distribution \& Logistics Management.

Blackstone, A. (2018). Principles of sociological inquiry: Qualitative and quantitative methods.

Boiral, O. (2003). ISO 9000: Outside the iron cage. Organization science, 14(6), 720-737.

Boiral, O. (2007). Corporate greening through ISO 14001: a rational myth?. Organization Science, 18(1), 127-146.

Boiral, O., \& Roy, M. J. (2007). ISO 9000: integration rationales and organizational impacts. International Journal of Operations \& Production Management.

Boxenbaum, E., \& Jonsson, S. (2008). Isomorphism, Diffusion and Decoupling. The SAGE Handbook of Organizational Institutionalism, 78-98.

Braithwaite, J., \& Makkai, T. (1991). Testing an expected utility model of corporate deterrence. Law \& Soc'y Rev., 25, 7.

Bromley, P., \& Powell, W. W. (2012). From Smoke and Mirrors to Walking the Talk:

Decoupling in the Contemporary World. The Academy of Management Annals, 6(1), 483530 .

Bronson, D. E., \& Davis, T. S. (2012). Finding and evaluating evidence: Systematic reviews and evidence-based practice. Oxford University Press.

BSI. (2017). BSI's Global supply chain intelligence report reveals top supply chain risks in 2016. Retrieved December 2019 from https://www.bsigroup.com/en-GB/about-bsi/mediacentre/press-releases/2017/may/BSIs-Global-Supply-Chain-Intelligence-report-reveals-topsupply-chain-risks-in-2016/

Cambridge Dictionary. (n.d.). Retrieved February 2020 from https://dictionary.cambridge.org/dictionary/english/compliance

Campos, M. L., Morini, C., Moraes, G. H. S. M. D., \& Inácio Júnior, E. (2018). A performance model for Public-Private Partnerships: the authorized economic operator as an example. RAUSP Management Journal, 53(2), 268-279.

Cedilnik, M., \& Ramsak, R. (2013). A Local Perspective to the Authorised Economic Operator (AEO) Concept. Lex Localis, 11(3), 673-685. 
Chad W. Autry, L. Michelle Bobbitt, (2008) "Supply chain security orientation: conceptual development and a proposed framework", The International Journal of Logistics

Management, Vol. 19 Iss: 1, pp.42 - 64

Chang, H. L., \& Wu, J. G. (2015). Exploring company ability to meet supply chain security validation criteria. International Journal of Physical Distribution \& Logistics Management, 45(7), 691-710.

Chang-Bong, K., Chun, H. U., \& Kwon, S. H. (2016). Impact of application factors of the AEO program on its performance. Journal of Korea Trade, 20(4), 332-348.

Chopra, S., \& Sodhi, M. S. (2004). Managing risk to avoid supply-chain breakdown. MIT Sloan management review, 46(1), 53.

Chopra, S., \& Sodhi, M. S. (2004). Managing risk to avoid supply-chain breakdown. MIT Sloan management review, 46(1), 53.

Chopra, S., Reinhardt, G., \& Mohan, U. (2007). The importance of decoupling recurrent and disruption risks in a supply chain. Naval Research Logistics (NRL), 54(5), 544-555.

Christmann, P., \& Taylor, G. (2006). Firm self-regulation through international certifiable standards: Determinants of symbolic versus substantive implementation. Journal of International Business Studies, 37(6), 863-878.

Christopher S. Tang, 2006, Robust strategies for mitigating supply chain disruptions, International Journal of Logistics Research and Applications, Vol. 9, Iss. 1,

Christopher, M., \& Peck, H. (2004). Building the resilient supply chain. The international journal of logistics management, 15(2), 1-14.

Christopher, M., Peck, H., \& Towill, D. (2006). A taxonomy for selecting global supply chain strategies. The International Journal of Logistics Management, 17(2), 277-287.

Closs, D. J., \& McGarrell, E. F. (2004). Enhancing security throughout the supply chain (pp. 10-12). Washington, DC: IBM Center for the Business of Government.

Crilly, D., Hansen, M., \& Zollo, M. (2016). The Grammar of Decoupling: A CognitiveLinguistic Perspective on Firms' Sustainability Claims and Stakeholders' Interpretation. Academy Of Management Journal, 59(2), 705-729.

C-TPAT: Customs-Trade Partnership Against Terrorism. CBP.gov. Retrieved 31 May 2016, from https://www.cbp.gov/border-security/ports-entry/cargo-security/c-tpat-customstrade-partnership-against-terrorism/NoAuthor

Daniel, F., Casati, F., D'Andrea, V., Mulo, E., Zdun, U., Dustdar, S., ... \& De Marchi, F. (2009, May). Business compliance governance in service-oriented architectures. In 2009 International Conference on Advanced Information Networking and Applications (pp. 113120). IEEE. 
David Swanson, R., \& Smith, R. J. (2013). A path to a public-private partnership: Commercial logistics concepts applied to disaster response. Journal of Business Logistics, 34(4), 335-346.

Dean, D. L., Mengüç, B., \& Myers, C. P. (2000). Revisiting firm characteristics, strategy, and export performance relationship:: A survey of the literature and an investigation of new zealand small manufacturing firms. Industrial Marketing Management, 29(5), 461-477.

DiMaggio, P. J., \& Powell, W. W. (1983). The iron cage revisited: Institutional isomorphism and collective rationality in organizational fields. American sociological review, 147-160.

Douglas M. Lambert, Margaret A. Emmelhainz, John T. Gardner, (1996) "Developing and Implementing Supply Chain Partnerships", The International Journal of Logistics Management, Vol. 7 Iss: 2, pp. 1 - 18

Dowling, J., \& Pfeffer, J. (1975). Organizational Legitimacy: Social Values and Organizational Behavior. The Pacific Sociological Review, 18(1), 122-136.

Edelman, L. B. (1992). Legal ambiguity and symbolic structures: Organizational mediation of civil rights law. American journal of Sociology, 97(6), 1531-1576.

Elsbach, K., \& Sutton, R. (1992). Acquiring Organizational Legitimacy through Illegitimate Actions: A Marriage of Institutional and Impression Management Theories. The Academy of Management Journal,35(4), 699-738.

Esper, T. L., \& Williams, L. R. (2003). The value of collaborative transportation management (CTM): its relationship to CPFR and information technology. Transportation journal, 55-65.

Étienne, J. (2010). Wendeln M. Compliance theories: A literature review. The Political Sociology of European Law, 60(2), 139-162.

Etienne, J. (2011). Compliance theory: A goal framing approach. Law \& Policy, 33(3), 305-333.

Etikan, I., Musa, S. A., \& Alkassim, R. S. (2016). Comparison of convenience sampling and purposive sampling. American journal of theoretical and applied statistics, 5(1), 1-4.

Etzioni, A. (1961). A comparative analysis of complex organizations: On power, involvement, and their correlates. Free Press; Collier-Macmillan.

Fairman, R., \& Yapp, C. (2005). Enforced self-regulation, prescription, and conceptions of compliance within small businesses: The impact of enforcement. Law \& Policy, 27(4), 491-519.

Filbeck, M., Kumar, S., Liu, J., \& Zhao, X. (2016). Supply chain finance and financial contagion from disruptions: Evidence from the automobile industry. International Journal of Physical Distribution and Logistics Management, 46(4), 414-438. 
Foorthuis, R., \& Bos, R. (2011, June). A framework for organizational compliance management tactics. In International Conference on Advanced Information Systems Engineering (pp. 259-268). Springer, Berlin, Heidelberg.

Fossey, E., Harvey, C., McDermott, F., \& Davidson, L. (2002). Understanding and evaluating qualitative research. Australian and New Zealand journal of psychiatry, 36(6), 717-732.

Garrett, M. (2007). Graphical techniques for exploratory and confirmatory analyses of longitudinal data. Handbook of Longitudinal Research: Design, Measurement, and Analysis, 199.

Gelderman, C. J., Ghijsen, P., \& Brugman, M. J. (2006). Public procurement and EU tendering directives-explaining non-compliance. International Journal of Public Sector Management.

Gelderman, K., Ghijsen, P., \& Schoonen, J. (2010). Explaining non-compliance with European Union procurement directives: a multidisciplinary perspective. JCMS: Journal of Common Market Studies, 48(2), 243-264.

Gilbert, D. U., Rasche, A., \& Waddock, S. (2011). Accountability in a global economy: The emergence of international accountability standards. Business Ethics Quarterly, 21(1), 23-44.

Grainger, A. (2014). The WTO trade facilitation agreement: Consulting the private sector. Journal of World Trade, 48(6), 1167-1188.

Greening, P., \& Rutherford, C. (2011). Disruptions and supply networks: A multi-level, multi-theoretical relational perspective. International Journal of Logistics Management, 22(1), pp. 104-126.

Greenwood, R., \& Meyer, R. E. (2008). Influencing Ideas: A Celebration of DiMaggio and Powell (1983). Journal of Management Inquiry, 17(4), 258-264.

Guler, I., Guillén, M., \& Macpherson, J. (2002). Global Competition, Institutions, and the Diffusion of Organizational Practices: The International Spread of ISO 9000 Quality Certificates. Administrative Science Quarterly, 47(2), 207-232.

Gunningham, N., \& Kagan, R. A. (2005). Regulation and business behavior. Law \& Pol'y, 27, 213.

Gutierrez, X., \& Hintsa, J. (2006, May). Voluntary supply chain security programs: a systematic comparison. In The International Conference on Information Systems, Logistics and Supply Chain, Lyon, France.

Gutiérrez, X., Hintsa, J., Wieser, P., \& Hameri, A. P. (2007). Voluntary supply chain security program impacts: an empirical study with BASC member companies. World Customs Journal, 1(2), 31-48.

Haelterman, H. (2011). Re-thinking the cost of supply chain security. Crime, law and social change, 56(4), 389-405. 
Hart, M. (2010). A matter of trust: expanding the Preclearance of Commerce between Canada and the United States. Commentary -CD. Howe Institute, 309, pp. 1-17

Hau L. Lee, Seungjin Whang, Higher supply chain security with lower cost: Lessons from total quality management, Quality in Supply Chain Management and Logistics, Volume 96, Issue 3, 18 June 2005, Pages 289-300

Hendricks, K. B., \& Singhal, V. R. (2005). An empirical analysis of the effect of supply chain disruptions on long-run stock price performance and equity risk of the firm.

Production and Operations management, 14(1), 35-52.

Herath, T., \& Rao, H. R. (2009). Encouraging information security behaviors in organizations: Role of penalties, pressures and perceived effectiveness. Decision Support Systems, 47(2), 154-165.

Herath, T., \& Rao, H. R. (2009). Protection motivation and deterrence: a framework for security policy compliance in organisations. European Journal of Information Systems, $18(2), 106-125$.

Hernes, H., \& Erdvik, G. K. (2014). Compliance and Non-Compliance with a Superordinate Directive Document. Public Organization Review, 14(1), 65-81.

Hervani, A. A., Helms, M. M., \& Sarkis, J. (2005). Performance measurement for green supply chain management. Benchmarking: An international journal.

Hirsch, P. M. (1975). Organizational analysis and industrial sociology: an instance of cultural lag. The American Sociologist, 3-12.

Hobbs, J. E. (2010). Public and Private Standards for Food Safety and Quality: International Trade Implications. Estey Centre Journal of International Law \& Trade Policy, 11(1).

Hopkins, A. (1994). COMPLIANCE WITH WHAT?: The Fundamental Regulatory Question. The British Journal of Criminology, 34(4), 431-443.

Hopkins, R. A. (2017). Grow your global markets: A handbook for successful market entry.

Hornok, C., \& Koren, M. (2015). Administrative barriers to trade. Journal of International Economics, 96, S110-S122.

Houe, T., \& Murphy, E. (2018). The AEO status as a source of competitive advantage. European Business Review, 30(5), 591-606.

Houlihan, J. B. (1985). International supply chain management. International Journal of Physical Distribution \& Materials Management, 15(1), 22-38.

Hsieh, H. F., \& Shannon, S. E. (2005). Three approaches to qualitative content analysis. Qualitative health research, 15(9), 1277-1288.

Ireland, R. (2009). The WCO SAFE Framework of Standards: avoiding excess in global supply chain security policy. Global Trade and Customs Journal, 4(11), 341-352. 
Jamali, D. (2010). MNCs and international accountability standards through an institutional lens: Evidence of symbolic conformity or decoupling. Journal of Business Ethics, 95(4), 617-640.

Janowska-Bucka, E. (2008). Customs security in the European Union-authorised economic operator (AEO). Journal of KONBiN, 4(1), 453-467.

Jüttner, U. (2005). Supply chain risk management: Understanding the business requirements from a practitioner perspective. The international journal of logistics management, 16(1), 120-141.

Jüttner, U., Peck, H., \& Christopher, M. (2003). Supply chain risk management: outlining an agenda for future research. International Journal of Logistics: Research and Applications, 6(4), 197-210.

Kagan, R. A., \& Scholz, J. T. (1980). The "criminology of the corporation" and regulatory enforcement strategies. In Organisation und recht (pp. 352-377). VS Verlag für Sozialwissenschaften.

Karlsson, L. (2017). Back to the future of Customs: A new AEO paradigm will transform the global supply chain for the better. World Customs Journal, (1), 11.

Keller, A. Z., \& Kazazi, A. (1993), Just-in-Time Manufacturing Systems: A Literature Review. Industrial Management \& Data Systems, 93(7), pp. 2 - 32

Kelman, H. C. (1958). Compliance, identification, and internalization three processes of attitude change. Journal of conflict resolution, 2(1), 51-60.

Kelman, H. C. (2006). Interests, relationships, identities: Three central issues for individuals and groups in negotiating their social environment. Annu. Rev. Psychol., 57, 126.

Killam, L. (2013). Research terminology simplified: Paradigms, axiology, ontology, epistemology and methodology. Laura Killam.

Kirton, J. J., \& Trebilcock, M. J. (2017). Hard choices, soft law: Voluntary standards in global trade, environment and social governance. Routledge.

Kleindorfer, P. R., \& Saad, G. H. (2005). Managing disruption risks in supply chains. Production and operations management, 14(1), 53-68.

Kostova, T., Roth, K., \& Dacin, M. (2008). Institutional Theory in the Study of Multinational Corporations: A Critique and New Directions. The Academy of Management Review, 33(4), 994-1006.

Kuada, J. (2009). Paradigms in International Business Research. Working Paper Series.

Kuhn, T. S. (1962). The structure of scientific revolutions. University of Chicago press.

Kuhn, T. S. (2012). The structure of scientific revolutions. University of Chicago press. 
Laden, M. D. (2007). The genesis of the US C-TPAT Program: Lessons learned and earned by the government and trade. World Customs Journal, 1(2), pp. $75-80$

Lange, B. (1999). Compliance construction in the context of environmental regulation. Social \& Legal Studies, 8(4), 549-567.

Langevoort, D. C. Cultures of Compliance '(2017). American Criminal Law Review, 54, 933.

Laszuk, M., \& Ryciuk, U. (2016). The importance of authorized economic operator institution for the security of supply chain in the international goods turnover of polish enterprises.

Lee, H. L., \& Whang, S. (2005). Higher supply chain security with lower cost: Lessons from total quality management. International Journal of Production Economics, 96(3), pp. 289-300.

Lee, H. L., \& Wolfe, M. (2003). Supply chain security without tears. Supply Chain Management Review, 7(1), pp. 12 - 19

Lincoln, Y. S., Lynham, S. A., \& Guba, E. G. (2011). Paradigmatic controversies, contradictions, and emerging confluences, revisited. The Sage handbook of qualitative research, 4, 97-128.

Lindenberg, S., \& Steg, L. (2007). Normative, gain and hedonic goal frames guiding environmental behavior. Journal of Social issues, 63(1), 117-137.

Liu, J., \& Tan, Y. H. (2010). Realising collaborative government-to-business business models: the case of the authorised economic operator. Electronic Government, an International Journal, 7(4), 330-345.

Liu, P. (2009, July). Private standards in international trade: issues and opportunities. In WTO's Workshop on Environment-Related Private Standards Certification and Labelling Requirements, Geneva, Switzerland (Vol. 9).

Llewellyn, S. (1993). Working in hermeneutic circles in management accounting research: some implications and applications. Management Accounting Research, 4(3), 231-249.

Locke, R., Amengual, M., \& Mangla, A. (2009). Virtue out of necessity? Compliance, commitment, and the improvement of labor conditions in global supply chains. Politics \& Society, 37(3), 319-351.

Loh, H. S., \& Van Thai, V. (2015). Cost consequences of a port-related supply chain disruption. The Asian Journal of Shipping and Logistics, 31(3), 319-340.

Lunenburg, F. C. (2012). Compliance theory and organizational effectiveness. International Journal of scholarly academic intellectual diversity, 14(1), 1-4.

Lunenburg, F., \& Ornstein, A. (2011). Educational administration: Concepts and practices. Nelson Education. 
Maclean, T. L., \& Behnam, M. (2010). The Dangers of Decoupling: The Relationship Between Compliance Programs, Legitimacy Perceptions, and Institutionalized Misconduct. Academy of Management Journal,53(6).

Manners-Bell, J. (2014). Supply Chain Risk: Understanding Emerging Threats to Global Supply Chains. Kogan Page Publishers.

Marschan-Piekkari, R., \& Welch, C. (2004). Qualitative research methods in international business: The state of the art. Handbook of qualitative research methods for international business, 24.

Marshall, M. N. (1996). Sampling for qualitative research. Family practice, 13(6), 522526.

Mason, A. (2011). The world of standards: Order or anarchy?. Journal of business continuity \& emergency planning, 5(1), 421-429.

Material Handling \& Logistics. (2017). Supply chain experiencing high rate of terrorist attacks. Retrieved December 2019 from https://www.mhlnews.com/global-supplychain/supply-chain-experiencing-high-rate-terrorist-attacks\#close-olyticsmodal

Meixell, M. J., \& Gargeya, V. B. (2005). Global supply chain design: A literature review and critique. Transportation Research Part E: Logistics and Transportation Review, 41(6), 531-550.

Melnyk, S. A., Ritchie, W. J., \& Calantone, R. J. (2013). The Case of the C-TPAT Border Security Initiative: Assessing the Adoption/Persistence Decisions When Dealing With a Novel, Institutionally Driven Administrative Innovation. Journal of Business Logistics, 34(4), 289-300.

Menard, S. (Ed.). (2007). Handbook of longitudinal research: Design, measurement, and analysis. Elsevier.

Mendoza, J. P., Dekker, H. C., \& Wielhouwer, J. L. (2016). Firms' compliance with complex regulations. Law and human behavior, 40(6), 721.

Mentzer, J. T., DeWitt, W., Keebler, J. S., Min, S., Nix, N. W., Smith, C. D., \& Zacharia, Z. G. (2001). Defining supply chain management. Journal of Business logistics, 22(2), 125 .

Meyer, J. W., \& Rowan, B. (1977). Institutionalized organizations: Formal structure as myth and ceremony. American journal of sociology, 83(2), 340-363.

Mitchell, R. B. (2007). Compliance theory: compliance, effectiveness, and behavior change in international environmental law. Oxford Handbook of International Environmental Law (Oxford University Press, 2007).

Mulford, C. L. (1978). Why They Don't Even When They Ought To. International Journal of Comparative Sociology, 19(1-2), 47-62. 
New Zealand Now. (2018). Economic overview. Retrieved from

https://www.newzealandnow.govt.nz/investing-in-nz/economic-overview

New Zealand Legislation. (n.d.). Goods and Services Tax Act 1985. Part 11 General Provisions., Retrieved January 2020 from

http://www.legislation.govt.nz/act/public/1985/0141/latest/DLM85281.html?search=sw 09 $\underline{6 \text { be8ed8191d6ed } \% 22 \text { keeping }+ \text { of }+ \text { records } \% 22 \quad 25 \text { se } \& p=1 \& s r=1}$

New Zealand Legislation. (n.d.). Customs and Excise Act 2018. Part 6 Final and miscellaneous provisions. Retrieved January 2020 from

http://www.legislation.govt.nz/act/public/2018/0004/latest/DLM7039809.html? search=sw 096be8ed $8192 \mathrm{f} 7 \mathrm{da} 7+$ years 25 se $\& \mathrm{p}=3 \& \mathrm{sr}=63$

New Zealand Legislation. (n.d.). Customs and Excise Act 2018. Schedule 6 Customsapproved secure export scheme. Retrieved January 2020 from http://www.legislation.govt.nz/act/public/2018/0004/latest/whole.html\#DLM7040150

New Zealand Customs Service. (n.d.). Secure Export Scheme. Retrieved January 2020 from https://www.customs.govt.nz/business/export/secure-exports-scheme/

New Zealand Customs Service. (n.d.). Customs Fact Sheet 34. Retrieved January 2020 from https://www.customs.govt.nz/globalassets/documents/fact-sheets/fact-sheet-34secure-exports-scheme.pdf

New Zealand Customs Service. (n.d.). Customs Fact Sheet 34A. Retrieved January 2020 from https://www.customs.govt.nz/globalassets/documents/fact-sheets/fact-sheet-34asecure-exports-scheme-security-plan.pdf

New Zealand Customs Service. (n.d.). Mutual Recognition Arrangements. Retrieved January 2020 from https://www.customs.govt.nz/business/export/mutual-recognitionarrangements/

New Zealand Trade and Enterprise. (n.d.). Investment statistics. Retrieved November 2019 from https://www.nzte.govt.nz/investment-and-funding/investment-statistics

Ni, J. Z., Melnyk, S. A., Ritchie, W. J., \& Flynn, B. F. (2016). Why be first if it doesn't pay? The case of early adopters of C-TPAT supply chain security certification. International Journal of Operations \& Production Management.

Nicholls, A. (2010, July). The legitimacy of social entrepreneurship'. reflexive isomorphism in a pre-paradigmatic field. Entrepreneurship: Theory and Practice, 34(4).

Nielsen, V. L., \& Parker, C. (2008). To what extent do third parties influence business compliance?. Journal of Law and Society, 35(3), 309-340.

Nielsen, V. L., \& Parker, C. (2012). Mixed motives: economic, social, and normative motivations in business compliance. Law \& Policy, 34(4), 428-462.

Nitsch, V., \& Schumacher, D. (2004). Terrorism and international trade: an empirical investigation. European Journal of Political Economy, 20(2), 423-433. 
Noorderhaven, N. (2000). Hermeneutic methodology and international management research. Företagsekonomiska institutionen.

Norrman, A., \& Jansson, U. (2004). Ericsson's proactive supply chain risk management approach after a serious sub-supplier accident. International journal of physical distribution \& logistics management, 34(5), 434-456.

OECD (2020), Enterprises by business size (indicator), Retrieved January 2020 from https://data.oecd.org/entrepreneur/enterprises-by-business-size.htm

\section{Okoboi, G. \& Kyanzi, M. (2018). THE IMPACT OF AUTHORIZED ECONOMIC OPERATOR ACCREDITATION ON TRADE FACILITATION: THE CASE OF UGANDA.}

Olivier Boiral. (2003). ISO 9000: Outside the Iron Cage. Organization Science, 14(6), 720737.

Partners In Protection. (22 Jul. 2014). Cbsa-asfc.gc.ca. Retrieved from http://www.cbsaasfc.gc.ca/security-securite/pip-pep/menu-eng.html/NoAuthor

Penley, L. E., \& Gould, S. (1988). Etzioni's model of organizational involvement: A perspective for understanding commitment to organizations. Journal of organizational Behavior, 9(1), 43-59.

Peterson, J., \& Treat, A. (2009). The post-9/11 global framework for cargo security. J. Int'l Com. \& Econ., 2, 1.

Pratama, D. H., \& Everett, S. (2017). Supply chain security initiatives: The authorized economic operator and Indonesia" s experience. Journal of International Logistics and Trade, 15(1), 10-18.

Prokop, D. (2017). Global supply chain security and management: appraising programs, preventing crimes. Butterworth-Heinemann.

Rasche, A. (2009). Toward a model to compare and analyze accountability standards-The case of the UN Global Compact. Corporate Social Responsibility and Environmental Management, 16(4), 192-205.

Rasche, A. (2010). The limits of corporate responsibility standards. Business Ethics: A European Review, 19(3), 280-291.

Rasche, A. (2012). Global policies and local practice: Loose and tight couplings in multistakeholder initiatives. Business Ethics Quarterly, 22(4), 679-708.

Rasmussen 2016, Jobs Supported by Exports 2015: An Update. U.S. Department of Commerce, International Trade Administration Retrieved from http://www.trade.gov/mas/ian/employment/index.asp

Reinecke, J., Manning, S., \& Von Hagen, O. (2012). The emergence of a standards market: Multiplicity of sustainability standards in the global coffee industry. Organization Studies, 33(5-6), 791-814. 
Reuvid, J., \& Sherlock, J. (2011). International Trade: An Essential Guide to the Principles and Practice of Export. London: Kogan Page.

Rice, J. B., \& Caniato, F. (2003). Building a secure and resilient supply network. SUPPLY CHAIN MANAGEMENT REVIEW, V. 7, NO. 5 (SEPT./OCT. 2003), P. 22-30: ILL.

Richer, S. (2008). There's more to compliance cooperation than just C-TPAT: underutilized business-to-government relationships facilitate supply chain risk management. World TradeMar, 21 (3), pp. 42-45

Ronald J. Burke, (2005) "International terrorism and threats to security: Implications for organizations and management", Disaster Prevention and Management: An International Journal, Vol. 14 Issue: 5,

Sadiq, S., Governatori, G., \& Namiri, K. (2007, September). Modeling control objectives for business process compliance. In International conference on business process management (pp. 149-164). Springer, Berlin, Heidelberg.

Samaha, K., \& Khlif, H. (2016). Adoption of and compliance with IFRS in developing countries: A synthesis of theories and directions for future research. Journal of Accounting in Emerging Economies, 6(1), 33-49.

Sarathy, R. (2006). Security and the global supply chain. Transportation journal, 28-51.

Scheffer, D., \& Kaeb, C. (2011). The five levels of CSR compliance: The resiliency of corporate liability under the alien tort statute and the case for a counterattack strategy in compliance theory. Berkeley J. Int'l L., 29, 334.

Scholz, J. T. (1984). Voluntary compliance and regulatory enforcement. Law \& Policy, 6(4), 385-404.

Scott, W. R. (1987). The adolescence of institutional theory. Administrative science quarterly, 493-511.

Scott, W. R. (1995). Institutions and organizations. Foundations for organizational science. London: A Sage Publication Series.

Scott, W. R. (2005). Institutional theory: Contributing to a theoretical research program. Great minds in management: The process of theory development, 37(2005), 460-484.

Secure Trade Partnership (STP) \& STP-Plus. (3 Mar. 2016). Customs.gov.sg. Retrieved from http://www.customs.gov.sg/businesses/customs-schemes-licences-framework/securetrade-partnership-stp/NoAuthor

Shafiu, I. (2015). Information security compliance behaviour in supply chain security (Doctoral dissertation, Auckland University of Technology).

Sheffi, Y. (1990). Third party logistics: Present and future prospects. Journal of Business Logistics, 11(2), 27. Retrieved from https://search-proquestcom.helicon.vuw.ac.nz/docview/212588530?accountid=14782 
Sheffi, Y. (2001).Supply Chain Management under the Threat of International Terrorism. The International Journal of Logistics Management, 12(2), pp. 1 - 11.

Sheffi, Y. (2005). The resilient enterprise: overcoming vulnerability for competitive advantage. MIT Press Books, 1 .

Sheffi, Y., \& Rice, J. B. Jr. (2005). A supply chain view of the resilient enterprise: an organization's ability to recover from disruption quickly can be improved by building redundancy and flexibility into its supply chain. While investing in redundancy represents a pure cost increase, investing in flexibility yields many additional benefits for day-to-day operations. MIT Sloan Management Review, 47(1), pp. 41 - 48

Sheu, C., Lee L., \& Niehoff, B. (2006). A voluntary logistics security program and international supply chain partnership. Supply Chain Management: An International Journal, 11(4), pp. $363-374$

Sheu, J. B. (2016). Supplier hoarding, government intervention, and timing for postdisaster crop supply chain recovery. Transportation Research Part E: Logistics and Transportation Review, 90, 134-160.

Siddiki, S., Espinosa, S., \& Heikkila, T. (Eds.). (2018). Contextualizing Compliance in the Public Sector: Individual Motivations, Social Processes, and Institutional Design.

Routledge.

Simatupang, T. M., \& Sridharan, R. (2002). The collaborative supply chain. The international journal of logistics management, 13(1), 15-30.

Slager, R., Gond, J. P., \& Moon, J. (2012). Standardization as institutional work: The regulatory power of a responsible investment standard. Organization Studies, 33(5-6), 763790.

Smith, K. W. (1990). Integrating three perspectives on noncompliance: A sequential decision model. Criminal Justice and Behavior, 17(3), 350-369.

Statistics New Zealand. (2018). Goods and services trade by country: year ended June 2018 - corrected. Retrieved November 2019 from https://www.stats.govt.nz/informationreleases/goods-and-services-trade-by-country-year-ended-june-2018

Statistics New Zealand. (n.d.). Estimated population of NZ. Retrieved January 2020 from https://www.stats.govt.nz/indicators/population-of-nz

Strang, D., \& Macy, M. W. (2001). In Search of Excellence: Fads, Success Stories, and Adaptive Emulation. American Journal of Sociology,107(1), 147-182.

Su, S. L. I., Kumar, S., Liu, J., \& Scutella, J. (2015). The impact of supply chain disruptions on stockholder wealth in India. International Journal of Physical Distribution \& Logistics Management.

Suchman, M. C. (1995). Managing legitimacy: Strategic and institutional approaches. Academy of Management.the Academy of Management Review, 20(3), 571. 
Supply Chain Security Branch, Singapore Customs. (2007). Singapore' s Supply Chain Security Program. World Customs Journal, 1(2), pp. 67 - 71

Sutinen, J. G., \& Kuperan, K. (1999). A socio-economic theory of regulatory compliance. International journal of social economics.

Svensson, G. (2000). A conceptual framework for the analysis of vulnerability in supply chains. International Journal of Physical Distribution \& Logistics Management, 30(9), 731-750.

Tang, C. S. (2006). Robust strategies for mitigating supply chain disruptions. International Journal of Logistics Research and Applications, 9(1), pp. 33-45

Terlaak, A. (2007). Order without law? The role of certified management standards in shaping socially desired firm behaviors. Academy of Management Review, 32(3), 968-985.

Trkman, P. and McCormack, K. (2009). Supply chain risk in turbulent environments-A conceptual model for managing supply chain network risk. International Journal of Production Economics, 119(2), pp. 247 - 258

Tyler, T. R., \& Darley, J. M. (1999). Building a law-abiding society: Taking public views about morality and the legitimacy of legal authorities into account when formulating substantive law. Hofstra L. Rev., 28, 707.

van Niekerk, S., Niemann, W., Kotzé, T., \& Mocke, K. (2017). Supply chain security orientation in the pharmaceutical industry. Southern African Business Review, 21(1), 446479 .

Van Snellenberg, T., \& van de Peppel, R. (2002). Perspectives on compliance: noncompliance with environmental licences in the Netherlands. European Environment, 12(3), 131-148.

Vandemoortele, T., \& Deconinck, K. (2013). When are private standards more stringent than public standards?. American Journal of Agricultural Economics, 96(1), 154-171.

Vidal, C. J., \& Goetschalckx, M. (1997). Strategic production-distribution models: A critical review with emphasis on global supply chain models. European journal of operational research, 98(1), 1-18.

Vieira, K. A. L., \& De Queiroz, G. M. (2017). Hermeneutic Content Analysis: a method of textual analysis. International Journal of Business Marketing and Management (IJBMM), 2(8), 8-15.

Voss, M. D., \& Williams, Z. (2013). Public-Private Partnerships and Supply Chain Security: C-TPAT as an Indicator of Relational Security. Journal of Business Logistics, 34(4), pp. $320-334$

Voss, M. D., \& Williams, Z. (2013). Public-private partnerships and supply chain security: C-TPAT as an indicator of relational security. Journal of Business Logistics, 34(4), 320334. 
Weaver, G., Treviño, L., \& Cochran, P. (1999). Integrated and Decoupled Corporate Social Performance: Management Commitments, External Pressures, and Corporate Ethics Practices. The Academy of Management Journal, 42(5), 539-552.

Westphal, J., \& Zajac, E. (2001). Decoupling Policy from Practice: The Case of Stock Repurchase Programs. Administrative Science Quarterly, 46(2).

Widdowson, D. (2016). Managing the border: a transformational shift to pre-export screening. World Customs Journal, 10(2), 3-15.

Widdowson, D., Blegen, B., Kashubsky, M., \& Grainger, A. (2014). Review of accredited operator schemes: an Australian study. World Customs Journal, 8(1), 17-34.

Wijen, F. (2014). Means Versus ends in Opaque Institutional Fields: Trading off Compliance and Achievement in Sustainability Standard Adoption. Academy Of Management Review, 39(3), 302-323.

Williams, Z., J., Lueg, J.E. \& LeMay,S.A. (2008).Supply chain security: an overview and research agenda. The International Journal of Logistics Management, 19(2), pp. 254 - 281

World Customs Organisation. (2018). AEO Validator guide. Retrieved August 2019 from http://www.wcoomd.org/-/media/wco/public/global/pdf/topics/facilitation/instruments-andtools/tools/safe-package/aeo-validator-guide.pdf?la=en

World Customs Organisation. (2019). Compendium of authorised economic operator programmes. Retrieved October 2019 from http://www.wcoomd.org/-

/media/wco/public/global/pdf/topics/facilitation/instruments-and-tools/tools/safepackage/aeo-compendium.pdf?db=web

World Customs Organisation. (2018). SAFE Framework of Standards. Retrieved August 2019 from http://www.wcoomd.org//media/wco/public/global/pdf/topics/facilitation/instruments-and-tools/tools/safepackage/safe-framework-of-standards.PDF?la=en

World Economic Forum. (2019). Regional Risks for Doing Business 2019. Retrieved November 2019 from

http://www3.weforum.org/docs/WEF Regional Risks Doing Business report 2019.pdf

Yossi Sheffi, (2001) "Supply Chain Management under the Threat of International Terrorism", The International Journal of Logistics Management, Vol. 12 Iss: 2, pp.1 - 11

Yukl, G. (1989). Managerial leadership: A review of theory and research. Journal of management, 15(2), 251-289.

Zachary Williams, Jason E. Lueg, Stephen A. LeMay, (2008) "Supply chain security: an overview and research agenda", The International Journal of Logistics Management, Vol.

19 Iss: 2 , pp. $254-281$

Zellmer-Bruhn, M., Caligiuri, P., \& Thomas, D. C. (2016). From the editors: Experimental designs in international business research. 
Zucker, L. (1987). Institutional Theories of Organization. Annual Review of Sociology, 13, 443-464. 
APPENDIX 1: New Zealand AEO Standards of Security and Required Best Practices

\begin{tabular}{|c|c|}
\hline STANDARDS & " BEST PRACTICES \\
\hline $\begin{array}{l}\text { One: } \\
\text { Requires firms using an approved package to } \\
\text { export goods and a pre-approved seal/marking or } \\
\text { devise utilised to secure the approved package. }\end{array}$ & $\begin{array}{l}\text { 1. Define the approved package or packages } \\
\text { that will be used to export goods. } \\
\text { 2. Define/agree the type or types of Customs } \\
\text { approved seal, marking, substance or device } \\
\text { used to secure the approved secure package. }\end{array}$ \\
\hline $\begin{array}{l}\text { Two: } \\
\text { Requires firms to provide and maintain an up to } \\
\text { date process map to confirm validation }\end{array}$ & $\begin{array}{l}\text { 3. Provide a process map to illustrate the } \\
\text { physical and documentary activities for the } \\
\text { export supply chain. }\end{array}$ \\
\hline $\begin{array}{l}\text { Three: } \\
\text { Requires firms to have pre-pack controls or } \\
\text { procedures in place to ensure that goods are } \\
\text { properly marked, weighed, counted and } \\
\text { subsequently documented in packing lists, } \\
\text { invoices, shipping and Customs documentation } \\
\text { prior to loading. }\end{array}$ & $\begin{array}{l}\text { 4. Documents are used to identify products to } \\
\text { be loaded. } \\
\text { 5. Checks are in place to verify the goods have } \\
\text { been properly marked, weighed, counted } \\
\text { and reconciled. } \\
\text { 6. Relevant documentation records the name } \\
\text { and signature of person undertaking the } \\
\text { final check for pre-load accuracy. } \\
\text { 7. Procedures are in place for the reporting of } \\
\text { errors in documentation or with product } \\
\text { lines. }\end{array}$ \\
\hline $\begin{array}{l}\text { Four: } \\
\text { Requires firms to have in place loading security } \\
\text { around containers and/or other packages to } \\
\text { prevent unauthorised access to containers or } \\
\text { other packages during packing and loading for } \\
\text { export. }\end{array}$ & $\begin{array}{l}\text { 8. Mandatory } 7 / 8 \text { point interior and exterior } \\
\text { inspection of the empty container is } \\
\text { undertaken prior to loading. The elements } \\
\text { of the } 7 / 8 \text { point container inspection are; } \\
\text { front wall, left side, right side, inside/ } \\
\text { outside doors, floor, ceiling/roof and } \\
\text { outside/undercarriage, motor area } \\
\text { (refrigerated containers only). } \\
\text { 9. Record all of the parties involved in } \\
\text { completing the } 7 / 8 \text { point inspection. } \\
\text { 10. Have procedures for checking goods during } \\
\text { loading_into the approved secure package } \\
\text { against documents and record the checks } \\
\text { and the position responsible for signing off } \\
\text { the load as correct. } \\
\text { 11. Have procedures to ensure that only goods } \\
\text { belonging to the SES exporter are loaded } \\
\text { into the approved secure package. } \\
\text { 12. Have continuous monitoring procedures } \\
\text { that will be maintained during } \\
\text { loading/packing of export product into the } \\
\text { approved secure package. } \\
\text { 13. Have personnel responsible for supervision } \\
\text { for approved package loading and any other } \\
\text { specific load out area controls in place. } \\
\text { 14. Have procedures that protect partially } \\
\text { packed approved secure packages from } \\
\text { unauthorised access during loading. } \\
\text { 15. Have procedures that protect partially } \\
\text { packed approved secure packages during } \\
\text { breaks with temporary locking process. } \\
\text { 16. Have procedures for multiple site load } \\
\text { pickups. }\end{array}$ \\
\hline
\end{tabular}




\begin{tabular}{|c|c|}
\hline & $\begin{array}{l}\text { 17. Have personnel responsible for applying the } \\
\text { Customs-approved seal/marking/ substance } \\
\text { or device immediately on the completion of } \\
\text { loading. If the approved package cannot be } \\
\text { sealed immediately detail the procedures to } \\
\text { ensure security of the product until the } \\
\text { package is sealed. } \\
\text { 18. Have personnel responsible to undertake the } \\
\text { physical check of the } \\
\text { seal/marking/substance or device. Identify } \\
\text { the documentation used to record this check } \\
\text { which confirms the seal number and that the } \\
\text { seal has been correctly applied. } \\
\text { 19. Have procedures for storage of approved } \\
\text { packages sealed but not immediately } \\
\text { transported to the port of loading that } \\
\text { maintain the integrity/security of the } \\
\text { approved package. } \\
\text { 20. Have documentation, signed by the } \\
\text { transport operator and retained by the site } \\
\text { that records the checks undertaken by the } \\
\text { road transport operator at the time of } \\
\text { collection of the approved secure package } \\
\text { (i.e., the physical check of the Customs- } \\
\text { approved seal and container number). } \\
\text { 21. Have, where applicable, documented checks } \\
\text { undertaken on receipt of made up packages } \\
\text { e.g., master packs etc. being transferred } \\
\text { between approved secure sites. Checks of } \\
\text { made up packages may include confirming } \\
\text { that the outside wrapping/packaging is } \\
\text { intact. }\end{array}$ \\
\hline $\begin{array}{l}\text { Five: } \\
\text { Requires firms to have secure procedures for the } \\
\text { reception, storage, access, usage and } \\
\text { accountability of the Customs-approved seal/ } \\
\text { marking/substance or device. }\end{array}$ & $\begin{array}{l}\text { 22. Have a register to record usage of approved } \\
\text { seals (in manual or electronic format) to } \\
\text { record the seal number, date of receipt, date } \\
\text { of usage and use (e.g. transferred to another } \\
\text { party, container number the seal has been } \\
\text { applied to, or if damaged and destroyed). } \\
\text { 23. Have security measures around storage and } \\
\text { access of the Customs-approved } \\
\text { seal/marking/ substance or device including. } \\
\text { 24. Have secure measures for control and } \\
\text { distribution of the Customs-approved } \\
\text { seal/marking/substance or device to } \\
\text { approved secure sites. }\end{array}$ \\
\hline $\begin{array}{l}\text { Six: } \\
\text { Requires firms to have procedures for reporting } \\
\text { anomalies, suspicious activity and/or illegal } \\
\text { activity when it is detected or suspected. }\end{array}$ & $\begin{array}{l}\text { 25. Have procedures for staff and contractors to } \\
\text { report any breaches of security to a } \\
\text { supervisor or manager. } \\
\text { 26. Have procedures for reporting to NZ } \\
\text { Customs Service all incidents relating to } \\
\text { Customs-approved seal/ marking/substance } \\
\text { or device tampering is suspected or } \\
\text { detected, breaches of security within site } \\
\text { and seal broken by other government } \\
\text { agency. } \\
\text { 27. Have procedures for reporting to Customs } \\
\text { when staff have suspicions or concerns } \\
\text { about any unusual cargo documentation or }\end{array}$ \\
\hline
\end{tabular}




\begin{tabular}{|c|c|c|}
\hline & 28 & $\begin{array}{l}\text { when receiving out of the ordinary requests } \\
\text { for information on shipments. } \\
\text { Have procedures to report missing or lost } \\
\text { Customs-approved seal/ marking/substance } \\
\text { or device. } \\
\text { Have Customs contact numbers } \\
\text { prominently displayed in the site. }\end{array}$ \\
\hline $\begin{array}{l}\text { Seven: } \\
\text { Requires firms to have documented working } \\
\text { business practices and methods to ensure that } \\
\text { policies in relation to goods for export are being } \\
\text { met. }\end{array}$ & 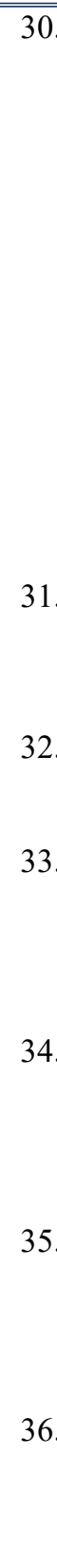 & 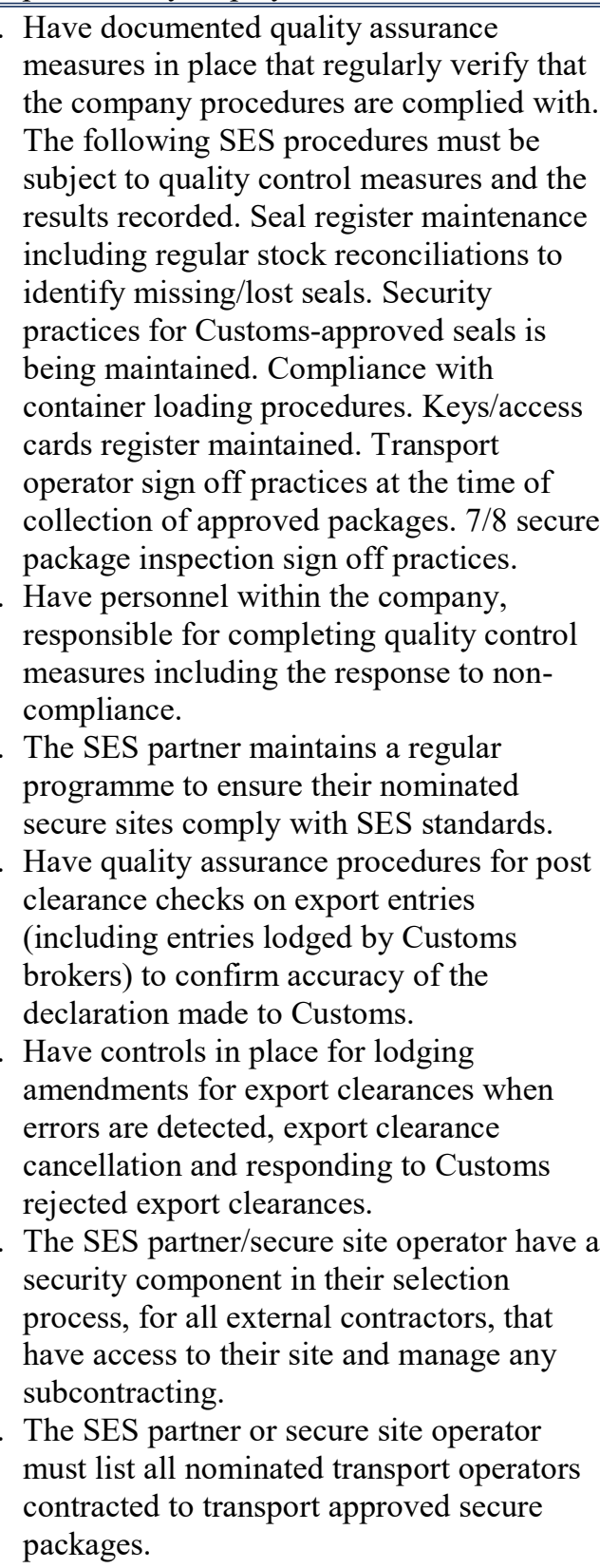 \\
\hline $\begin{array}{l}\text { Eight: } \\
\text { Requires firms to have in place contingency plans } \\
\text { for emergency/security situations. }\end{array}$ & 37 & $\begin{array}{l}\text { Have documented procedures on how the } \\
\text { security of sensitive areas, such as, Storage } \\
\text { areas, Office and Container loading areas } \\
\text { are maintained during building/site } \\
\text { evacuations and how staff, visitors and } \\
\text { contractors on site are accounted for. }\end{array}$ \\
\hline
\end{tabular}




\begin{tabular}{|c|c|}
\hline $\begin{array}{l}\text { Nine: } \\
\text { Requires firms to have or implement document } \\
\text { security procedures that ensure information } \\
\text { stated on export entries, other Customs } \\
\text { declarations, and other documentation cannot be } \\
\text { tampered with. }\end{array}$ & $\begin{array}{l}\text { 38. Have export documents, including invoices } \\
\text { and export clearances, stored securely. } \\
\text { 39. Export documentation archives are retained } \\
\text { in hard copy or electronic format for seven } \\
\text { years. }\end{array}$ \\
\hline $\begin{array}{l}\text { Ten: } \\
\text { Requires firms to have security controls around } \\
\text { Information technology. }\end{array}$ & $\begin{array}{l}\text { 40. Have controls to ensure the security and } \\
\text { prevention of misuse of Customs } \\
\text { declarant/unique user identifier codes } \\
\text { allocated to the firms' employees by } \\
\text { Customs. } \\
\text { 41. Have controls to ensure the security and } \\
\text { prevention of misuse of the firms' Customs } \\
\text { client code(s). } \\
\text { 42. Have information security controls in place } \\
\text { to protect the computer systems from } \\
\text { unauthorised access including policies that } \\
\text { prohibit the sharing of passwords. }\end{array}$ \\
\hline $\begin{array}{l}\text { Eleven: } \\
\text { Requires firms to have physical security covering } \\
\text { the buildings and sites where export goods are } \\
\text { packed and stored and are resistant to } \\
\text { unauthorised entry. }\end{array}$ & $\begin{array}{l}\text { 43. Have physical security measures in place } \\
\text { that control access to the site e.g. perimeter } \\
\text { fencing, gates, access points. } \\
\text { 44. Have security features that restrict access to } \\
\text { key buildings and sensitive areas including } \\
\text { hours of operation. } \\
\text { 45. Have a maintenance programme for } \\
\text { checking and maintaining buildings, } \\
\text { lighting and site perimeter controls. } \\
\text { 46. Have a type of internal or external security } \\
\text { lighting facilities in operation for office, } \\
\text { storage and loading areas to contribute to } \\
\text { security. } \\
\text { 47. Have in place a type of security locking } \\
\text { systems in place to control access to export } \\
\text { documentation and export goods areas } \\
\text { inside/outside business hours. } \\
\text { 48. The issue of access keys/codes/cards is } \\
\text { specifically controlled by management or } \\
\text { security personnel and a register of security } \\
\text { keys/cards/alarm codes is maintained in a } \\
\text { secure manner. } \\
\text { 49. Where firms have CCTV in place these } \\
\text { should have operating procedures around } \\
\text { recording, monitoring and storage. } \\
\text { 50. Have security arrangements, including } \\
\text { contractual agreements with external } \\
\text { security contractors, concerning procedures } \\
\text { for monitoring alarms, responding to } \\
\text { activation, and alarm system maintenance. } \\
\text { 51. Have alarm codes deactivation individually } \\
\text { assigned and restricted to only those with a } \\
\text { need to have access to the premises. } \\
\text { 52. Have procedures for the periodic review of } \\
\text { alarm deactivation to identify patterns of } \\
\text { unusual access. } \\
\text { 53. Have different treatment used, such as, } \\
\text { specific branding/marking or physical }\end{array}$ \\
\hline
\end{tabular}




\begin{tabular}{|c|c|c|}
\hline & & $\begin{array}{l}\text { separation applied to goods destined for } \\
\text { international or domestic market. }\end{array}$ \\
\hline $\begin{array}{l}\text { Twelve: } \\
\text { Requires firms to have access controls measures } \\
\text { to maintain positive identification and control of } \\
\text { company personnel and visitors to the } \\
\text { site/premises, in order to protect company assets } \\
\text { and prevent unauthorised access. }\end{array}$ & $\begin{array}{l} \\
55 . \\
56 . \\
\\
57 . \\
58 . \\
59 .\end{array}$ & $\begin{array}{l}\text { Have a system in place to identify } \\
\text { individuals on site as company personnel } \\
\text { (e.g. small number of staff all known by } \\
\text { management, biometric identification, } \\
\text { branded overalls, ID tags, high visibility } \\
\text { safety wear with company brand depicted). } \\
\text { Have controls on staff access into and } \\
\text { around the site. } \\
\text { During load out activity and unless } \\
\text { specifically authorised, only personnel } \\
\text { directly involved in the loading of the } \\
\text { container/secure package are present in the } \\
\text { load out area. } \\
\text { Have access controls for visitors arriving at } \\
\text { and moving around site, including sign in, } \\
\text { positive identification and sign out } \\
\text { procedures. } \\
\text { Have procedures for how contractors are } \\
\text { identified and monitored on site including } \\
\text { reporting procedures used for recognition } \\
\text { and work allocation. } \\
\text { Have designated company staff(s) that are } \\
\text { responsible for monitoring } \\
\text { visitors/contractors whilst on site. }\end{array}$ \\
\hline $\begin{array}{l}\text { Thirteen: } \\
\text { Requires firms to have measures used to keep } \\
\text { unauthorised vehicles separate from export cargo } \\
\text { handling, packing and loading areas, and to } \\
\text { control transport operators during } \\
\text { collection/delivery. }\end{array}$ & $\begin{array}{l}60 . \\
61 . \\
62 .\end{array}$ & $\begin{array}{l}\text { The vehicle parking facilities provided for } \\
\text { visitors, company personnel and contractors } \\
\text { are within clearly designated areas. } \\
\text { The vehicle parking facilities during load } \\
\text { out are restricted unless specifically } \\
\text { authorized by company, in which case, have } \\
\text { measures in place to protect the export } \\
\text { product. } \\
\text { Have vehicle access controls for transport } \\
\text { operators during and after business hours. }\end{array}$ \\
\hline $\begin{array}{l}\text { Fourteen: } \\
\text { Requires firms to have procedures that maintain } \\
\text { assurance over the integrity of personnel in } \\
\text { positions directly involved with order processing, } \\
\text { packing, storing or shipping export cargo, or } \\
\text { completing company documentation. }\end{array}$ & 63. & $\begin{array}{l}\text { List the key company roles/positions that } \\
\text { have management responsibility, for export } \\
\text { documentation, packing goods and the } \\
\text { loading of goods for export. } \\
\text { Have pre-employment checks conducted for } \\
\text { all positions and ongoing procedures to } \\
\text { maintain personnel integrity for key } \\
\text { positions. } \\
\text { Have procedures in place for cessation of } \\
\text { employment for personnel involved in } \\
\text { international supply chain positions (e.g. } \\
\text { return of ID cards, company branded } \\
\text { property, company uniforms, } \\
\text { keys/codes/cards and removal of computer } \\
\text { access). }\end{array}$ \\
\hline
\end{tabular}




\section{Fifteen:}

Requires firms to have ongoing communication of security policies and awareness training provided to promote the identification of potential security risks.
66. Have in place security induction and basic SES awareness training, including the challenging of persons found in areas where access is not authorized, is delivered to company personnel and as appropriate provided to relevant contractors/transport operators.

67. Have in place additional SES awareness training for personnel in key positions including supervisors, staff in loading area and export documentation officers.

Source: adapted from Fact Sheet 34A Secure Export Scheme Security Plan, issued on April 2011. 
APPENDIX 2: Full Results by Best Practices among the Three Audit Periods (A1, A2 and A3)

\begin{tabular}{|c|c|c|c|c|c|c|c|c|}
\hline \multicolumn{9}{|c|}{ Best practice 1: Approved secure package } \\
\hline Audit periods & A1 & A1\% & $\mathbf{A 2}$ & A2\% & A3 & $\mathbf{A 3} \%$ & Total & Total \% \\
\hline Compliance & 103 & $100.00 \%$ & 68 & $100.00 \%$ & 25 & $100.00 \%$ & 196 & $100.00 \%$ \\
\hline Non-compliance & 0 & "0.00\% & 0 & $0.00 \%$ & 0 & 0.00\% & 0 & 0.00\% \\
\hline Total & 103 & $100.00 \%$ & 68 & $100.00 \%$ & 25 & $100.00 \%$ & 196 & $100.00 \%$ \\
\hline \multicolumn{9}{|c|}{ Best practice 2: Approved seal/marking or devise utilised } \\
\hline Audit periods & A1 & $\mathbf{A 1 \%}$ & $\mathbf{A 2}$ & $\mathbf{A 2 \%}$ & A3 & $\mathbf{A 3} \%$ & Total & Total \% \\
\hline Compliance & 102 & $99.03 \%$ & 66 & $97.06 \%$ & 24 & $96.00 \%$ & 192 & $97.96 \%$ \\
\hline Non-compliance & 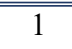 & $0.97 \%$ & 2 & $2.94 \%$ & 1 & $4.00 \%$ & 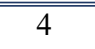 & $2.04 \%$ \\
\hline Grand Total & 103 & $100.00 \%$ & 68 & $100.00 \%$ & 25 & $100.00 \%$ & 196 & $100.00 \%$ \\
\hline \multicolumn{9}{|c|}{ Best practice 3: the process map is updated when changes occur } \\
\hline Audit periods & A1 & $\mathbf{A 1 \%}$ & $\mathbf{A 2}$ & $\mathbf{A 2 \%}$ & A3 & $\mathbf{A 3} \%$ & Total & Total\% \\
\hline Compliance & 99 & $96.12 \%$ & 63 & $92.65 \%$ & 21 & $84.00 \%$ & 183 & $93.37 \%$ \\
\hline Non-compliance & 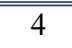 & $3.88 \%$ & $\overline{25}$ & $7.35 \%$ & 4 & $16.00 \%$ & 13 & $6.63 \%$ \\
\hline Total & 103 & $100.00 \%$ & 68 & $100.00 \%$ & 25 & $100.00 \%$ & 196 & $100.00 \%$ \\
\hline \multicolumn{9}{|c|}{ Best practice 4: documents are used to identify products to be loaded } \\
\hline Audit periods & A1 & A1\% & $\mathbf{A 2}$ & A2\% & A3 & A3\% & Total & Total\% \\
\hline Compliance & 101 & $98.06 \%$ & 68 & $100.00 \%$ & 25 & $100.00 \%$ & 194 & $98.98 \%$ \\
\hline Non-compliance & 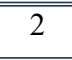 & $1.94 \%$ & 0 & $0.00 \%$ & 0 & $0.00 \%$ & 2 & $1.02 \%$ \\
\hline Total & 103 & $100.00 \%$ & 68 & $100.00 \%$ & 25 & $100.00 \%$ & 196 & $100.00 \%$ \\
\hline \multicolumn{9}{|c|}{ Best practice 5: Checks are in place to verify the goods have been properly marked, weighed, counted and reconciled. } \\
\hline Audit periods & A1 & $\mathbf{A 1 \%}$ & $\mathbf{A 2}$ & $\mathbf{A 2 \%}$ & $\mathbf{A 3}$ & $\mathbf{A 3 \%}$ & Total & Total\% \\
\hline Compliance & 101 & $98.06 \%$ & 68 & $100.00 \%$ & 25 & $100.00 \%$ & 194 & $98.98 \%$ \\
\hline Non-compliance & 2 & $1.94 \%$ & 0 & $0.00 \%$ & 0 & $0.00 \%$ & 2 & $1.02 \%$ \\
\hline Total & 103 & $100.00 \%$ & 68 & $100.00 \%$ & 25 & $100.00 \%$ & 196 & $100.00 \%$ \\
\hline \multicolumn{9}{|c|}{$\begin{array}{l}\text { Best practice 6: The relevant documentation records the name and signature of person undertaking the final check for pre } \\
\text { load accuracy. }\end{array}$} \\
\hline Audit periods & A1 & A1\% & $\mathbf{A 2}$ & A2\% & A3 & A3\% & Total & Total\% \\
\hline Compliance & 102 & $99.03 \%$ & 66 & $97.06 \%$ & 23 & $92.00 \%$ & 191 & $97.45 \%$ \\
\hline Non-compliance & 1 & $0.97 \%$ & 2 & $2.94 \%$ & 2 & $8.00 \%$ & 5 & $2.55 \%$ \\
\hline Total & 103 & $100.00 \%$ & 68 & $100.00 \%$ & 25 & $100.00 \%$ & 196 & $100.00 \%$ \\
\hline \multicolumn{9}{|c|}{ Best practice 7: Procedures are in place for the reporting of errors in documentation or with product lines. } \\
\hline Audit periods & A1 & $\mathbf{A 1 \%}$ & $\mathbf{A 2}$ & $\mathbf{A 2} \%$ & $\mathbf{A 3}$ & $\mathbf{A 3} \%$ & Total & Total \\
\hline Compliance & 100 & $97.09 \%$ & 65 & $95.59 \%$ & 25 & $100.00 \%$ & 190 & $96.94 \%$ \\
\hline Non-compliance & 3 & $2.91 \%$ & 3 & $4.41 \%$ & 0 & $0.00 \%$ & 6 & $3.06 \%$ \\
\hline Total & 103 & $100.00 \%$ & 68 & $100.00 \%$ & 25 & $100.00 \%$ & 196 & $100.00 \%$ \\
\hline \multicolumn{9}{|c|}{ Best practice 8: conducting the $7 / 8$ container check. } \\
\hline Audit periods & A1 & $\mathbf{A 1 \%}$ & $\mathbf{A 2}$ & $\mathbf{A 2 \%}$ & A3 & $\mathbf{A 3} \%$ & Total & Total \\
\hline Compliance & 93 & $90.29 \%$ & 54 & $79.41 \%$ & 21 & $84.00 \%$ & 168 & $85.71 \%$ \\
\hline Non-compliance & 10 & $9.71 \%$ & 14 & $20.59 \%$ & 4 & $16.00 \%$ & 28 & $14.29 \%$ \\
\hline
\end{tabular}




\begin{tabular}{|c|c|c|c|c|c|c|c|c|}
\hline Total & 103 & $100.00 \%$ & 68 & $100.00 \%$ & 25 & $100.00 \%$ & 196 & $100.00 \%$ \\
\hline \multicolumn{9}{|c|}{ Best practice 9: record all of the parties involved in completing container inspection. } \\
\hline Audit periods & $\mathbf{A 1}$ & $\mathbf{A 1 \%}$ & A2 & $\mathbf{A 2 \%}$ & $\mathbf{A 3}$ & $\mathbf{A 3} \%$ & Total & Total\% \\
\hline Compliance & 93 & $90.29 \%$ & 62 & $91.18 \%$ & 23 & $92.00 \%$ & 178 & $90.82 \%$ \\
\hline Non-compliance & 10 & $9.71 \%$ & 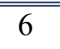 & $8.82 \%$ & 2 & $8.00 \%$ & 18 & $9.18 \%$ \\
\hline Total & 103 & $100.00 \%$ & 68 & $100.00 \%$ & 25 & $100.00 \%$ & 196 & $100.00 \%$ \\
\hline \multicolumn{9}{|c|}{$\begin{array}{l}\text { Best practice 10: Have procedures for checking goods during loading into the approved secure package against documents } \\
\text { and record the checks and the position responsible for signing off the load as correct. }\end{array}$} \\
\hline Audit periods & A1 & A1\% & A2 & A2\% & $\mathbf{A 3}$ & $\mathbf{A 3} \%$ & Total & Total\% \\
\hline Compliance & 102 & $99.03 \%$ & 67 & $98.53 \%$ & 25 & $100.00 \%$ & 194 & $98.98 \%$ \\
\hline Non-compliance & 1 & $0.97 \%$ & 1 & $1.47 \%$ & 0 & $0.00 \%$ & 2 & $1.02 \%$ \\
\hline Total & 103 & $100.00 \%$ & 68 & $100.00 \%$ & 25 & $100.00 \%$ & 196 & $100.00 \%$ \\
\hline \multicolumn{9}{|c|}{$\begin{array}{l}\text { Best practice 11: Have procedures to ensure that only goods belonging to the SES exporter are loaded into the approved } \\
\text { secure package. }\end{array}$} \\
\hline Audit periods & A1 & A1\% & $\mathbf{A 2}$ & A2\% & $\mathbf{A 3}$ & $\mathbf{A 3 \%}$ & Total & Total\% \\
\hline Compliance & 98 & $95.15 \%$ & 65 & $95.59 \%$ & 24 & $96.00 \%$ & 187 & $95.41 \%$ \\
\hline Non-compliance & 5 & $4.85 \%$ & 3 & $4.41 \%$ & 1 & $4.00 \%$ & 9 & $4.59 \%$ \\
\hline Total & 103 & $100.00 \%$ & 68 & $100.00 \%$ & 25 & $100.00 \%$ & 196 & $100.00 \%$ \\
\hline \multicolumn{9}{|c|}{$\begin{array}{l}\text { Best practice 12: Have continuous monitoring procedures that will be maintained during loading/packing of export } \\
\text { product into the approved secure package. }\end{array}$} \\
\hline Audit periods & A1 & A1\% & A2 & A2\% & $\mathbf{A 3}$ & $\mathbf{A 3} \%$ & Total & Total\% \\
\hline Compliance & 93 & $90.29 \%$ & 64 & $94.12 \%$ & 24 & $96.00 \%$ & 181 & $92.35 \%$ \\
\hline Non-compliance & 10 & $9.71 \%$ & 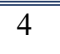 & $5.88 \%$ & 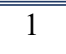 & $4.00 \%$ & 15 & $7.65 \%$ \\
\hline Total & 103 & $100.00 \%$ & 68 & $100.00 \%$ & 25 & $100.00 \%$ & 196 & $100.00 \%$ \\
\hline \multicolumn{9}{|c|}{$\begin{array}{l}\text { Best practice 13: Have personnel responsible for supervision for approved package loading and any other specific load out } \\
\text { area controls in place. }\end{array}$} \\
\hline Audit periods & $\mathbf{A 1}$ & A1\% & A2 & $\mathbf{A 2 \%}$ & $\mathbf{A 3}$ & $\mathbf{A 3} \%$ & Total & Total\% \\
\hline Compliance & 97 & $94.17 \%$ & 68 & $100.00 \%$ & 25 & $100.00 \%$ & 190 & $96.94 \%$ \\
\hline Non-compliance & 6 & $5.83 \%$ & 0 & $0.00 \%$ & 0 & $0.00 \%$ & 6 & $3.06 \%$ \\
\hline Total & 103 & $100.00 \%$ & 68 & $100.00 \%$ & 25 & $100.00 \%$ & 196 & $100.00 \%$ \\
\hline \multicolumn{9}{|c|}{$\begin{array}{l}\text { Best practice 14: Have procedures that protect partially packed approved secure packages from unauthorised access } \\
\text { during loading. }\end{array}$} \\
\hline Audit periods & A1 & A1\% & A2 & $\mathbf{A 2 \%}$ & $\mathbf{A 3}$ & $\mathbf{A 3} \%$ & Total & Total\% \\
\hline Compliance & 97 & $94.17 \%$ & 68 & $100.00 \%$ & 25 & $100.00 \%$ & 190 & $96.94 \%$ \\
\hline Non-compliance & 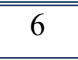 & $5.83 \%$ & 0 & $0.00 \%$ & 0 & $0.00 \%$ & 6 & $3.06 \%$ \\
\hline Total & 103 & $100.00 \%$ & 68 & $100.00 \%$ & 25 & $100.00 \%$ & 196 & $100.00 \%$ \\
\hline \multicolumn{9}{|c|}{$\begin{array}{l}\text { Best practice 15: Have procedures that protect partially packed approved secure packages during breaks with temporary } \\
\text { locking process. }\end{array}$} \\
\hline Audit periods & $\mathbf{A 1}$ & A1\% & A2 & A2\% & $\mathbf{A 3}$ & $\mathbf{A 3 \%}$ & Total & Total\% \\
\hline Compliance & 96 & $93.20 \%$ & 64 & $94.12 \%$ & 25 & $100.00 \%$ & 185 & $94.39 \%$ \\
\hline Non-compliance & 7 & $6.80 \%$ & 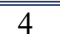 & $5.88 \%$ & 0 & $0.00 \%$ & 11 & $5.61 \%$ \\
\hline Total & 103 & $100.00 \%$ & 68 & $100.00 \%$ & 25 & $100.00 \%$ & 196 & $100.00 \%$ \\
\hline \multicolumn{9}{|c|}{ Best practice 16: Have procedures for multiple site load pickups. } \\
\hline Audit periods & A1 & $\mathbf{A 1 \%}$ & $\mathbf{A 2}$ & A2\% & $\mathbf{A 3}$ & $\mathbf{A 3 \%}$ & Total & Total\% \\
\hline Compliance & 96 & $93.20 \%$ & 66 & $97.06 \%$ & 24 & $96.00 \%$ & 186 & $94.90 \%$ \\
\hline
\end{tabular}




\begin{tabular}{|c|c|c|c|c|c|c|c|c|}
\hline Non-compliance & 7 & $6.80 \%$ & 2 & $2.94 \%$ & 1 & $4.00 \%$ & 10 & $5.10 \%$ \\
\hline Total & 103 & $100.00 \%$ & 68 & $100.00 \%$ & 25 & $100.00 \%$ & 196 & $100.00 \%$ \\
\hline \multicolumn{9}{|c|}{$\begin{array}{l}\text { Best practice 17: Have personnel responsible for applying the Customs-approved seal/marking/ substance or device } \\
\text { immediately on the completion of loading. }\end{array}$} \\
\hline Audit periods & $\mathbf{A 1}$ & A1\% & A2 & A2\% & $\mathbf{A 3}$ & A3\% & Total & Total\% \\
\hline Compliance & 96 & $93.20 \%$ & 64 & $94.12 \%$ & 23 & $92.00 \%$ & 183 & $93.37 \%$ \\
\hline Non-compliance & 7 & $6.80 \%$ & 4 & $5.88 \%$ & 2 & $8.00 \%$ & 13 & $6.63 \%$ \\
\hline Total & 103 & $100.00 \%$ & 68 & $100.00 \%$ & 25 & $100.00 \%$ & 196 & $100.00 \%$ \\
\hline \multicolumn{9}{|c|}{ Best practice 18: have personnel responsible to undertake the final physical check of the seal and record this process. } \\
\hline Audit periods & A1 & A1\% & $\mathbf{A 2}$ & $\mathbf{A 2 \%}$ & $\mathbf{A 3}$ & $\mathbf{A 3 \%}$ & Total & Total\% \\
\hline Compliance & 97 & $94.17 \%$ & 62 & $91.18 \%$ & 23 & $92.00 \%$ & 182 & $92.86 \%$ \\
\hline Non-compliance & 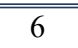 & $5.83 \%$ & 6 & $8.82 \%$ & 2 & $8.00 \%$ & 14 & $7.14 \%$ \\
\hline Total & 103 & $100.00 \%$ & 68 & $100.00 \%$ & 25 & $100.00 \%$ & 196 & $100.00 \%$ \\
\hline \multicolumn{9}{|c|}{ Best practice 19: Have procedures for storage of approved packages sealed but not immediately transported. } \\
\hline Audit periods & A1 & $\mathbf{A 1 \%}$ & $\mathbf{A 2}$ & $\mathbf{A 2 \%}$ & $\mathbf{A 3}$ & $\mathbf{A 3} \%$ & Total & Total\% \\
\hline Compliance & 94 & $91.26 \%$ & 62 & $91.18 \%$ & 23 & $92.00 \%$ & 179 & $91.33 \%$ \\
\hline Non-compliance & 9 & $8.74 \%$ & 6 & $8.82 \%$ & 2 & $8.00 \%$ & 17 & $8.67 \%$ \\
\hline Total & 103 & $100.00 \%$ & 68 & $100.00 \%$ & 25 & $100.00 \%$ & 196 & $100.00 \%$ \\
\hline \multicolumn{9}{|c|}{$\begin{array}{l}\text { Best practice 20: Have documentation to proof the sign over of the container to the transport operator and checks } \\
\text { undertaken on the seal and container. }\end{array}$} \\
\hline Audit periods & A1 & A1\% & A2 & A2\% & $\mathbf{A 3}$ & $\mathbf{A 3} \%$ & Total & Total\% \\
\hline Compliance & 90 & $87.38 \%$ & 56 & $82.35 \%$ & 19 & $76.00 \%$ & 165 & $84.18 \%$ \\
\hline Non-compliance & 13 & $12.62 \%$ & 12 & $17.65 \%$ & 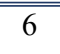 & $24.00 \%$ & 31 & $15.82 \%$ \\
\hline Total & 103 & $100.00 \%$ & 68 & $100.00 \%$ & 25 & $100.00 \%$ & 196 & $100.00 \%$ \\
\hline \multicolumn{9}{|c|}{$\begin{array}{l}\text { Best practice 21: Have, where applicable, documented checks undertaken on receipt of made up packages being } \\
\text { transferred between approved secure sites }\end{array}$} \\
\hline Audit periods & $\mathbf{A 1}$ & A1\% & $\mathbf{A 2}$ & A2\% & $\mathbf{A 3}$ & $\mathbf{A 3} \%$ & Total & Total\% \\
\hline Compliance & 100 & $97.09 \%$ & 67 & $98.53 \%$ & 24 & $96.00 \%$ & 191 & $97.45 \%$ \\
\hline Non-compliance & 3 & $2.91 \%$ & 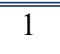 & $1.47 \%$ & 1 & $4.00 \%$ & $\overline{5}$ & $2.55 \%$ \\
\hline Total & 103 & $100.00 \%$ & 68 & $100.00 \%$ & 25 & $100.00 \%$ & 196 & $100.00 \%$ \\
\hline \multicolumn{9}{|c|}{ Best practice 22: Have a register to record usage of approved seals } \\
\hline Audit periods & $\mathbf{A 1}$ & A1\% & A2 & A2\% & $\mathbf{A 3}$ & $\mathbf{A 3} \%$ & Total & Total\% \\
\hline Compliance & 73 & $70.87 \%$ & 49 & $72.06 \%$ & 14 & $56.00 \%$ & 136 & $69.39 \%$ \\
\hline Non-compliance & 30 & $29.13 \%$ & 19 & $27.94 \%$ & 11 & $444.00 \%$ & 60 & $30.61 \%$ \\
\hline Total & 103 & $100.00 \%$ & 68 & $100.00 \%$ & 25 & $100.00 \%$ & 196 & $100.00 \%$ \\
\hline \multicolumn{9}{|c|}{$\begin{array}{l}\text { Best practice 23: Have security measures around storage and access of the Customs-approved seal/marking/ substance or } \\
\text { device including. }\end{array}$} \\
\hline Audit periods & A1 & A1\% & A2 & A2\% & $\mathbf{A 3}$ & $\mathbf{A 3} \%$ & Total & Total\% \\
\hline Compliance & 80 & $77.67 \%$ & 61 & $89.71 \%$ & 21 & $84.00 \%$ & 162 & $82.65 \%$ \\
\hline Non-compliance & 23 & $22.33 \%$ & 7 & $10.29 \%$ & 4 & $16.00 \%$ & 34 & $17.35 \%$ \\
\hline Total & 103 & $100.00 \%$ & 68 & $100.00 \%$ & 25 & $100.00 \%$ & 196 & $100.00 \%$ \\
\hline \multicolumn{9}{|c|}{$\begin{array}{l}\text { Best practice 24: Have secure measures for control and distribution of the Customs-approved seal/marking/substance or } \\
\text { device to approved secure sites. }\end{array}$} \\
\hline Audit periods & A1 & A1\% & A2 & A2\% & A3 & $\mathbf{A 3} \%$ & Total & Total\% \\
\hline Compliance & 93 & $90.29 \%$ & 65 & $95.59 \%$ & 24 & $96.00 \%$ & 182 & $92.86 \%$ \\
\hline
\end{tabular}




\begin{tabular}{|c|c|c|c|c|c|c|c|c|}
\hline Non-compliance & 10 & $9.71 \%$ & 3 & $4.41 \%$ & 1 & $4.00 \%$ & 14 & $7.14 \%$ \\
\hline Total & 103 & $100.00 \%$ & 68 & $100.00 \%$ & 25 & $100.00 \%$ & 196 & $100.00 \%$ \\
\hline \multicolumn{9}{|c|}{ Best practice 25: Have procedures for staff and contractors to report any breaches of security to a supervisor or manager. } \\
\hline Audit periods & A1 & A1\% & $\mathbf{A 2}$ & A2\% & $\mathbf{A 3}$ & $\mathbf{A 3 \%}$ & Total & Total\% \\
\hline Compliance & 101 & $98.06 \%$ & 688 & $100.00 \%$ & 25 & $100.00 \%$ & 194 & $98.98 \%$ \\
\hline Non-compliance & 2 & $1.94 \%$ & 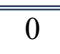 & $0.00 \%$ & 0 & $0.00 \%$ & 2 & $1.02 \%$ \\
\hline Total & 103 & $100.00 \%$ & 68 & $100.00 \%$ & 25 & $100.00 \%$ & 196 & $100.00 \%$ \\
\hline \multicolumn{9}{|c|}{$\begin{array}{l}\text { Best Practice 26: Have procedures for reporting to NZ Customs Service all incidents re seal tampering is suspected or } \\
\text { detected, breaches of security within site and seal broken by other government agency. }\end{array}$} \\
\hline Audit periods & A1 & $\mathbf{A 1 \%}$ & $\mathbf{A 2}$ & A2\% & $\mathbf{A 3}$ & $\mathbf{A 3} \%$ & Total & Total\% \\
\hline Compliance & 89 & $86.41 \%$ & 66 & $97.06 \%$ & 23 & $92.00 \%$ & 178 & $90.82 \%$ \\
\hline Non-compliance & 14 & $13.59 \%$ & 2 & $2.94 \%$ & 2 & $8.00 \%$ & 18 & $9.18 \%$ \\
\hline Total & 103 & $100.00 \%$ & 68 & $100.00 \%$ & 25 & $100.00 \%$ & 196 & $100.00 \%$ \\
\hline \multicolumn{9}{|c|}{$\begin{array}{l}\text { Best practice 27: Have procedures for staff to report suspicions or concerns about any unusual cargo documentation or } \\
\text { when receiving out of the ordinary requests for information on shipments. }\end{array}$} \\
\hline Audit periods & A1 & A1\% & $\mathbf{A 2}$ & $\mathbf{A 2} \%$ & $\mathbf{A 3}$ & A3\% & Total & Total\% \\
\hline Compliance & 101 & $98.06 \%$ & 68 & $100.00 \%$ & 24 & $96.00 \%$ & 193 & $98.47 \%$ \\
\hline Non-compliance & 2 & $1.94 \%$ & 0 & $0.00 \%$ & 1 & $4.00 \%$ & 3 & $1.53 \%$ \\
\hline Total & 103 & $100.00 \%$ & 68 & $1000.00 \%$ & 25 & $100.00 \%$ & 196 & $100.00 \%$ \\
\hline \multicolumn{9}{|c|}{ Best practice 28: Have procedures to report missing or lost Customs-approved seal/ marking/substance or device. } \\
\hline Audit periods & A1 & A1\% & A2 & A2\% & $\mathbf{A 3}$ & $\mathbf{A 3} \%$ & Total & Total\% \\
\hline Compliance & 101 & $98.06 \%$ & 67 & $98.53 \%$ & 24 & $96.00 \%$ & 192 & $97.96 \%$ \\
\hline Non-compliance & 2 & $1.94 \%$ & 1 & $1.47 \%$ & 1 & $4.00 \%$ & 4 & $2.04 \%$ \\
\hline Total & 103 & $100.00 \%$ & 68 & $100.00 \%$ & 25 & $100.00 \%$ & 196 & $100.00 \%$ \\
\hline \multicolumn{9}{|c|}{ Best practice 29: Have Customs contact numbers prominently displayed in the site. } \\
\hline Audit periods & A1 & A1\% & A2 & A2\% & $\mathbf{A 3}$ & $\mathbf{A 3} \%$ & Total & Total\% \\
\hline Compliance & 69 & $66.99 \%$ & 48 & $70.59 \%$ & 16 & $64.00 \%$ & 133 & $67.86 \%$ \\
\hline Non-compliance & 34 & $33.01 \%$ & 20 & $29.41 \%$ & 9 & $36.00 \%$ & 63 & $32.14 \%$ \\
\hline Total & 103 & $100.00 \%$ & 68 & $100.00 \%$ & 25 & $100.00 \%$ & 196 & $100.00 \%$ \\
\hline \multicolumn{9}{|c|}{$\begin{array}{l}\text { Best practice 30: companies to develop quality assurance measures to verify procedures with the SES programme are } \\
\text { complied with. }\end{array}$} \\
\hline Audit periods & A1 & A1\% & A2 & A2\% & $\overline{\mathrm{A3}}$ & A3\% & Total & Total\% \\
\hline Compliance & 71 & $68.93 \%$ & 42 & $61.76 \%$ & 17 & $68.00 \%$ & 130 & $66.33 \%$ \\
\hline Non-compliance & 32 & $31.07 \%$ & 26 & $38.24 \%$ & 8 & $32.00 \%$ & 66 & $33.67 \%$ \\
\hline Total & 103 & $100.00 \%$ & 68 & $100.00 \%$ & 25 & $100.00 \%$ & 196 & $100.00 \%$ \\
\hline \multicolumn{9}{|c|}{$\begin{array}{l}\text { Best practice 31: Have personnel within the company, responsible for completing quality control measures including the } \\
\text { response to non-compliance. }\end{array}$} \\
\hline Audit periods & A1 & A1\% & $\mathbf{A 2}$ & A2\% & $\mathbf{A 3}$ & $\mathbf{A 3 \%}$ & Total & Total\% \\
\hline Compliance & 101 & $98.06 \%$ & 64 & $94.12 \%$ & 24 & $96.00 \%$ & 189 & $96.43 \%$ \\
\hline Non-compliance & 2 & $1.94 \%$ & 4 & $5.88 \%$ & 1 & $4.00 \%$ & 7 & $3.57 \%$ \\
\hline Total & 103 & $100.00 \%$ & 68 & $100.00 \%$ & 25 & $100.00 \%$ & 196 & $100.00 \%$ \\
\hline \multicolumn{9}{|c|}{$\begin{array}{l}\text { Best practice 32: The SES partner maintains a regular programme to ensure their nominated secure sites comply with SES } \\
\text { standards. }\end{array}$} \\
\hline Audit periods & A1 & A1\% & A2 & A2\% & A3 & A3\% & Total & Total\% \\
\hline
\end{tabular}




\begin{tabular}{|c|c|c|c|c|c|c|c|c|}
\hline Compliance & 81 & $78.64 \%$ & 60 & $88.24 \%$ & 20 & $80.00 \%$ & 161 & $82.14 \%$ \\
\hline Non-compliance & 22 & $21.36 \%$ & 8 & $11.76 \%$ & 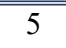 & $20.00 \%$ & 35 & $17.86 \%$ \\
\hline Total & 103 & $100.00 \%$ & 68 & $100.00 \%$ & 25 & $100.00 \%$ & 196 & $100.00 \%$ \\
\hline \multicolumn{9}{|c|}{$\begin{array}{l}\text { Best practice 33: Have quality assurance procedures for post clearance checks on export entries (including entries lodged } \\
\text { by Customs brokers). }\end{array}$} \\
\hline Audit periods & A1 & A1\% & $\mathbf{A 2}$ & A2\% & $\mathbf{A 3}$ & $\mathbf{A 3} \%$ & Total & Total\% \\
\hline Compliance & 44 & $42.72 \%$ & 39 & $57.35 \%$ & 14 & $56.00 \%$ & 97 & $49.49 \%$ \\
\hline Non-compliance & 59 & $57.28 \%$ & 29 & $42.65 \%$ & 11 & $44.00 \%$ & 99 & $50.51 \%$ \\
\hline Total & 103 & $100.00 \%$ & 68 & $100.00 \%$ & 25 & $100.00 \%$ & 196 & $100.00 \%$ \\
\hline \multicolumn{9}{|c|}{$\begin{array}{l}\text { Best practice 34: Have controls in place for lodging amendments for export clearances when errors are detected, export } \\
\text { clearance cancellation and responding to Customs rejected export clearances. }\end{array}$} \\
\hline Audit periods & A1 & A1\% & $\mathbf{A 2}$ & A2\% & $\mathbf{A 3}$ & $\mathbf{A 3} \%$ & Total & Total\% \\
\hline Compliance & 97 & $94.17 \%$ & 64 & $94.12 \%$ & 23 & $92.00 \%$ & 184 & $93.88 \%$ \\
\hline Non-compliance & 6 & $5.83 \%$ & 4 & $5.88 \%$ & 2 & $8.00 \%$ & 12 & $6.12 \%$ \\
\hline Total & 103 & $100.00 \%$ & 68 & $100.00 \%$ & 25 & $100.00 \%$ & 196 & $100.00 \%$ \\
\hline \multicolumn{9}{|c|}{$\begin{array}{l}\text { Best practice 35: The SES partner/secure site operator have a security component in their selection process, for all external } \\
\text { contractors, that have access to their site and manage any subcontracting. }\end{array}$} \\
\hline Audit periods & A1 & A1\% & $\mathbf{A 2}$ & A2\% & $\mathbf{A 3}$ & $\mathbf{A 3} \%$ & Total & Total\% \\
\hline Compliance & 85 & $82.52 \%$ & 60 & $88.24 \%$ & 24 & $96.00 \%$ & 169 & $86.22 \%$ \\
\hline Non-compliance & 18 & $17.48 \%$ & 8 & $11.76 \%$ & 1 & $4.00 \%$ & 27 & $13.78 \%$ \\
\hline Total & 103 & $100.00 \%$ & 68 & $100.00 \%$ & 25 & $100.00 \%$ & 196 & $100.00 \%$ \\
\hline \multicolumn{9}{|c|}{$\begin{array}{l}\text { Best practice 36: The SES partner or secure site operator must have an updated list all nominated transport operators } \\
\text { contracted to transport approved secure packages. }\end{array}$} \\
\hline Audit periods & A1 & A1\% & $\mathbf{A 2}$ & A2\% & $\mathbf{A 3}$ & $\mathbf{A 3} \%$ & Total & Total\% \\
\hline Compliance & 95 & $92.23 \%$ & 56 & $82.35 \%$ & 22 & $88.00 \%$ & 173 & $88.27 \%$ \\
\hline Non-compliance & 8 & $7.77 \%$ & 12 & $17.65 \%$ & 3 & $12.00 \%$ & 23 & $11.73 \%$ \\
\hline Total & 103 & $100.00 \%$ & 68 & $100.00 \%$ & 25 & $100.00 \%$ & 196 & $100.00 \%$ \\
\hline \multicolumn{9}{|c|}{$\begin{array}{l}\text { Best practice 37: Have documented procedures on how the security of sensitive areas, such as, Storage areas, Office and } \\
\text { Container loading areas are maintained during building/site evacuations and how staff, visitors and contractors on site are } \\
\text { accounted for. }\end{array}$} \\
\hline Audit periods & A1 & $\mathbf{A 1 \%}$ & $\mathbf{A 2}$ & $\mathbf{A 2} \%$ & $\mathbf{A 3}$ & $\mathbf{A 3} \%$ & Total & Total\% \\
\hline Compliance & 95 & $92.23 \%$ & 66 & $97.06 \%$ & 22 & $88.00 \%$ & 183 & $93.37 \%$ \\
\hline Non-compliance & 8 & $7.77 \%$ & 2 & $2.94 \%$ & 3 & $12.00 \%$ & 13 & $6.63 \%$ \\
\hline Total & 103 & $100.00 \%$ & 68 & $100.00 \%$ & 25 & $100.00 \%$ & 196 & $100.00 \%$ \\
\hline \multicolumn{9}{|c|}{ Best practice 38: Have export documents, including invoices and export clearances, stored securely. } \\
\hline Audit periods & A1 & $\mathbf{A 1 \%}$ & $\mathbf{A 2}$ & $\mathbf{A 2 \%}$ & $\mathbf{A 3}$ & $\mathbf{A 3} \%$ & Total & Total\% \\
\hline Compliance & 97 & $94.17 \%$ & 65 & $95.59 \%$ & 25 & $100.00 \%$ & 187 & $95.41 \%$ \\
\hline Non-compliance & 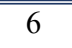 & $5.83 \%$ & 3 & 4.41\% & 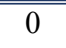 & $0.00 \%$ & 9 & $4.59 \%$ \\
\hline Total & 103 & $100.00 \%$ & 68 & $100.00 \%$ & 25 & $100.00 \%$ & 196 & $100.00 \%$ \\
\hline \multicolumn{9}{|c|}{ Best practice 39: Export documentation archives are retained in hard copy or electronic format for seven years. } \\
\hline Audit periods & A1 & A1\% & $\mathbf{A 2}$ & A2\% & $\mathbf{A 3}$ & $\mathbf{A 3} \%$ & Total & Total\% \\
\hline Compliance & 101 & $98.06 \%$ & 68 & $100.00 \%$ & 25 & $100.00 \%$ & 194 & $98.98 \%$ \\
\hline Non-compliance & 2 & $1.94 \%$ & 0 & $0.00 \%$ & 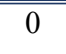 & $0.00 \%$ & 2 & $1.02 \%$ \\
\hline Total & 103 & $100.00 \%$ & 68 & $100.00 \%$ & 25 & $100.00 \%$ & 196 & $100.00 \%$ \\
\hline
\end{tabular}




\begin{tabular}{|c|c|c|c|c|c|c|c|c|}
\hline Audit periods & A1 & A1\% & $\mathbf{A 2}$ & A2\% & A3 & A3\% & Total & Total\% \\
\hline Compliance & 97 & $94.17 \%$ & 66 & $97.06 \%$ & 25 & $100.00 \%$ & 188 & $95.92 \%$ \\
\hline Non-compliance & 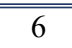 & $5.83 \%$ & 2 & $2.94 \%$ & 0 & $0.00 \%$ & 8 & $4.08 \%$ \\
\hline Total & 103 & $100.00 \%$ & 68 & $100.00 \%$ & 25 & $100.00 \%$ & 196 & $100.00 \%$ \\
\hline \multicolumn{9}{|c|}{ Best practice 41: Have controls to ensure the security and prevention of misuse of the firms' Customs client code(s). } \\
\hline Audit periods & A1 & $\mathbf{A 1 \%}$ & $\mathbf{A 2}$ & A2\% & A3 & $\mathbf{A 3} \%$ & Total & Total\% \\
\hline Compliance & 101 & $98.06 \%$ & 64 & $94.12 \%$ & 25 & $100.00 \%$ & 190 & $96.94 \%$ \\
\hline Non-compliance & 2 & $1.94 \%$ & 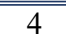 & $5.88 \%$ & 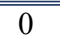 & $0.00 \%$ & 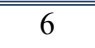 & $3.06 \%$ \\
\hline Total & 103 & $100.00 \%$ & 68 & $100.00 \%$ & 25 & $100.00 \%$ & 196 & $100.00 \%$ \\
\hline \multicolumn{9}{|c|}{$\begin{array}{l}\text { Best practice 42: Have information security controls in place to protect the computer systems from unauthorised access } \\
\text { including policies that prohibit the sharing of passwords. }\end{array}$} \\
\hline Audit periods & A1 & A1\% & $\mathbf{A 2}$ & A2\% & A3 & $\mathrm{A3} \%$ & Total & Total\% \\
\hline Compliance & 95 & $92.23 \%$ & 65 & $95.59 \%$ & 24 & $96.00 \%$ & 184 & $93.88 \%$ \\
\hline Non-compliance & 8 & $7.77 \%$ & 3 & $4.41 \%$ & 1 & $4.00 \%$ & 12 & $6.12 \%$ \\
\hline Total & 103 & $100.00 \%$ & 68 & $100.00 \%$ & 25 & $100.00 \%$ & 196 & $100.00 \%$ \\
\hline \multicolumn{9}{|c|}{$\begin{array}{l}\text { Best practice 43: Have physical security measures in place that control access to the site e.g. perimeter fencing, gates, } \\
\text { access points. }\end{array}$} \\
\hline Audit periods & A1 & A1\% & $\mathbf{A 2}$ & A2\% & A3 & $\mathbf{A 3 \%}$ & Total & Total\% \\
\hline Compliance & 91 & $88.35 \%$ & 66 & $97.06 \%$ & 24 & $96.00 \%$ & 181 & $92.35 \%$ \\
\hline Non-compliance & 12 & $11.65 \%$ & 2 & $2.94 \%$ & 1 & $4.00 \%$ & 15 & $7.65 \%$ \\
\hline Total & 103 & $100.00 \%$ & 68 & $100.00 \%$ & 25 & $100.00 \%$ & 196 & $100.00 \%$ \\
\hline \multicolumn{9}{|c|}{$\begin{array}{l}\text { Best practice 44: Have security features that restrict access to key buildings and sensitive areas including hours of } \\
\text { operation. }\end{array}$} \\
\hline Audit periods & A1 & A1\% & $\mathbf{A 2}$ & $\mathbf{A 2} \%$ & A3 & A3\% & Total & Total\% \\
\hline Compliance & 91 & $88.35 \%$ & 65 & $95.59 \%$ & 24 & $96.00 \%$ & 180 & $91.84 \%$ \\
\hline Non-compliance & 12 & $11.65 \%$ & 3 & $4.41 \%$ & 1 & $4.00 \%$ & 16 & $8.16 \%$ \\
\hline Total & 103 & $100.00 \%$ & 68 & $100.00 \%$ & 25 & $100.00 \%$ & 196 & $100.00 \%$ \\
\hline \multicolumn{9}{|c|}{$\begin{array}{l}\text { Best practice 45: Have a maintenance programme for checking and maintaining buildings, lighting and site perimeter } \\
\text { controls. }\end{array}$} \\
\hline Audit periods & A1 & A1\% & $\mathbf{A 2}$ & A2\% & A3 & A3\% & Total & Total\% \\
\hline Compliance & 101 & $98.06 \%$ & 67 & $98.53 \%$ & 25 & $100.00 \%$ & 193 & $98.47 \%$ \\
\hline Non-compliance & 2 & $1.94 \%$ & 1 & $1.47 \%$ & 0 & $0.00 \%$ & 3 & $1.53 \%$ \\
\hline Total & 103 & $100.00 \%$ & 68 & $100.00 \%$ & 25 & $100.00 \%$ & 196 & $100.00 \%$ \\
\hline \multicolumn{9}{|c|}{$\begin{array}{l}\text { Best practice 46: Have a type of internal or external security lighting facilities in operation for office, storage and loading } \\
\text { areas to contribute to security. }\end{array}$} \\
\hline Audit periods & A1 & A1\% & $\mathbf{A 2}$ & A2\% & A3 & $\mathbf{A 3} \%$ & Total & Total\% \\
\hline Compliance & 102 & $99.03 \%$ & 66 & $97.06 \%$ & 24 & $96.00 \%$ & 192 & $97.96 \%$ \\
\hline Non-compliance & 1 & $0.97 \%$ & 2 & $2.94 \%$ & 1 & $4.00 \%$ & 4 & $2.04 \%$ \\
\hline Total & 103 & $100.00 \%$ & 68 & $100.00 \%$ & 25 & $100.00 \%$ & 196 & $100.00 \%$ \\
\hline \multicolumn{9}{|c|}{$\begin{array}{l}\text { Best practice 47: Have in place a type of security locking systems in place to control access to export documentation and } \\
\text { export goods areas inside/outside business hours. }\end{array}$} \\
\hline Audit periods & A1 & A1\% & $\mathbf{A 2}$ & A2\% & A3 & A3\% & Total & Total\% \\
\hline Compliance & 102 & $99.03 \%$ & 66 & $97.06 \%$ & 24 & $96.00 \%$ & 192 & $97.96 \%$ \\
\hline Non-compliance & 1 & $0.97 \%$ & 2 & $2.94 \%$ & 1 & $4.00 \%$ & 4 & $2.04 \%$ \\
\hline Total & 103 & $100.00 \%$ & 68 & $100.00 \%$ & 25 & $100.00 \%$ & 196 & $100.00 \%$ \\
\hline
\end{tabular}




\begin{tabular}{|c|c|c|c|c|c|c|c|c|}
\hline Audit periods & A1 & A1\% & A2 & A2\% & $\mathbf{A 3}$ & A3\% & Total & Total\% \\
\hline Compliance & 101 & $98.06 \%$ & 63 & $92.65 \%$ & 23 & $92.00 \%$ & 187 & $95.41 \%$ \\
\hline Non-compliance & 2 & "1.94\% & 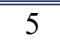 & $7.35 \%$ & 2 & $8.00 \%$ & 9 & 4.59\% \\
\hline Total & 103 & $100.00 \%$ & 68 & $100.00 \%$ & 25 & $100.00 \%$ & 196 & $100.00 \%$ \\
\hline \multicolumn{9}{|c|}{$\begin{array}{l}\text { Best practice 49: Where firms have CCTV in place these should have operating procedures around recording, monitoring } \\
\text { and storage. }\end{array}$} \\
\hline Audit periods & A1 & A1\% & A2 & A2\% & $\mathbf{A 3}$ & $\mathbf{A 3} \%$ & Total & Total\% \\
\hline Compliance & 103 & $100.00 \%$ & 68 & $100.00 \%$ & 25 & $100.00 \%$ & 196 & $100.00 \%$ \\
\hline Non-compliance & 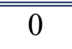 & $0.00 \%$ & 0 & $0.00 \%$ & 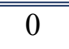 & $0.00 \%$ & 0 & $0.00 \%$ \\
\hline Total & 103 & $100.00 \%$ & 68 & $100.00 \%$ & 25 & $100.00 \%$ & 196 & $100.00 \%$ \\
\hline \multicolumn{9}{|c|}{$\begin{array}{l}\text { Best practice 50: Have security arrangements, including contractual agreements with external security contractors, } \\
\text { concerning procedures for monitoring alarms, responding to activation, and alarm system maintenance. }\end{array}$} \\
\hline Audit periods & A1 & A1\% & A2 & A2\% & $\mathbf{A 3}$ & $\mathbf{A 3} \%$ & Total & Total\% \\
\hline Compliance & 103 & $100.00 \%$ & 68 & $100.00 \%$ & 25 & $100.00 \%$ & 196 & $100.00 \%$ \\
\hline Non-compliance & 0 & $0.00 \%$ & 0 & $0.00 \%$ & 0 & $0.00 \%$ & 0 & $0.00 \%$ \\
\hline Total & 103 & $100.00 \%$ & 688 & $100.00 \%$ & 25 & $100.00 \%$ & 196 & $100.00 \%$ \\
\hline \multicolumn{9}{|c|}{$\begin{array}{l}\text { Best practice 51: Have alarm codes deactivation individually assigned and restricted to only those with a need to have } \\
\text { access to the premises. }\end{array}$} \\
\hline Audit periods & A1 & A1\% & $\mathbf{A 2}$ & A2\% & $\mathbf{A 3}$ & $\mathbf{A 3 \%}$ & Total & Total\% \\
\hline Compliance & 102 & $99.03 \%$ & 67 & $98.53 \%$ & 25 & $100.00 \%$ & 194 & $98.98 \%$ \\
\hline Non-compliance & 1 & $0.97 \%$ & 1 & $1.47 \%$ & 0 & $0.00 \%$ & 2 & $1.02 \%$ \\
\hline Total & 103 & $100.00 \%$ & 68 & $100.00 \%$ & 25 & $100.00 \%$ & 196 & $100.00 \%$ \\
\hline \multicolumn{9}{|c|}{ Best practice 52: Have procedures for the periodic review of alarm deactivation to identify patterns of unusual access. } \\
\hline Audit periods & A1 & $\mathbf{A 1 \%}$ & $\mathbf{A 2}$ & $\mathbf{A 2 \%}$ & 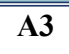 & $\mathbf{A 3 \%}$ & Total & Total\% \\
\hline Compliance & 102 & $99.03 \%$ & 67 & $98.53 \%$ & 25 & $100.00 \%$ & 194 & $98.98 \%$ \\
\hline Non-compliance & 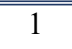 & 0.97\% & 1 & $1.47 \%$ & 0 & "0.00\% & 2 & $1.02 \%$ \\
\hline Total & 103 & $100.00 \%$ & 68 & $100.00 \%$ & 25 & $100.00 \%$ & 196 & $100.00 \%$ \\
\hline \multicolumn{9}{|c|}{$\begin{array}{l}\text { Best practice 53: Have different treatment used, such as, specific branding/marking or physical separation applied to goods } \\
\text { destined for international or domestic market. }\end{array}$} \\
\hline Audit periods & A1 & A1\% & A2 & A2\% & A3 & A3\% & Total & Total\% \\
\hline Compliance & 103 & $100.00 \%$ & 68 & $100.00 \%$ & 25 & $100.00 \%$ & 196 & $100.00 \%$ \\
\hline Non-compliance & 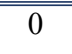 & $0.00 \%$ & 0 & $0.00 \%$ & 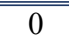 & $0.00 \%$ & 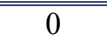 & $0.00 \%$ \\
\hline Total & 103 & $100.00 \%$ & 688 & $100.00 \%$ & 25 & $100.00 \%$ & 196 & $100.00 \%$ \\
\hline \multicolumn{9}{|c|}{ Best practice 54: Have a system in place to identify individuals on site as company personnel. } \\
\hline Audit periods & A1 & $\mathbf{A 1 \%}$ & $\mathbf{A 2}$ & $\mathbf{A 2 \%}$ & $\mathbf{A 3}$ & $\mathbf{A 3 \%}$ & Total & Total\% \\
\hline Compliance & 100 & $97.09 \%$ & 67 & $98.53 \%$ & 24 & $96.00 \%$ & 191 & $97.45 \%$ \\
\hline Non-compliance & 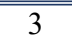 & $2.91 \%$ & 1 & $1.47 \%$ & 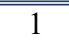 & $4.00 \%$ & 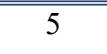 & $2.55 \%$ \\
\hline Total & 103 & $100.00 \%$ & 68 & $100.00 \%$ & 25 & $100.00 \%$ & 196 & $100.00 \%$ \\
\hline \multicolumn{9}{|c|}{ Best practice 55: Have controls on staff access into and around the site. } \\
\hline Audit periods & A1 & A1\% & A2 & $\mathbf{A 2 \%}$ & $\mathbf{A 3}$ & $\mathbf{A 3} \%$ & Total & Total\% \\
\hline Compliance & 99 & $96.12 \%$ & 67 & $98.53 \%$ & 24 & $96.00 \%$ & 190 & $96.94 \%$ \\
\hline Non-compliance & 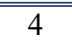 & $3.88 \%$ & 1 & $1.47 \%$ & 1 & $4.00 \%$ & 6 & $3.06 \%$ \\
\hline Total & 103 & $100.00 \%$ & 268 & $100.00 \%$ & 25 & $100.00 \%$ & 196 & $100.00 \%$ \\
\hline
\end{tabular}




\begin{tabular}{|l||c||c||c||c||c||c||c||c||}
\hline \hline Audit periods & $\mathbf{A 1}$ & $\mathbf{A 1 \%}$ & $\mathbf{A 2}$ & $\mathbf{A 2} \%$ & $\mathbf{A 3}$ & $\mathbf{A 3 \%}$ & Total & Total\% \\
\hline \hline Compliance & 101 & $98.06 \%$ & 68 & $100.00 \%$ & 24 & $96.00 \%$ & 193 & $98.47 \%$ \\
\hline \hline Non-compliance & 2 & $1.94 \%$ & 0 & $0.00 \%$ & 1 & $4.00 \%$ & 3 & $1.53 \%$ \\
\hline \hline Total & 103 & $100.00 \%$ & 68 & $100.00 \%$ & 25 & $100.00 \%$ & 196 & $100.00 \%$ \\
\hline \hline $\begin{array}{l}\text { Best practice 57: Have access controls for visitors arriving at and moving around site, including sign in, positive } \\
\text { identification and sign out procedures. }\end{array}$ & $\mathbf{A 1}$ & $\mathbf{A 1 \%}$ & $\mathbf{A 2}$ & $\mathbf{A 2} \%$ & $\mathbf{A 3}$ & $\mathbf{A 3 \%}$ & Total & Total\% \\
\hline \hline Audit periods & 92 & $89.32 \%$ & 63 & $92.65 \%$ & 22 & $88.00 \%$ & 177 & $90.31 \%$ \\
\hline \hline Compliance & 11 & $10.68 \%$ & 5 & $7.35 \%$ & 3 & $12.00 \%$ & 19 & $9.69 \%$ \\
\hline \hline Non-compliance & 103 & $100.00 \%$ & 68 & $100.00 \%$ & 25 & $100.00 \%$ & 196 & $100.00 \%$ \\
\hline \hline Total &
\end{tabular}

Best practice 58: Have procedures for how contractors are identified and monitored on site including reporting procedures used for recognition and work allocation.

\begin{tabular}{|l||c||c||c||c||c||c||c||c||c|}
\hline \hline Audit periods & A1 & $\mathbf{A 1 \%}$ & $\mathbf{A 2}$ & $\mathbf{A 2 \%}$ & $\mathbf{A 3}$ & $\mathbf{A 3 \%}$ & Total & Total\% \\
\hline \hline Compliance & 100 & $97.09 \%$ & 68 & $100.00 \%$ & 24 & $96.00 \%$ & 192 & $97.96 \%$ \\
\hline \hline Non-compliance & 3 & $2.91 \%$ & 0 & $0.00 \%$ & 1 & $4.00 \%$ & 4 & $2.04 \%$ \\
\hline \hline Total & 103 & $100.00 \%$ & 68 & $100.00 \%$ & 25 & $100.00 \%$ & 196 & $100.00 \%$ \\
\hline
\end{tabular}

Best practice 59: Have designated company staff(s) that are responsible for monitoring visitors/contractors whilst on site.

\begin{tabular}{|l||c||c||c||c||c||c||c||c||}
\hline Audit periods & $\mathbf{A 1}$ & $\mathbf{A 1 \%}$ & $\mathbf{A 2}$ & $\mathbf{A 2 \%}$ & $\mathbf{A 3}$ & $\mathbf{A 3 \%}$ & Total & Total\% \\
\hline \hline Compliance & 103 & $100.00 \%$ & 68 & $100.00 \%$ & 25 & $100.00 \%$ & 196 & $100.00 \%$ \\
\hline \hline Non-compliance & 0 & $0.00 \%$ & 0 & $0.00 \%$ & 0 & $0.00 \%$ & 0 & $0.00 \%$ \\
\hline \hline Total & 103 & $100.00 \%$ & 68 & $100.00 \%$ & 25 & $100.00 \%$ & 196 & $100.00 \%$ \\
\hline \hline
\end{tabular}

Best practice 60: The vehicle parking facilities provided for visitors, company personnel and contractors are within clearly designated areas.

\begin{tabular}{|l||c||c||c||c||c||c||c||c|}
\hline \hline Audit periods & A1 & $\mathbf{A 1 \%}$ & $\mathbf{A 2}$ & $\mathbf{A 2 \%}$ & $\mathbf{A 3}$ & $\mathbf{A 3 \%}$ & Total & Total\% \\
\hline \hline Compliance & 100 & $97.09 \%$ & 67 & $98.53 \%$ & 24 & $96.00 \%$ & 191 & $97.45 \%$ \\
\hline \hline Non-compliance & 3 & $2.91 \%$ & 1 & $1.47 \%$ & 1 & $4.00 \%$ & 5 & $2.55 \%$ \\
\hline \hline Total & 103 & $100.00 \%$ & 68 & $100.00 \%$ & 25 & $100.00 \%$ & 196 & $100.00 \%$ \\
\hline \hline
\end{tabular}

Best practice 61: The vehicle parking facilities during load out are restricted unless specifically authorized by company, in which case, have measures in place to protect the export product.

\begin{tabular}{|l||c||c||c||c||c||c||c||c||}
\hline \hline Audit periods & A1 & $\mathbf{A 1 \%}$ & $\mathbf{A 2}$ & $\mathbf{A 2 \%}$ & $\mathbf{A 3}$ & $\mathbf{A 3 \%}$ & Total & Total\% \\
\hline \hline Compliance & 101 & $98.06 \%$ & 67 & $98.53 \%$ & 23 & $92.00 \%$ & 191 & $97.45 \%$ \\
\hline \hline Non-compliance & 2 & $1.94 \%$ & 1 & $1.47 \%$ & 2 & $8.00 \%$ & 5 & $2.55 \%$ \\
\hline \hline Total & 103 & $100.00 \%$ & 68 & $100.00 \%$ & 25 & $100.00 \%$ & 196 & $100.00 \%$ \\
\hline
\end{tabular}

Best practice 62: Have vehicle access controls for transport operators during and after business hours.

\begin{tabular}{||l||c||c||c||c||c||c||c||c|}
\hline \hline Audit periods & $\mathbf{A 1}$ & $\mathbf{A 1 \%}$ & $\mathbf{A 2}$ & $\mathbf{A 2 \%}$ & $\mathbf{A 3}$ & $\mathbf{A 3 \%}$ & Total & Total\% \\
\hline \hline Compliance & 98 & $95.15 \%$ & 67 & $98.53 \%$ & 23 & $92.00 \%$ & 188 & $95.92 \%$ \\
\hline \hline Non-compliance & 5 & $4.85 \%$ & 1 & $1.47 \%$ & 2 & $8.00 \%$ & 8 & $4.08 \%$ \\
\hline \hline Total & 103 & $100.00 \%$ & 68 & $100.00 \%$ & 25 & $100.00 \%$ & 196 & $100.00 \%$ \\
\hline \hline
\end{tabular}

Best practice 63: List the key company roles/positions that have management responsibility, for export documentation, packing goods and the loading of goods for export.

\begin{tabular}{|c|c|c|c|c|c|c|c|c|}
\hline Audit periods & A1 & A1\% & $\mathbf{A 2}$ & A2\% & $\mathbf{A 3}$ & A3\% & Total & Total\% \\
\hline Compliance & 100 & $97.09 \%$ & 67 & $98.53 \%$ & 25 & $100.00 \%$ & 192 & $97.96 \%$ \\
\hline Non-compliance & 3 & $2.91 \%$ & 1 & $1.47 \%$ & 0 & $0.00 \%$ & 4 & $2.04 \%$ \\
\hline Total & 103 & $100.00 \%$ & 68 & $100.00 \%$ & 25 & $100.00 \%$ & 196 & $100.00 \%$ \\
\hline
\end{tabular}

Best practice 64: Have pre-employment checks conducted for all positions and ongoing procedures to maintain personnel integrity for key positions. 


\begin{tabular}{|c|c|c|c|c|c|c|c|c|}
\hline Audit periods & A1 & A1\% & A2 & A2\% & $\mathbf{A 3}$ & $\mathbf{A 3} \%$ & Total & Total\% \\
\hline Compliance & 102 & $99.03 \%$ & 67 & $98.53 \%$ & 25 & $100.00 \%$ & 194 & $98.98 \%$ \\
\hline Non-compliance & 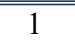 & 0.97\% & 1 & $1.47 \%$ & 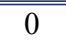 & 0.00\% & 2 & $1.02 \%$ \\
\hline Total & 103 & $100.00 \%$ & 68 & $100.00 \%$ & 25 & $100.00 \%$ & 196 & $100.00 \%$ \\
\hline \multicolumn{9}{|c|}{$\begin{array}{l}\text { Best practice 65: Have procedures in place for cessation of employment for personnel involved in international supply } \\
\text { chain positions. }\end{array}$} \\
\hline Audit periods & $\mathbf{A 1}$ & A1\% & $\mathbf{A 2}$ & A2\% & $\mathbf{A 3}$ & $\mathbf{A 3} \%$ & Total & Total\% \\
\hline Compliance & 100 & $97.09 \%$ & 66 & $97.06 \%$ & 25 & $100.00 \%$ & 191 & $97.45 \%$ \\
\hline Non-compliance & 3 & $2.91 \%$ & 2 & $2.94 \%$ & 0 & $0.00 \%$ & 5 & $2.55 \%$ \\
\hline Total & 103 & $100.00 \%$ & 68 & $100.00 \%$ & 25 & $100.00 \%$ & 196 & $100.00 \%$ \\
\hline \multicolumn{9}{|c|}{ Best practice 66: Have in place security induction and basic SES awareness training. } \\
\hline Audit periods & A1 & $\mathbf{A 1 \%}$ & $\mathbf{A 2}$ & A2\% & $\mathbf{A 3}$ & $\mathbf{A 3} \%$ & Total & Total\% \\
\hline Compliance & 80 & $77.67 \%$ & 53 & $77.94 \%$ & 20 & $80.00 \%$ & 153 & $78.06 \%$ \\
\hline Non-compliance & 23 & $22.33 \%$ & 15 & $22.06 \%$ & 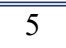 & $20.00 \%$ & 43 & $21.94 \%$ \\
\hline Total & 103 & $100.00 \%$ & 68 & $100.00 \%$ & 25 & $100.00 \%$ & 196 & $100.00 \%$ \\
\hline \multicolumn{9}{|c|}{$\begin{array}{l}\text { Best practice 67: Have in place additional SES awareness training for personnel in key positions including supervisors, } \\
\text { staff in loading area and export documentation officers. }\end{array}$} \\
\hline Audit periods & A1 & A1\% & A2 & A2\% & $\mathbf{A 3}$ & $\mathbf{A 3} \%$ & Total & Total\% \\
\hline Compliance & 94 & $91.26 \%$ & 56 & $82.35 \%$ & 24 & $96.00 \%$ & 174 & $88.78 \%$ \\
\hline Non-compliance & 9 & $8.74 \%$ & 12 & $17.65 \%$ & 1 & $4.00 \%$ & 22 & $11.22 \%$ \\
\hline Total & 103 & $100.00 \%$ & 68 & $100.00 \%$ & 25 & $100.00 \%$ & 196 & $100.00 \%$ \\
\hline
\end{tabular}


APPENDIX 3: Full Results Cohort of 25 Firms' three Audit Periods (T1, T2 and T3)

\begin{tabular}{|c|c|c|c|c|c|c|}
\hline \multirow{2}{*}{$\begin{array}{c}\mathbf{n}=\mathbf{2 5} \\
\text { Best } \\
\text { Practices }\end{array}$} & \multicolumn{2}{|c|}{ "Audit T1 } & \multicolumn{2}{|c|}{ " Audit T2 } & \multicolumn{2}{|c|}{ "Audit T3 } \\
\hline & $\begin{array}{l}\text { Percentage } \\
\text { Compliance }\end{array}$ & $\begin{array}{l}\text { Percentage } \\
\text { Non- } \\
\text { compliance }\end{array}$ & $\begin{array}{l}\text { Percentage } \\
\text { Compliance }\end{array}$ & $\begin{array}{l}\text { Percentage } \\
\text { Non- } \\
\text { compliance }\end{array}$ & $\begin{array}{l}\text { Percentage } \\
\text { Compliance }\end{array}$ & $\begin{array}{l}\text { Percentage } \\
\text { Non- } \\
\text { compliance }\end{array}$ \\
\hline 1 & $100 \%$ & $0 \%$ & $100 \%$ & $0 \%$ & $100 \%$ & $0 \%$ \\
\hline 2 & $96 \%$ & $4 \%$ & $92 \%$ & $8 \%$ & $96 \%$ & $4 \%$ \\
\hline 3 & $88 \%$ & $12 \%$ & $100 \%$ & $0 \%$ & $84 \%$ & $16 \%$ \\
\hline 4 & $100 \%$ & $0 \%$ & $100 \%$ & $0 \%$ & $100 \%$ & $0 \%$ \\
\hline 5 & $100 \%$ & $0 \%$ & $100 \%$ & $0 \%$ & $100 \%$ & $0 \%$ \\
\hline 6 & $100 \%$ & $0 \%$ & $100 \%$ & $0 \%$ & $92 \%$ & $8 \%$ \\
\hline 7 & $100 \%$ & $0 \%$ & $100 \%$ & $0 \%$ & $100 \%$ & $0 \%$ \\
\hline 8 & $88 \%$ & $12 \%$ & $76 \%$ & $24 \%$ & $84 \%$ & $16 \%$ \\
\hline 9 & $96 \%$ & $4 \%$ & $92 \%$ & $8 \%$ & $92 \%$ & $8 \%$ \\
\hline 10 & $100 \%$ & $0 \%$ & $100 \%$ & $0 \%$ & $100 \%$ & $0 \%$ \\
\hline 11 & $96 \%$ & $4 \%$ & $92 \%$ & $8 \%$ & $96 \%$ & $4 \%$ \\
\hline 12 & $84 \%$ & $16 \%$ & $96 \%$ & $4 \%$ & $96 \%$ & $4 \%$ \\
\hline 13 & $96 \%$ & $4 \%$ & $100 \%$ & $0 \%$ & $100 \%$ & $0 \%$ \\
\hline 14 & $88 \%$ & $12 \%$ & $100 \%$ & $0 \%$ & $100 \%$ & $0 \%$ \\
\hline 15 & $80 \%$ & $20 \%$ & $88 \%$ & $12 \%$ & $100 \%$ & $0 \%$ \\
\hline 16 & $96 \%$ & $4 \%$ & $92 \%$ & $8 \%$ & $96 \%$ & $4 \%$ \\
\hline 17 & $88 \%$ & $12 \%$ & $92 \%$ & $8 \%$ & $92 \%$ & $8 \%$ \\
\hline 18 & $92 \%$ & $8 \%$ & $88 \%$ & $12 \%$ & $92 \%$ & $8 \%$ \\
\hline 19 & $96 \%$ & $4 \%$ & $88 \%$ & $12 \%$ & $92 \%$ & $8 \%$ \\
\hline 20 & $88 \%$ & $12 \%$ & $84 \%$ & $16 \%$ & $76 \%$ & $24 \%$ \\
\hline 21 & $96 \%$ & $4 \%$ & $96 \%$ & $4 \%$ & $96 \%$ & $4 \%$ \\
\hline 22 & $72 \%$ & $28 \%$ & $60 \%$ & $40 \%$ & $56 \%$ & $44 \%$ \\
\hline 23 & $72 \%$ & $28 \%$ & $76 \%$ & $24 \%$ & $84 \%$ & $16 \%$ \\
\hline 24 & $92 \%$ & $8 \%$ & $96 \%$ & $4 \%$ & $96 \%$ & $4 \%$ \\
\hline 25 & $100 \%$ & $0 \%$ & $100 \%$ & $0 \%$ & $100 \%$ & $0 \%$ \\
\hline 26 & $84 \%$ & $16 \%$ & $92 \%$ & $8 \%$ & $92 \%$ & $8 \%$ \\
\hline 27 & $100 \%$ & $0 \%$ & $100 \%$ & $0 \%$ & $96 \%$ & $4 \%$ \\
\hline 28 & $100 \%$ & $0 \%$ & $100 \%$ & $0 \%$ & $96 \%$ & $4 \%$ \\
\hline 29 & $64 \%$ & $36 \%$ & $56 \%$ & $44 \%$ & $64 \%$ & $36 \%$ \\
\hline 30 & $80 \%$ & $20 \%$ & $56 \%$ & $44 \%$ & $68 \%$ & $32 \%$ \\
\hline 31 & $100 \%$ & $0 \%$ & $100 \%$ & $0 \%$ & $96 \%$ & $4 \%$ \\
\hline 32 & $80 \%$ & $20 \%$ & $88 \%$ & $12 \%$ & $80 \%$ & $20 \%$ \\
\hline 33 & $44 \%$ & $56 \%$ & $60 \%$ & $40 \%$ & $56 \%$ & $44 \%$ \\
\hline 34 & $96 \%$ & $4 \%$ & $100 \%$ & $0 \%$ & $92 \%$ & $8 \%$ \\
\hline 35 & $84 \%$ & $16 \%$ & $92 \%$ & $8 \%$ & $96 \%$ & $4 \%$ \\
\hline 36 & $100 \%$ & $0 \%$ & $80 \%$ & $20 \%$ & $88 \%$ & $12 \%$ \\
\hline
\end{tabular}




\begin{tabular}{|c|c|c|c|c|c|c|}
\hline 37 & $96 \%$ & $4 \%$ & $96 \%$ & $4 \%$ & $88 \%$ & $12 \%$ \\
\hline 38 & $96 \%$ & $4 \%$ & $96 \%$ & $4 \%$ & $100 \%$ & $0 \%$ \\
\hline 39 & $100 \%$ & $0 \%$ & $100 \%$ & $\overline{20 \%}$ & $100 \%$ & $\overline{20 \%}$ \\
\hline 40 & $96 \%$ & $4 \%$ & $96 \%$ & $4 \%$ & $100 \%$ & $0 \%$ \\
\hline 41 & $100 \%$ & $0 \%$ & $100 \%$ & $0 \%$ & $100 \%$ & $0 \%$ \\
\hline 42 & $88 \%$ & $12 \%$ & $92 \%$ & $8 \%$ & $96 \%$ & $4 \%$ \\
\hline 43 & $92 \%$ & $8 \%$ & $96 \%$ & $4 \%$ & $96 \%$ & $4 \%$ \\
\hline 44 & $80 \%$ & $20 \%$ & $88 \%$ & $12 \%$ & $96 \%$ & $4 \%$ \\
\hline 45 & $100 \%$ & $0 \%$ & $96 \%$ & $4 \%$ & $100 \%$ & $0 \%$ \\
\hline 46 & $100 \%$ & $0 \%$ & $100 \%$ & $0 \%$ & $96 \%$ & $4 \%$ \\
\hline 47 & $100 \%$ & $0 \%$ & $100 \%$ & $0 \%$ & $96 \%$ & $4 \%$ \\
\hline 48 & $100 \%$ & $0 \%$ & $92 \%$ & $8 \%$ & $92 \%$ & $8 \%$ \\
\hline 49 & $100 \%$ & $0 \%$ & $100 \%$ & $0 \%$ & $100 \%$ & $0 \%$ \\
\hline 50 & $100 \%$ & $0 \%$ & $100 \%$ & $0 \%$ & $100 \%$ & $0 \%$ \\
\hline 51 & $100 \%$ & $0 \%$ & $96 \%$ & $4 \%$ & $100 \%$ & $0 \%$ \\
\hline 52 & $100 \%$ & $0 \%$ & $96 \%$ & $4 \%$ & $100 \%$ & $0 \%$ \\
\hline 53 & $100 \%$ & $0 \%$ & $100 \%$ & $0 \%$ & $100 \%$ & $0 \%$ \\
\hline 54 & $96 \%$ & $4 \%$ & $100 \%$ & $0 \%$ & $96 \%$ & $4 \%$ \\
\hline 55 & $96 \%$ & $4 \%$ & $100 \%$ & $0 \%$ & $96 \%$ & $4 \%$ \\
\hline 56 & $96 \%$ & $4 \%$ & $100 \%$ & $0 \%$ & $96 \%$ & $4 \%$ \\
\hline 57 & $96 \%$ & $4 \%$ & $92 \%$ & $8 \%$ & $88 \%$ & $12 \%$ \\
\hline 58 & $96 \%$ & $4 \%$ & $100 \%$ & $0 \%$ & $96 \%$ & $4 \%$ \\
\hline 59 & $100 \%$ & $0 \%$ & $100 \%$ & $0 \%$ & $100 \%$ & $0 \%$ \\
\hline 60 & $96 \%$ & $4 \%$ & $96 \%$ & $4 \%$ & $96 \%$ & $4 \%$ \\
\hline 61 & $96 \%$ & $4 \%$ & $100 \%$ & $0 \%$ & $92 \%$ & $8 \%$ \\
\hline 62 & $92 \%$ & $8 \%$ & $100 \%$ & $0 \%$ & $92 \%$ & $8 \%$ \\
\hline 63 & $96 \%$ & $4 \%$ & $100 \%$ & $0 \%$ & $100 \%$ & $0 \%$ \\
\hline 64 & $100 \%$ & $0 \%$ & $100 \%$ & $0 \%$ & $100 \%$ & $0 \%$ \\
\hline 65 & $100 \%$ & $0 \%$ & $96 \%$ & $4 \%$ & $100 \%$ & $0 \%$ \\
\hline 66 & $80 \%$ & $20 \%$ & $76 \%$ & $24 \%$ & $80 \%$ & $20 \%$ \\
\hline 67 & $96 \%$ & $4 \%$ & $88 \%$ & $12 \%$ & $96 \%$ & $4 \%$ \\
\hline
\end{tabular}


APPENDIX 4: Copy of Customs Fact Sheet Guide to Requirements of the Secure Export Scheme

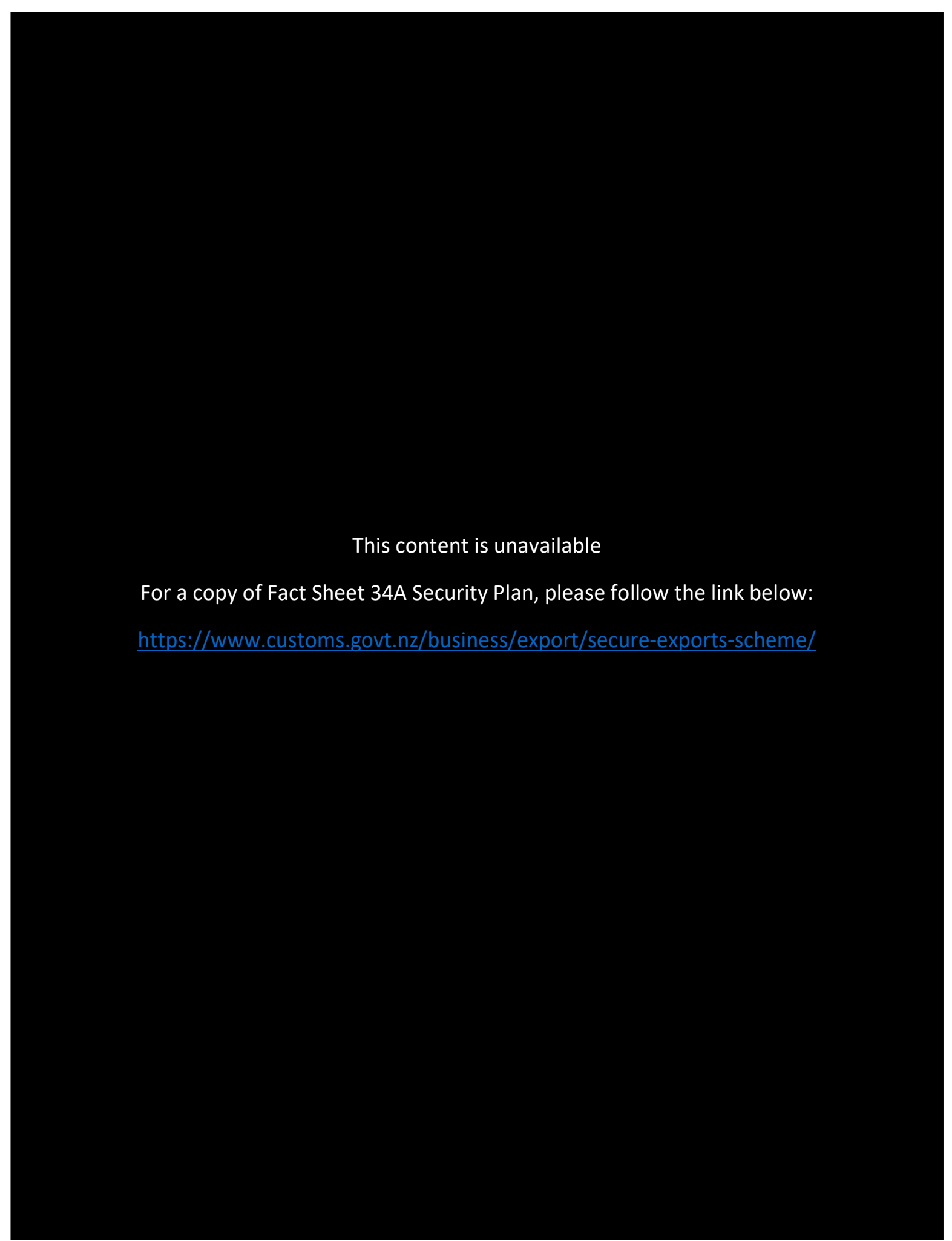

Source: Fact Sheet 34A Secure Export Scheme Security Plan, extracted from the New Zealand Customs Service website 


\section{This content is unavailable}

For a copy of Fact Sheet 34A Security Plan, please follow the link below:

https://www.customs.govt.nz/business/export/secure-exports-scheme/

Source: Fact Sheet 34A Secure Export Scheme Security Plan, extracted from the New Zealand Customs Service website 


\section{This content is unavailable}

For a copy of Fact Sheet 34A Security Plan, please follow the link below:

https://www.customs.govt.nz/business/export/secure-exports-scheme/

Source: Fact Sheet 34A Secure Export Scheme Security Plan, extracted from the New Zealand Customs Service website 


\section{This content is unavailable}

For a copy of Fact Sheet 34A Security Plan, please follow the link below:

https://www.customs.govt.nz/business/export/secure-exports-scheme/

Source: Fact Sheet 34A Secure Export Scheme Security Plan, extracted from the New Zealand Customs Service website 
This content is unavailable

For a copy of Fact Sheet 34A Security Plan, please follow the link below:

https://www.customs.govt.nz/business/export/secure-exports-scheme/

Source: Fact Sheet 34A Secure Export Scheme Security Plan, extracted from the New Zealand Customs Service website 


\section{This content is unavailable}

For a copy of Fact Sheet 34A Security Plan, please follow the link below:

https://www.customs.govt.nz/business/export/secure-exports-scheme/

Source: Fact Sheet 34A Secure Export Scheme Security Plan, extracted from the New Zealand Customs Service website 
This content is unavailable

For a copy of Fact Sheet 34A Security Plan, please follow the link below:

https://www.customs.govt.nz/business/export/secure-exports-scheme/

Source: Fact Sheet 34A Secure Export Scheme Security Plan, extracted from the New Zealand Customs Service website 
This content is unavailable

For a copy of Fact Sheet 34A Security Plan, please follow the link below:

https://www.customs.govt.nz/business/export/secure-exports-scheme/

Source: Fact Sheet 34A Secure Export Scheme Security Plan, extracted from the New Zealand Customs Service website 